BRUNO REGO SALOMÉ

Gerenciamento de escopo em projetos de TI: estudo de caso em uma instituição financeira brasileira 
BRUNO REGO SALOMÉ

\section{Gerenciamento de escopo em projetos de TI: estudo de caso em uma instituição financeira brasileira}

Dissertação apresentada à Escola de Artes, Ciências e Humanidades da Universidade de São Paulo para obtenção do título de Mestre em Ciências pelo Programa de Pós-graduação em Sistemas de Informação.

Área de Concentração: Sistemas de Informação

Versão corrigida contendo as alterações solicitadas pela comissão julgadora em 14 de Outubro de 2015. A versão original encontra-se em acervo reservado na Biblioteca da EACHUSP e na Biblioteca Digital de Teses e Dissertações da USP (BDTD), de acordo com a Resolução CoPGr 6018, de 13 de outubro de 2011.

Orientador: Prof. Dr. Edmir Parada Vasques Prado

São Paulo 
Autorizo a reprodução e divulgação total ou parcial deste trabalho, por qualquer meio convencional ou eletrônico, para fins de estudo e pesquisa, desde que citada a fonte.

CATALOGAÇÃO-NA-PUBLICAÇÃO

(Universidade de São Paulo. Escola de Artes, Ciências e Humanidades. Biblioteca)

Salomé, Bruno Rego

Gerenciamento de escopo em projetos de TI : estudo de caso em uma instituição financeira brasileira / Bruno Rego Salomé ;

orientador, Edmir Parada Vasques Prado. - São Paulo, 2015 114 f. : il.

Dissertação (Mestrado em Ciências) - Programa de PósGraduação em Sistemas de Informação, Escola de Artes, Ciências e Humanidades, Universidade de São Paulo Versão corrigida

1. Administração de projetos. 2. Sistemas de Informação Projeto - Gerenciamento. I. Prado, Edmir Parada Vasques, orient. II. Título

CDD 22.ed.- 658.404 
Dissertação de autoria de Bruno Rego Salomé, sob o título "Gerenciamento de escopo em projetos de TI: estudo de caso em uma instituição financeira brasileira", apresentada à Escola de Artes, Ciências e Humanidades da Universidade de São Paulo, para obtenção do título de Mestre em Ciências pelo Programa de Pós-graduação em Sistemas de Informação, na área de concentração Sistemas de Informação, aprovada em 14 de Outubro de 2015 pela comissão julgadora constituída pelos doutores:

Prof. Dr. Edmir Parada Vasques Prado

Presidente

Escola de Artes, Ciências e Humanidades - Universidade de São Paulo

Profa. Dra. Fátima de Lourdes dos Santos Nunes Marques

Escola de Artes, Ciências e Humanidades - Universidade de São Paulo

Prof. Dr. Otávio Prospero Sanchez

Fundação Getúlio Vargas 
Dedico àqueles que estiveram sempre comigo com amor e interesse verdadeiro, independente dos momentos ou adversidades: Antonio Carlos Pacheco Salomé, Helena Maria Rego Salomé, Isabel Maria Vale D’asnes Rego, Maria do Céu Martins Rego e Carolina Lima de Melo. 


\section{Agradecimentos}

Agradeço...

Primeiramente a Deus por todas as oportunidades e conquistas em meu caminho, as quais certamente só pude alcançar com Seu apoio e sustentação.

Ao programa PPGSI e à Universidade de São Paulo, Escolha de Artes, Ciências e Humanidades, por proporcionarem a oportunidade de pesquisa tão valiosa e com suporte e fomento consideráveis para sua realização.

Ao meu orientador, Prof. Dr. Edmir Parada Vasques Prado, por todas as horas dedicadas e contribuições imprescindíveis, com muita paciência e muito conhecimento compartilhado, possibilitando que o atual trabalho fosse concluído com qualidade e nosso objetivo de pesquisa fosse alcançado com êxito. À Profa. Dra. Fátima de Lourdes dos Santos Nunes Marques, ao Prof. Dr. Luciano Araújo e ao Prof. Dr. Otávio Sanchez pelas relevantes contribuições nas bancas de qualificação e de defesa. Foram fundamentais para o sucesso da pesquisa e para minha evolução acadêmica e pessoal.

À minha família, em especial meu pai e minha mãe, por todo apoio nos momentos mais difíceis, contribuindo para que o trabalho continuasse em andamento por mais complexas que fossem as adversidades ou empecilhos, sempre motivando e apoiando com amor e dedicação. À minha tia, avó, irmã e sobrinhos, especialmente Lucas Salomé Piva Tamaio, que souberam compreender os momentos de ausência e dedicação exclusiva à pesquisa.

À minha noiva, Carolina Lima de Melo, que acompanhou toda a trajetória e sempre auxiliou com o desenvolvimento do trabalho, sendo fundamental na motivação e incentivo a buscar resultados cada vez melhores, com total compreensão sobre a inevitável ausência durante o período de dedicação à pesquisa.

Aos amigos Bruno André Lima Ribeiro, Guilherme Banduki e Phillipe Nino Soares, por todo o apoio, dicas valiosas sobre pesquisa científica e assuntos correlatos ao tema estudado, com interesse na pesquisa e em seus objetivos, contribuindo com as discussões.

A todos os pares e parceiros da organização, que contribuíram para a obtenção de informações imprescindíveis à pesquisa, contribuindo para o alinhamento de necessidades e desenvolvimento na academia e nas organizações. 
"A tarefa não é tanto ver aquilo que ninguém viu, mas pensar o que ninguém ainda pensou sobre aquilo que todo mundo vê." (Arthur Schopenhauer) 


\section{Resumo}

SALOMÉ, Bruno Rego. Gerenciamento de escopo em projetos de TI: estudo de caso em uma instituição financeira brasileira. 2015. 111 f. Dissertação (Mestrado em Ciências) Escola de Artes, Ciências e Humanidades, Universidade de São Paulo, São Paulo, 2015.

O gerenciamento de projetos é amplamente utilizado por organizações em âmbito mundial. Projetos de sistemas de informação, especificamente, auxiliam tais organizações a obterem sistemas a serem utilizados em suas atividades operacionais com alinhamento estratégico junto a seus objetivos, garantindo maior eficiência, alcance de melhores resultados e perenidade de sua atuação no mercado. O gerenciamento de escopo é uma das áreas de conhecimento do gerenciamento de projetos, responsável por garantir que todos os objetivos do projeto sejam conhecidos por todos os envolvidos, declarando o que será entregue e qual será o trabalho necessário para tal. O gerenciamento de escopo demanda alto nível de relacionamento entre equipes desenvolvedoras dos projetos e os clientes solicitantes. Tais clientes possuem expectativas e limitações quanto aos projetos solicitados, sendo necessário seu acompanhamento e alinhamento com a área executora para garantir que suas necessidades sejam atendidas de acordo com seu planejamento e expectativa. Acompanhar o desempenho em diversas dimensões dos projetos é importante para garantir que o resultado final esteja adequado às necessidades originais, tanto considerando-se o produto entregue pelo projeto quanto a execução do projeto em si. Duas das características mais relevantes para os projetos são seu custo e tempo de execução. Desempenhos adequados de custo e tempo dos projetos são importantes, considerando-se que as entregas são relevantes para um determinado tempo de término e com um determinado custo para sua realização. Nesta pesquisa foi realizada a avaliação da relação de processos de planejamento do gerenciamento de escopo com desempenhos de custo e tempo de projetos de SI de uma organização brasileira de grande porte do setor financeiro. Por meio da avaliação da aderência dos processos executados na instituição estudada às práticas indicadas pela literatura, foi possível identificar o nível de aderência da instituição quanto ao gerenciamento de escopo. Esta avaliação foi então relacionada aos desempenhos de custo e tempo, identificando possíveis influências. Considerando-se ainda a amostra de projetos, os gerentes de projetos que os conduziram responderam questionários indicando problemas ocorridos relacionados ao desempenho de custo e tempo dos projetos, possibilitando a identificação de impactos provenientes do gerenciamento de escopo. Por fim, foram aplicadas entrevistas aos clientes que solicitaram os projetos selecionados à área de tecnologia da informação da organização, com o objetivo de identificar causas e comportamentos das relações identificadas anteriormente. Foi possível concluir que a organização analisada possuía baixa aderência às práticas de gerenciamento de escopo. $\mathrm{O}$ processo de coleta de requisitos foi identificado como o principal processo relacionado aos desempenhos dos projetos e como o processo foco de maior atenção dos gerentes de projetos e clientes, com maior conhecimento de processos do modelo de desenvolvimento de sistemas de informação do que do gerenciamento de projetos. Nos projetos analisados o planejamento do gerenciamento de escopo não foi uma variável que teve um alto grau de associação com os desempenhos de custo e tempo, podendo explicá-lo adequadamente. Por outro lado, o gerenciamento de escopomostrou ser um fator de forte influência no desempenho dos projetos, pois ensejou mudanças na organização.

Palavras-chave: gerenciamento de projetos. gerenciamento de escopo. desempenho de custo. desempenho de tempo. 


\begin{abstract}
SALOMÉ, Bruno Rego. Scope Management in IT projects: a case at a brasilian financial institution. 2015. 111 p. Dissertation (Master of Science) - School of Arts, Sciences and Humanities, University of São Paulo, São Paulo, 2015.
\end{abstract}

Project management is widely used by organizations worldwide. Information systems projects, specifically, assist such organizations get systems to be used in its operational activities with strategic alignment to your goals, ensuring greater efficiency, better results reach and perenniality of its market performance. The scope management is one of the project management's knowledge areas, responsible for ensuring that all project objectives are known by everyone involved, declaring what will be delivered and what will be the work required to such. Scope management demands high level of relationship between developers teams of the projects and the requesting clients. Such customers possess expectations and limitations with the requested projects, being necessary monitoring and alignment with the executing area to ensure that the needs will be met according with their planning and expectation. Track the performance in several dimensions of the projects is important to ensure that the end result is suited to unique needs, both considering the delivered product, as the course of entire project. Two of the most important characteristics of the projects are cost and runtime. Suitable cost performances and time of execution in the projects are important, considering that often such characteristics of projects are directly related to the expected results. In this research was held the assess the relationship the planning processes of scope management with performances of cost and time of SI projects of a Brazilian big organization in the financial sector. Through valuation of adherence of processes executed to good practices, was possible to identify the organization's maturity level about the scope management. This review was then related to costs and times of the projects, identifying possible influences. Considering still the selected projects for research, project managers responsible for these projects responded questionnaires indicating occurred problems related to performances of cost and time, enabling the identification of impacts coming from the scope management. Finally, interviews were applied to customers who requested the selected projects to the organization's information technology area, aiming to identify causes and behaviors of previously identified relations. It was possible to conclude that the analyzed organization possessed a low level of maturity about the management scope, having low adherence to good practices presented in the literature and followed by the organization. The process of requirements gathering was identified as the main proceedings related to the performance of the projects and as the process focus of more attention from projects managers and customers, with greater knowledge of information systems development methodology processes than project management processes. In the analyzed projects, scope management's planning was not a variable that had a high degree of association with the cost and time performances, explaining it properly. Moreover, scope management proved to be a strong influencing factor in the performance of projects, because gave rise changes in the organization.

Keywords: project management. scope management. cost performance. time performance. 


\section{Lista de figuras}

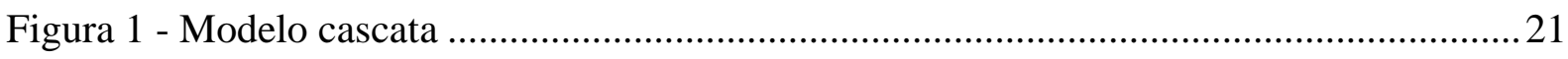

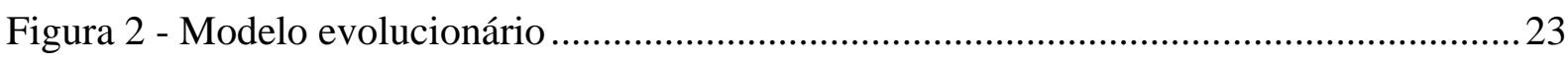

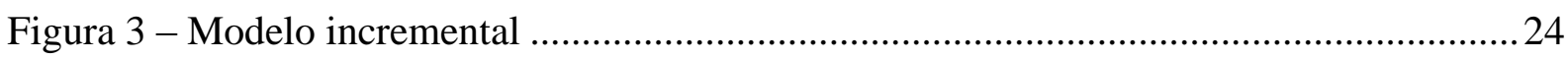

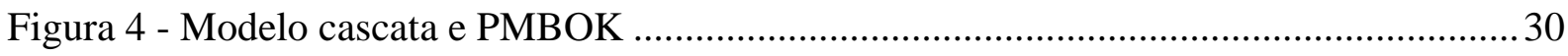

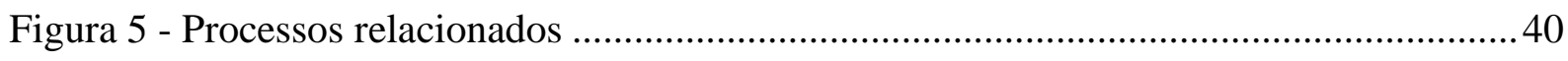

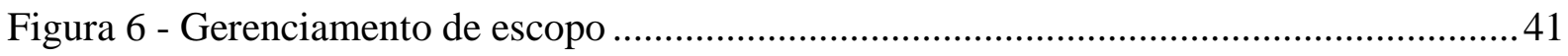

Figura 7 - Matriz de rastreabilidade de requisitos .............................................................. 46

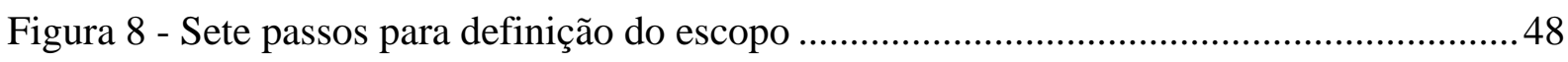

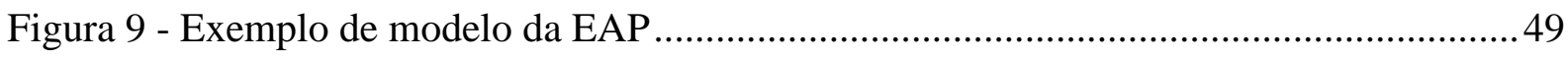

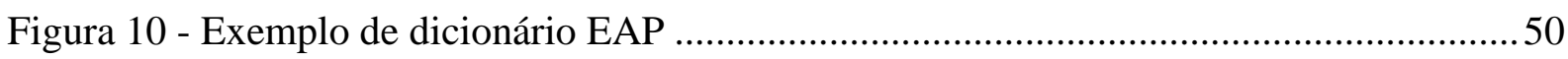

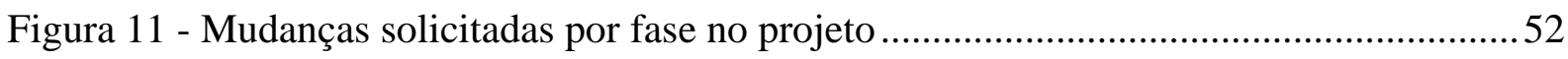

Figura 12 - Custo das mudanças ao longo do projeto .........................................................52

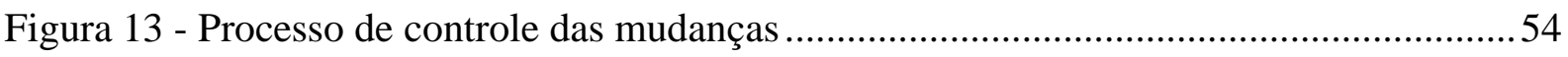

Figura 14 - Estrutura organizacional da instituição BANCO ................................................63

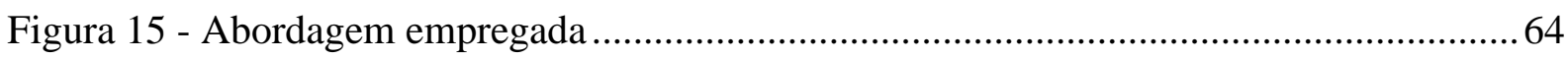

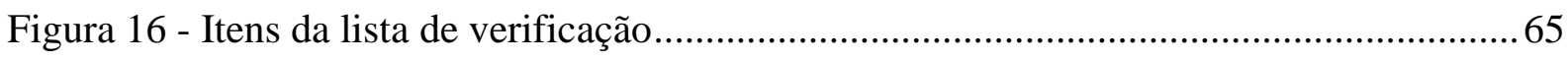

Figura 17 - Modelo de desenvolvimento de sistemas adaptado ............................................72

Figura 18 - Gráfico de desempenho de custo .................................................................. 78

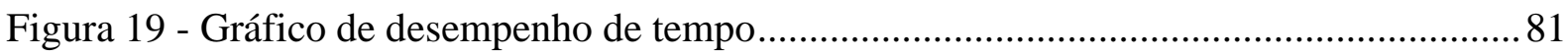




\section{Lista de tabelas}

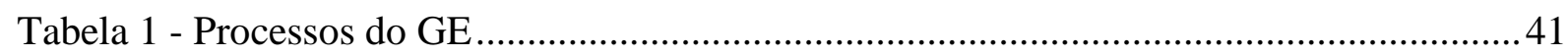

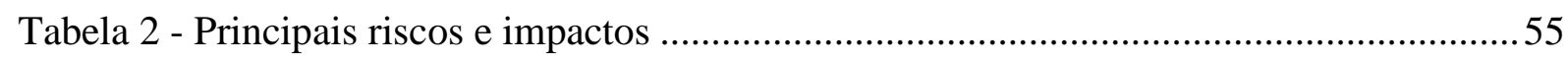

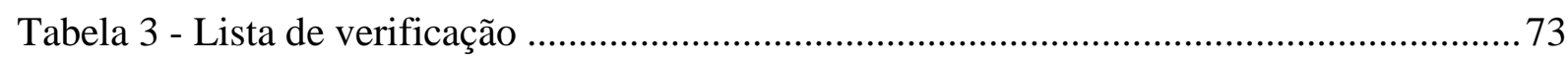

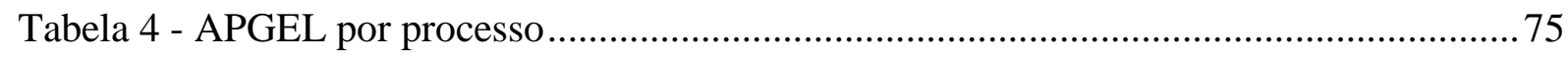

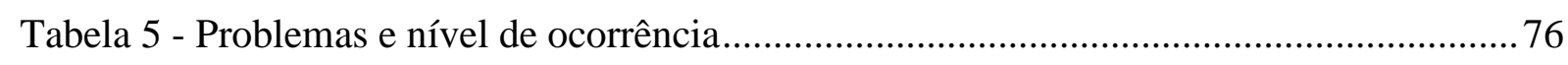

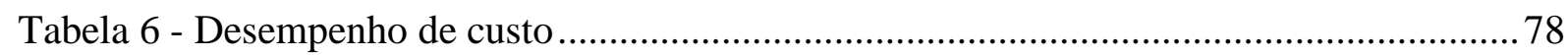

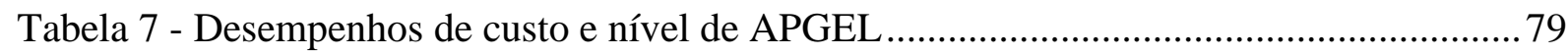

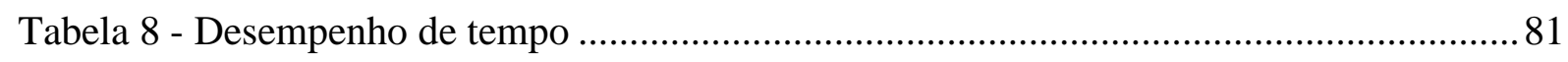

Tabela 9 - Desempenho de tempo e nível de APGEL ......................................................... 82 


\section{Lista de abreviaturas e siglas}

APGEL

EAP

GE

GPPGE

MDS

MGP

SI
Aderência às práticas do gerenciamento de escopo apresentadas na literatura

Estrutura analítica do projeto

Gerenciamento de escopo

Grupo de processos de planejamento do GE

Modelo de desenvolvimento de sistemas

Modelo de gerenciamento de projetos

Sistemas de informação 


\section{Sumário}

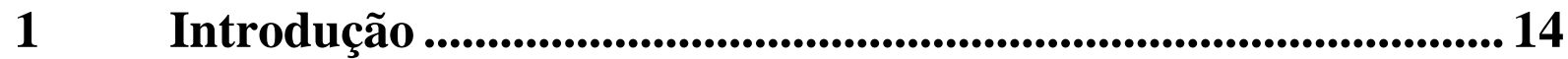

1.1 Formulação da situação problema...................................................................15

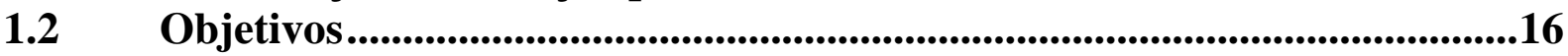

1.3 Estrutura da dissertação .........................................................................16

2 Desenvolvimento de SI ......................................................... 18

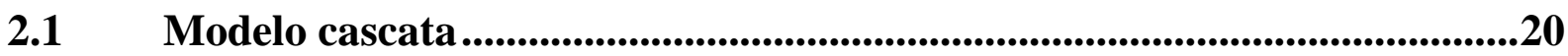

2.2 Modelo formal..............................................................................................21

2.3 Modelo orientado a reuso ........................................................................22

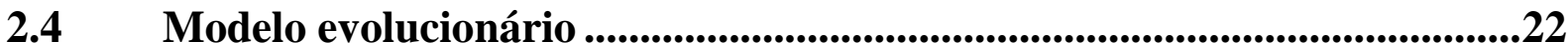

2.5 Modelo incremental..................................................................................23

2.6 Modelos ágeis ...........................................................................................................25

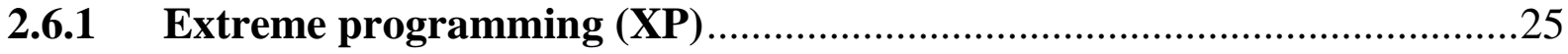

2.6.2 SCRUM

3 Gerenciamento de projetos......................................................... 29

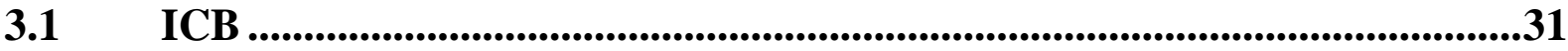

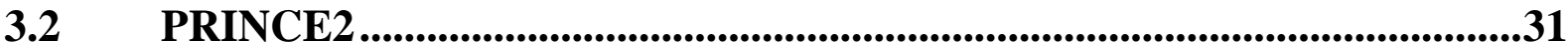

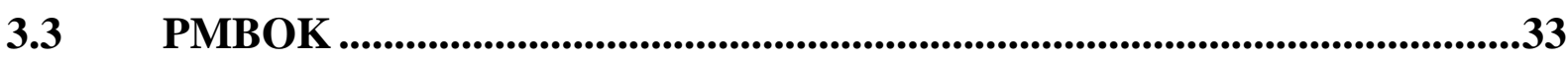

3.4 Gerenciamento ágil de projetos...................................................................................36

$4 \quad$ Gerenciamento de escopo...........................................................39

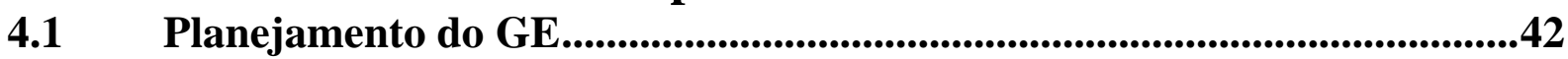

4.2 Coleta de requisitos ...............................................................................................43

4.3 Definição do escopo ....................................................................................................46

4.4 Criação da EAP ......................................................................................................49

$4.5 \quad$ Validação do escopo .............................................................................................51

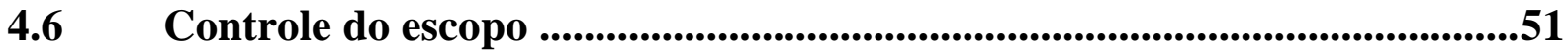

4.7 Riscos que influenciam custo e tempo dos projetos..........................................54

4.8 Critérios para avaliação do GE..................................................................56

$5 \quad$ Trabalhos correlatos...................................................................... 58

$5.1 \quad$ Problemas no gerenciamento de projetos ..........................................................58

5.2 Aumento de sucesso em projetos de TI por conta do GE ...........................59

5.3 Inspeção de documentos de GE por inspeção com lista de verificação....60

6 Método de pesquisa ..........................................................................6 61

6.1 Estratégia da pesquisa.......................................................................61

6.2 Objeto de estudo .........................................................................................................62

6.3 Etapas da pesquisa ...............................................................................................63

6.4 Coleta de dados e instrumentos..................................................................65

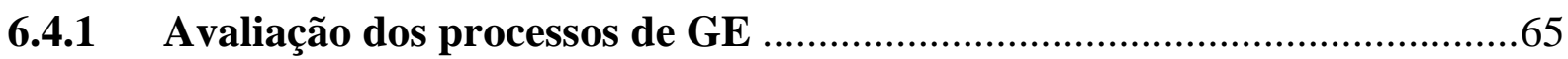

6.4.2 Problemas que impactam o desempenho dos projetos..............................66

6.4.3 Desempenhos de custo e tempo dos projetos..............................................67 
6.4.4 Investigação a respeito de como ocorreram as influências.........................68

6.5 Limitaçôes da pesquisa....................................................................69

$7 \quad$ Contextualização do estudo de caso ........................................... 70

$8 \quad$ Apresentação dos resultados ........................................................ 72

8.1 Aderência do GE às práticas apresentadas na literatura .............................73

8.2 Problemas no gerenciamento de projetos relacionados ao GE ...................76

8.3 Desempenho dos projetos em termos de custo e planejamento do GE ....77

8.4 Desempenho dos projetos em termos de tempo e planejamento do GE...80

$9 \quad$ Análises e discussão .................................................................... 84

9.1 Aderência do GE às práticas apresentadas na literatura .............................84

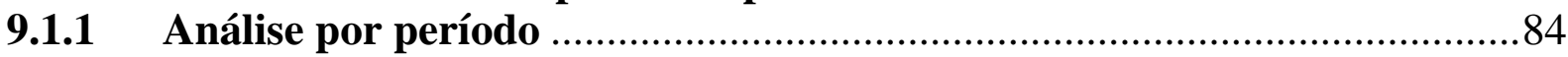

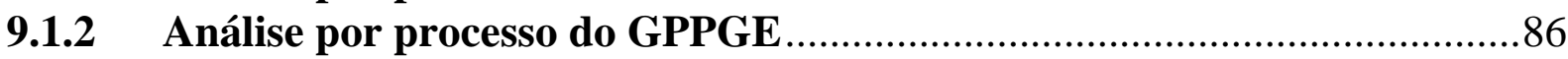

9.2 Problemas no gerenciamento de projetos relacionados ao GE ..................89

9.3 Desempenho dos projetos em termos de custo e planejamento do GE ....92

9.4 Desempenho dos projetos em termos de tempo e planejamento do GE...95

10 Conclusão...................................................................................... 98

Referências ........................................................................................................... 102

Apêndice A - Critérios da lista de verificação e grupos de processos 109

Apêndice B - Questionário sobre influências nos resultados dos projetos

Apêndice C - Influências dos processos de planejamento do GE nos resultados, de acordo com os gerentes de projetos................... 112

Anexo A - Documento texto de escopo do projeto ................................ 113

Anexo B - Documento planilha eletrônica de escopo do projeto ........ 114 


\section{Introdução}

Sistemas de informação (SI) são responsáveis por processar, armazenar e transmitir informações, sendo adotados por organizações que utilizam informações como insumo para a realização de tarefas operacionais ou para a tomada de decisão (FILHO; JOSÉ; LUDMER, 2005). O gerenciamento desses sistemas se tornou cada vez mais importante conforme o avanço do desenvolvimento de SI (FILHO; JOSÉ; LUDMER, 2005). Portanto, a implementação de um SI deve estar de acordo com a estratégia de uso da tecnologia de informação (TI) na organização, sendo esta, por sua vez, alinhada com a estratégia de negócio (ALBERTIN, 1996). O desenvolvimento de SI está diretamente relacionado aos objetivos da organização que irá utilizar tais sistemas.

Com esta significância e impacto para as organizações, iniciou-se a utilização de gerenciamento de projetos para o desenvolvimento de SI. Projeto é uma ocorrência não repetitiva, representada por uma cadeia de eventos com início, meio e fim determinado. Tem por meta entregar algo que se espera, considerando dispender tempo, custo e recursos previamente estipulados (VARGAS, 2003).

Atualmente o gerenciamento de projetos é amplamente estudado e aplicado pelas organizações, principalmente na área de TI. Sua utilização proporciona melhores resultados e custos reduzidos (AMARAL; CONFORTO, 2007).

Para disseminar práticas recomendadas no gerenciamento de projetos, existem guias que apresentam as práticas sugeridas, como o ICB (IPMA, 2006), PRINCE2 (OGC, 1996) e PMBOK (PMI, 2013).

Uma das áreas de conhecimento do gerenciamento de projetos é o gerenciamento de escopo (GE). O GE visa garantir que todo o trabalho necessário, e somente o trabalho necessário, seja empenhado para que o projeto seja concluído com sucesso. É fundamental para que o projeto atenda às expectativas dos usuários de um sistema computacional a ser desenvolvido ou aprimorado.

O GE ocorre por meio de processos que podem ser agrupados em processos de planejamento, execução e controle. Os processos de planejamento são a chave para o sucesso na execução do projeto (FROTA, 2009) e são fundamentais para que ocorra a devida execução e controle, guiando o que deve ser feito e como, atingindo os objetivos do projeto com entregas aderentes ao escopo determinado. 
Existe uma relação de dependência entre tempo, custo e escopo do projeto, de forma que a alteração de um destes causa variações nos demais (VALLE, 2007), mas não foram localizados, nas bases selecionadas para pesquisa, trabalhos com enfoque a respeito do real possível impacto originado no GE, especificamente sobre os processos de planejamento.Motivação e justificativa

O Standish Group realiza anualmente um levantamento a respeito do gerenciamento de projetos, conhecido como CHAOS REPORT (STANDISH GROUP, 2014). Trata-se de um conjunto de relatórios acerca de sucessos e falhas de projetos, fatores críticos, dentre outros. No CHAOS REPORT de 2012, dentre os projetos analisados, 39\% obtiveram sucesso enquanto os demais falharam. 59\% dos projetos apresentaram variações inadequadas de custo, 74\% variações inadequadas de tempo e $69 \%$ não contemplaram todo o escopo inicialmente solicitado (projetos podem pertencer a mais de um desses grupos).

O GE é comumente apresentado sendo responsável em determinado nível pelo desempenho dos projetos. Bomfin, Nunes e Hastenreiter (2012), por exemplo, destacam que o custo e o tempo dos projetos evoluem de acordo com o GE. Já Gonçalves e Figueiredo (2008) citam que a definição do escopo e o GE são os processos mais críticos no gerenciamento de projetos.

Dada a importância do GE no gerenciamento de projetos, é relevante para esse campo de conhecimento identificar o grau de influência do GE no desempenho do custo e tempo de um determinado projeto.

\subsection{Formulação da situação problema}

O gerenciamento de projetos é composto por diversos processos, que ocorrem em momentos diferentes. O grupo de processos de planejamento é fundamental para o sucesso dos grupos de execução e controle, pois aqueles definem estes e como serão conduzidos (PMI, 2013).

Como o escopo está diretamente relacionado ao tempo e custo dos projetos, o GE pode influenciar o desempenho dos projetos, contudo não foram localizados trabalhos sobre o quanto cada processo do GE pode influenciar nos desempenhos, principalmente sobre os processos de planejamento, momento no qual os envolvidos nos projetos podem estimar os desempenhos desejados e se preparar para fazer com que sejam atingidos. 
A pergunta de pesquisa que este trabalho visa responder é, portanto: "Como os processos de planejamento de gerenciamento de escopo influenciam o desempenho de custo e o desempenho de tempo em projetos de SI?".

\subsection{Objetivos}

O presente trabalho visa analisar, na área de TI de uma grande organização brasileira do setor financeiro, como os processos de planejamento do GE em projetos de desenvolvimento de SI podem influenciar o desempenho de custo e o desempenho de tempo de tais projetos.

Além de apresentar conceitos de gerenciamento de projetos e, especificamente, de GE, o trabalho apresenta também as práticas e os modelos de GE descritos na literatura científica.

Com base neste objetivo geral, o trabalho apresenta os seguintes objetivos específicos:

a) Descrever as práticas de GE apresentados na literatura;

b) Avaliar a aderência às práticas de GE apresentadas na literatura em projetos de SI;

c) Identificar os problemas no gerenciamento de projetos de SI relacionados ao GE;

d) Analisar a influência dos processos de planejamento do GE no desempenho relacionado ao custo dos projetos de SI;

e) Analisar a influência dos processos de planejamento do GE no desempenho relacionado ao tempo de execução dos projetos de SI.

\subsection{Estrutura da dissertação}

Este documento está dividido nos seguintes itens:

Capítulo 1 - Introdução: capítulo corrente que aborda a introdução ao tema, justificativa, formulação da situação problema, objetivos e organização do presente trabalho.

Capítulo 2 - Desenvolvimento de SI: Descrição do que é um SI e quais os modelos atualmente conhecidos para seu desenvolvimento.

Capítulo 3 - Gerenciamento de projetos: Explora questões relacionadas a projetos e seu gerenciamento, tratando sobre modelos tradicionais e ágeis.

Capítulo 4 - Gerenciamento de escopo: Enfoque no GE, apresentando os conceitos relacionados e detalhando o seu processo de gerenciamento na abordagem tradicional de gerenciamento de projetos. 
Capítulo 5 - Método de pesquisa - Método utilizado para realização do trabalho, baseado em critérios científicos de pesquisa.

Capítulo 6 - Contextualização do estudo de caso - Apresenta-se a instituição selecionada e seu contexto no momento da realização da pesquisa.

Capítulo 7 - Apresentação dos resultados - Apresenta-se quais foram os resultados obtidos com a coleta de dados.

Capítulo 8 - Análises e discussão - Embasando-se nas análises de resultados, discutese a respeito de todas as perspectivas exploradas durante a pesquisa, relacionando-as.

Capítulo 9 - Conclusão - Após as discussões são apresentadas as conclusões individuais de cada aspecto estudado e conclusão geral da pesquisa. 


\section{Desenvolvimento de SI}

Um SI é a sistematização de processos manuais realizados com um conjunto de informações, a fim de gerar novas informações ou realizar determinadas ações (ELRAGAL; LAUDON; LAUDON, 2013). Com o avanço das tecnologias disponíveis para criação de SI estes se tornaram cada vez mais sofisticados e complexos. Seu papel ganhou importância nas organizações e acabaram por se tornar fundamentais para o cotidiano destas.

O desenvolvimento de SI foi responsável por grande parte da evolução de diversos setores da economia. Em mercado de capitais, por exemplo, a presença de SI tornou-se fundamental na bolsa de valores de Nova York, desde os anos 60 (MADEO, 2012). Já o setor de logística, por sua vez, teve grande ganho com a utilização de SI quando de sua popularização (NAZÁRIO, 1999). Um dos setores que sempre mais investiu em TI, principalmente no Brasil, é o bancário, desde o início do advento tecnológico (PETERS, 1993). Esse alto investimento em tecnologia pelo setor bancário se mantém até os dias atuais (EDMILSON et al., 2013).

Um SI é composto por funcionalidades que representem resoluções de problemas para a instituição que utilizará o sistema. Estas funcionalidades podem ser denominadas como requisitos.

O BABOK (IIBA, 2009) é um guia de conhecimentos a respeito da área de análise de negócios, que visa entender, analisar e estudar os processos de negócios de uma organização, com o intuito de guiá-la em direção aos seus objetivos. Segundo esse guia, um requisito é uma condição ou capacidade necessária para um indivíduo ou solução desenvolvida alcançar um determinado objetivo.

Os requisitos podem ainda ser classificados em requisitos de (IIBA, 2009):

a) Negócios: são definições de alto nível a respeito dos objetivos ou necessidades da organização. Estes requisitos visam apresentar os objetivos da organização de forma ampla, sem especificidade de áreas ou envolvidos.

b) Envolvidos: são definições das necessidades particulares de envolvidos ou grupos de envolvidos em algum investimento da organização. Trata-se de uma especificação dos requisitos de negócios, pois os objetivos dos envolvidos têm de estar alinhados aos objetivos da organização. 
c) Solução: descrevem as características de uma solução que atenda aos requisitos de negócios e aos requisitos de envolvidos. Normalmente podem ser divididos em subcategorias, principalmente em desenvolvimento de SI.

d) Transição: descrevem as capacidades necessárias para que a solução possibilite uma transição de um estado atual da organização para um estado futuro desejado, mas que não será definitivo. Estes requisitos possuem, portanto, uma natureza transitória.

Requisitos da solução podem ainda ser classificados em funcionais e não funcionais. Requisitos funcionais são as definições que descrevem o comportamento do produto final do projeto, como processos, dados e interações possíveis com o produto. Requisitos não funcionais são funcionalidades suplementares e descrevem condições de ambiente ou qualidades necessárias para que o produto entregue seja efetivo, como segurança, confiabilidade, nível de serviços, dentre outros (KASSAB; ORMANDJIEVA; DANEVA, 2009).

Os requisitos podem começar em um alto nível e tronarem-se progressivamente mais detalhados conforme mais informações são conhecidas. Requisitos devem ser mensuráveis e passíveis de testes, rastreáveis, completos, consistentes e aceitáveis para as principais partes interessadas (KUMAR, 2006).

Para que os SI estejam disponíveis para os usuários finais, de forma a cumprir devidamente sua finalidade, é necessário que alguém os desenvolva adequadamente. Desenvolver um SI, entretanto, não é uma atividade que por si só é capaz de atender às necessidades dos usuários. Dentre as atividades que auxiliam a produção de um SI, destacamse (SOARES, 2004):

a) Especificação: definição das funcionalidades e restrições do SI. Importante a participação do cliente e usuários nesta fase da produção do sistema.

b) Implementação: construção efetivamente do SI, com utilização de diagramas e linguagens de programação.

c) Validação: ocorre a validação do sistema construído, verificando-se se as funcionalidades previstas foram devidamente implementadas.

d) Evolução: o sistema precisa de constante evolução para continuar sendo útil ao cliente. 
O SWEBOK (IEEE, 2004) é um guia de processos para desenvolvimento de SI, que apresenta dez áreas de conhecimento relacionadas. São: requisitos, projeto, construção, teste, manutenção, gerenciamento de configuração, gerenciamento da engenharia, processo da engenharia, ferramentas e métodos da engenharia e qualidade.

É possível observar que as áreas de requisitos, projeto, construção, teste e manutenção em muito se assemelham às atividades apresentadas anteriormente, baseadas no trabalho de Soares (2004).

Cada uma dessas atividades deve ser realizada e conectada com a seguinte de forma a compor toda a evolução do SI que está sendo construído. Para isso, há diversos modelos de desenvolvimento de sistemas, alguns destes apresentados brevemente a seguir.

\subsection{Modelo cascata}

O modelo cascata é um dos mais utilizados pelas organizações (PARIDA, 2006), sendo composto por diferentes fases: análise e definição de requisitos, projeto de sistemas, implementação e testes unitários, integração e teste de sistemas e, por fim, operação e manutenção (SOMMERVILLE, 2007). Estas fases podem ser separadas de acordo com outras classificações como: comunicação, planejamento, modelagem, construção e emprego (PRESSMAN, 2011). Independente dos processos, o modelo cascata assume que cada fase deve ser executada em ordem sequencial, sendo que o resultado da anterior serve como insumo da seguinte, conforme ilustrado pela figura 1.

Nesse modelo, a fase inicial é a de análise e definição de requisitos, na qual se identifica e documenta quais são os requisitos do sistema que se está construindo.

$\mathrm{Na}$ fase de projeto de sistema, os requisitos especificados na fase anterior são agrupados, compondo sistemas ou partes de sistemas. Em seguida, o projeto de sistema é compreendido como um conjunto de programas computacionais, que são construídos e testados separadamente.

Na fase de integração e teste de sistemas, os programas testados separadamente na fase anterior, são interligados e os testes de todo o sistema são realizados. Ao final desta fase, o SI construído é entregue ao cliente. 
A fase de operação e manutenção se refere à correção de erros que não foram descobertos em estágios anteriores e ao aumento das funcionalidades do sistema conforme novos requisitos se façam necessários (SOMMERVILLE, 2007).

Figura 1 - Modelo cascata

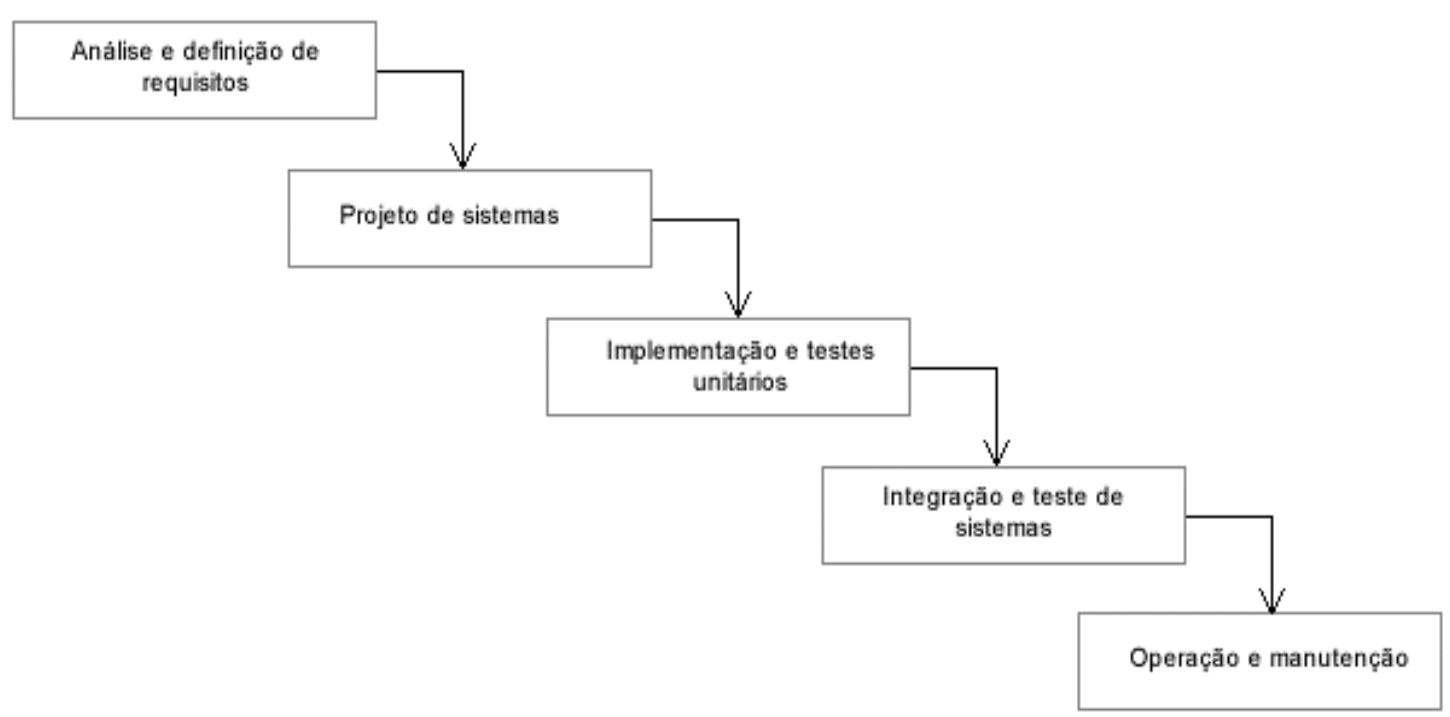

Fonte: Adaptado de Sommerville (2007)

\subsection{Modelo formal}

O modelo formal se assemelha ao modelo cascata, entretanto as especificações são transformadas em expressões matemáticas formais que originam o sistema que se está construindo (SOMMERVILLE, 2007). Acarreta em um maior esforço na etapa de construção do sistema propriamente dita, entretanto sistemas que exijam confiabilidade, segurança e precisão altamente qualificadas podem se utilizar de tal modelo para poder comprovar de forma mais fácil que cumprem com as solicitações.

A notação matemática exigida na concepção de um SI através do modelo formal impede ambiguidades, imaginação ou interpretações incorretas das solicitações realizadas pelo cliente (MARTINS, 1995).

No modelo formal há transformações nas quais o modelo é mais detalhado, gradativamente, até que se torne uma representação de sistema mais detalhada, mas ainda 
matematicamente correta (MARTINS, 1995). Essas alterações não são muito espaçadas, fazendo com que haja uma evolução gradativa que pode ser acompanhada e validada mais rapidamente. Desta forma é possível garantir que o sistema final é exatamente a especificação inicial, transformada através do método formal.

\subsection{Modelo orientado a reuso}

O reuso é a técnica de utilizar algo já previamente construído como base para o novo desenvolvimento que se necessita. O reuso de códigos fontes de SI pode ser amplamente utilizado, garantindo uma aceleração na fase de construção do sistema (SOMMERVILLE, 2007).

O modelo orientado a reuso utiliza dessa abordagem para, através de uma base de componentes de sistemas reutilizáveis, repetir soluções e as integrando para alcançar novos resultados.

Há vantagens na utilização do modelo orientado a reuso, como a velocidade de entrega do SI, tendo em vista que se economiza muito código de sistema e, consequentemente tempo. Como há a utilização de códigos previamente construídos, testados e já utilizados, pode haver ainda redução de determinados riscos e custos. Como ponto de atenção nesta abordagem, há riscos específicos, como erros que se replicam para as diversas soluções, dependência entre projetos de SI e dificuldades de adaptação dos sistemas para total atendimento dos requisitos.

\subsection{Modelo evolucionário}

O desenvolvimento evolucionário propõe uma implementação inicial do produto solicitado e, de acordo com a observação desta primeira entrega, evoluir o produto através da criação de versões até que o mesmo esteja adequado às expectativas (SOMMERVILLE, 2007).

O modelo evolucionário pode se dar através de dois diferentes tipos de desenvolvimento: "Desenvolvimento exploratório" e "criação de protótipos". No desenvolvimento exploratório, o objetivo é trabalhar com o cliente, definindo os requisitos conforme o projeto evolui. Dessa forma, são realizadas entregas e os clientes adicionam funcionalidades às mesmas, gerando uma próxima entrega. Na criação de protótipos, a proposta é realizar a construção de propostas de solução, de acordo com o entendimento dos requisitos (DIMITROV; DUMKE; SCHMIETENDORF, 2002). Os protótipos são validados ou refutados 
pelo cliente, que orienta os acertos ou erros de cada um deles. A figura 2 representa o conceito geral do modelo evolucionário.

Figura 2 - Modelo evolucionário

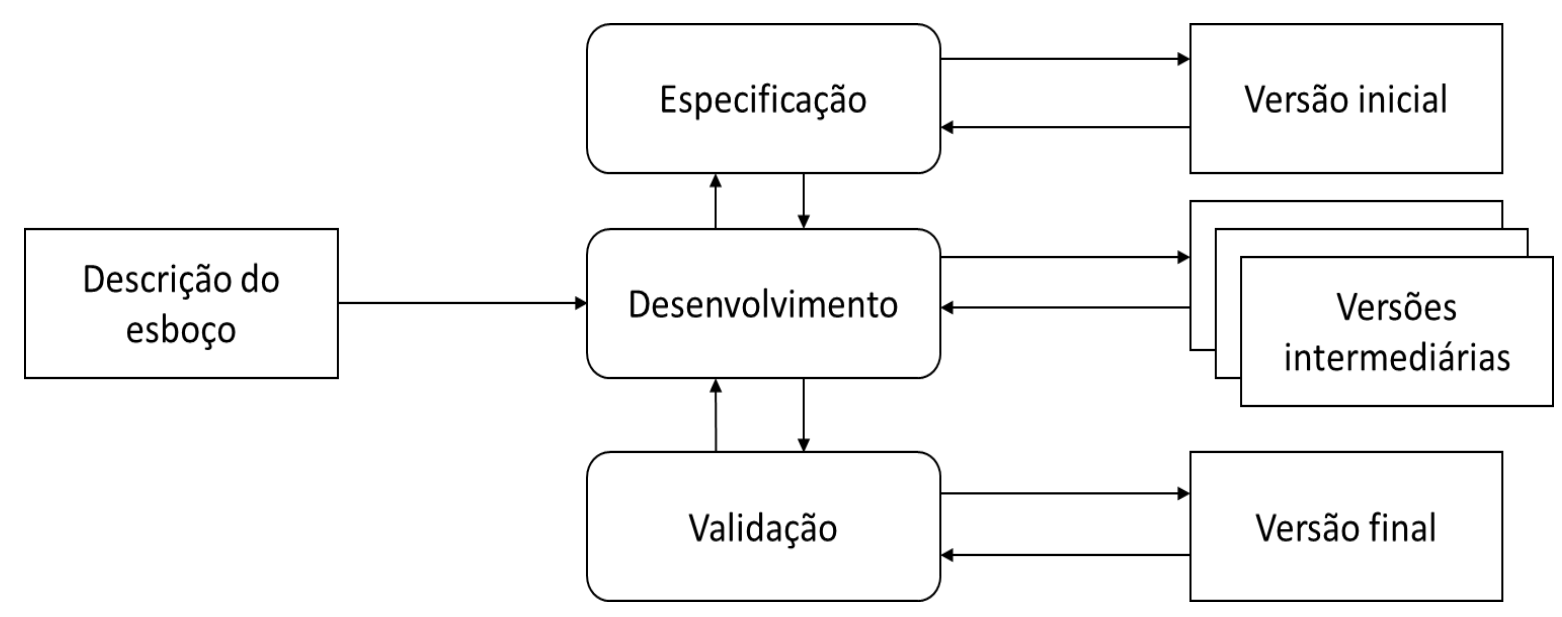

Fonte: Sommerville (2007)

Esse modelo possibilita uma evolução gradativa do escopo como grande benefício, mas possui problemas também (BOEHM, 1988). Há uma perda de controle dos gestores, pois controlar e acompanhar o avanço dos desenvolvimentos fica mais difícil, dada a dinamicidade. Além disso, os sistemas podem se tornar mal estruturados a medida que novas modificações de escopo são incorporadas, alterando o que havia sido construído até então.

\subsection{Modelo incremental}

No modelo incremental, a proposta é identificar os requisitos prioritários para o projeto e desenvolver o sistema com estes requisitos. Os clientes podem validar os requisitos e detalhálos, evoluindo o sistema gradativamente. Com isso, além de os clientes terem a liberdade de definir requisitos ao longo do tempo, conforme a evolução do projeto, ainda há a possibilidade de utilizar o sistema com as funcionalidades já entregues, fazendo com que os benefícios do sistema desenvolvido já sejam observados desde as primeiras entregas do projeto (RUPARELIA, 2010). A figura 3 apresenta os processos realizados no modelo incremental, visando alcançar este objetivo. 
Figura 3 - Modelo incremental

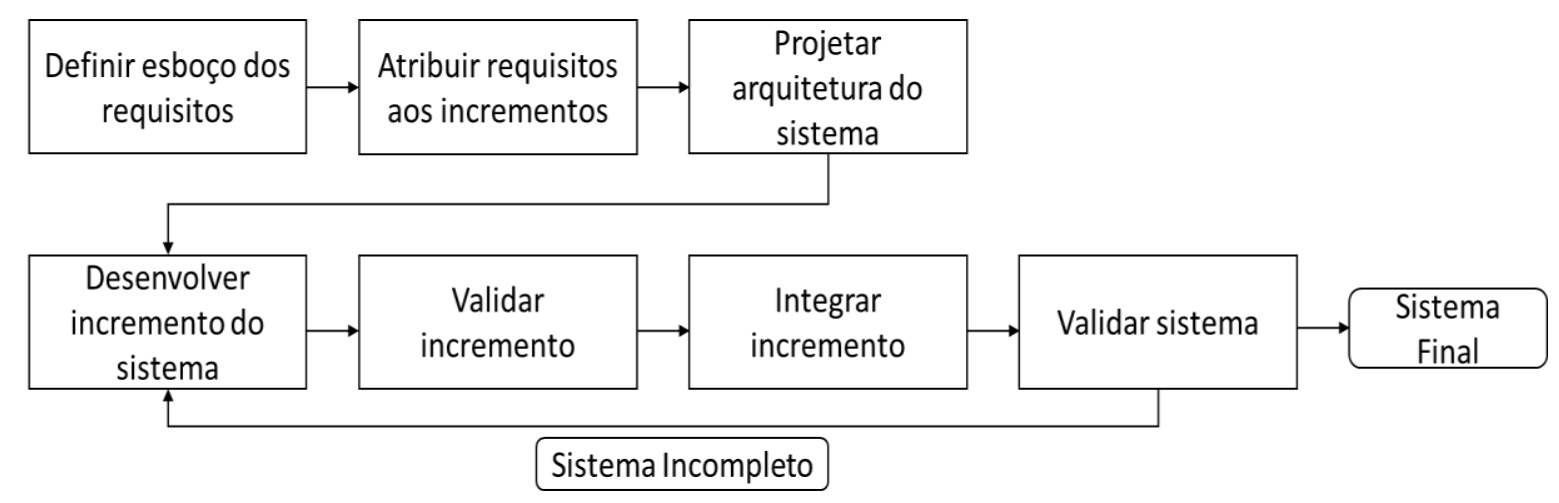

Fonte: Sommerville (2007)

O sistema entregue ao final do processo incremental tende a ser mais confiável, com uma maior qualidade, tendo em vista que diversos testes foram realizados (para todas as funcionalidades entregues), e as funcionalidades principais, geralmente as primeiras a serem entregues, foram testadas diversas vezes. Além disso há outras vantagens, como, por exemplo, redução de riscos, estimativa facilitada do tempo de projeto e maior visibilidade sobre o processo (CORDEIRO, 2003).

As limitações neste modelo residem na estrutura geral do sistema, pois uma construção iniciada sem uma completa definição de requisitos pode não atender futuras solicitações, trazendo dificuldades na evolução do sistema. Isso se dá, pois sem a clareza inicial do todo a respeito do desenvolvimento, a estrutura selecionada para a construção pode não ser facilmente alterada futuramente, gerando retrabalho ou, em casos extremos, reinício de todo o desenvolvimento. Há também a necessidade de forte esforço para manter a documentação atualizada e relacionamentos entre fases bem planejados (CORDEIRO, 2003).

Este modelo de desenvolvimento de sistema influenciou os modelos de desenvolvimento ágeis, apresentados a seguir. 


\subsection{Modelos ágeis}

Os modelos ágeis seguem a proposta do modelo incremental, sugerindo escopos não definidos totalmente antes do início do desenvolvimento, acarretando em entregas parciais até a composição da entrega final (CHIN, 2004).

O termo "modelos ágeis" se popularizou em 2011, quando dezessete especialistas em processos de desenvolvimento de sistemas demonstraram propostas de novos modelos com características comuns entre elas (SOARES, 2004). Eles formaram a "Aliança ágill" e publicaram um documento conhecido como "Manifesto Ágil”" (AGILEALLIANCE, 2001).

O manifesto ágil apresenta algumas diretrizes principais a serem seguidas:

a) Mais indivíduos e interações do que processos e ferramentas.

b) Mais SI em funcionamento do que documentação.

c) Mais colaboração com o cliente do que negociação de contratos.

d) Mais respostas a mudanças do que planos a seguir.

O manifesto ágil foi um guia para todos os modelos ágeis, mas cada um deles também possui características particulares, como o Extreme programming - XP (SOARES, 2004), o SCRUM (MACHADO; MEDINA, 2009), o LEAN (CAWLEY; RICHARDSON; WANG, 2010) e o FDD (FELSING; PALMER, 2001). Os mais conhecidos e utilizados pelas organizações são XP e SCRUM, apresentados nas seções seguintes (SOARES, 2004).

\subsubsection{Extreme programming (XP)}

O modelo extreme programming (XP) é aconselhável para equipes pequenas que precisem desenvolver SI com requisitos pouco definidos e com grandes chances de sofrer alterações. No XP devem haver retornos constantes por parte dos clientes e usuários, a abordagem é incremental e a comunicação entre as pessoas é encorajada (SOARES, 2004).

O modelo se baseia em 12 principais práticas (BECK, 2004):

a) Planejamento: Nesta fase ocorre a decisão a respeito de quais serão as primeiras funcionalidades a serem implementadas no projeto. Neste momento, o cliente e os desenvolvedores atuam em conjunto, de forma cooperativa. Enquanto os clientes decidem a respeito do escopo esperado e datas almejadas, os desenvolvedores devem realizar estimativas de prazo e elaborar o cronograma. 
b) Entregas frequentes: A proposta é que os primeiros requisitos entregues sejam os mais importantes para o projeto. Cada lote de entregas deve ser realizado preferencialmente entre um e dois meses e os clientes devem fornecer retornos rápidos e eficientes a respeito das entregas, garantindo atualizações que satisfaçam suas necessidades.

c) Metáforas: Com o trabalho em conjunto entre clientes e desenvolvedores proposto pelo XP, é importante não utilizar linguagens demasiadamente técnicas. Assim, a utilização de metáforas auxilia significativamente a comunicação entre os envolvidos.

d) Simplicidade: O SI desenvolvido através deste modelo deve ser o mais simples possível, contemplando sempre os requisitos já conhecidos e urgentes para o cliente. Não se deve pensar em requisitos futuros ou implementar funcionalidades adicionais.

e) Testes: O modelo é focado em testes. Os desenvolvedores iniciam a construção pelos testes, primando pela automatização sempre que possível.

f) Programação em pares: Através desta técnica os programadores trabalham sempre em pares, sendo que enquanto um dos programadores controla o mouse e teclado, construindo o sistema, o outro observa indicando possíveis erros. Os papéis são constantemente alternados. Uma das principais vantagens deste modelo é o aprendizado mútuo dos desenvolvedores.

g) Refatoração: Visa a simplificação do código do sistema na evolução do projeto.

h) Propriedade coletiva: Esta propriedade garante que o código do sistema pertença a todos os membros da equipe. Desta forma qualquer membro da equipe pode trabalhar em qualquer parte do código.

i) Integração contínua: Com o processo de integração contínua, os desenvolvedores podem interagir e evoluir o sistema diversas vezes por dia, fazendo com que as evoluções sejam aceleradas, mas controladas.

j) 40 horas de trabalho semanal: Isso significa dizer que neste modelo não se aconselha fazer horas extras com frequência. Caso em duas semanas seguidas o trabalho passe de 40 horas, é um forte indicativo de problemas no projeto, exigindo um replanejamento de forma a não sobrecarregar as pessoas. 
k) Cliente presente: $\mathrm{O}$ cliente deve estar presente durante todo o tempo junto à equipe de desenvolvimento, evitando problemas de comunicação e dúvidas sobre requisitos.

1) Código padrão: A padronização da arquitetura do código é importante para o melhor entendimento de todos os membros da equipe.

\subsubsection{SCRUM}

O termo SCRUM foi associado ao desenvolvimento pela primeira vez na obra "The New Product Development Game” (NONAKA; TAKEUCHI, 1986). O foco dos autores era reforçar a necessidade de toda a equipe trabalhar em conjunto para atingir um objetivo (MACHADO; MEDINA, 2009).

O SCRUM é um conjunto de práticas sugeridas para utilização em casos de trabalhos complexos nos quais não é possível prever os acontecimentos (MACHADO; MEDINA, 2009).

A equipe do SCRUM é composta por (COSTA; FREIRE; LIMA, 2012):

a) Product Owner: Responsável por representar todos os clientes. Conhece profundamente todas as regras de negócio e é responsável pelo retorno financeiro do projeto.

b) Scrum Master: Responsável por conduzir o time de desenvolvimento e eliminar possíveis obstáculos que surgem ao longo do desenvolvimento do sistema.

c) Scrum Team: Consiste na equipe de desenvolvimento, constituída por até dez pessoas em que cada membro tem uma habilidade em determinada área, mas que atuam em qualquer uma das áreas. Com integração e esse conhecimento geral de cada um dos participantes, caso haja a saída de algum membro da equipe, o impacto é minimizado.

O SCRUM possui alguns conceitos importantes a considerar (MACHADO; MEDINA, 2009):

a) Product Backlog: Lista que contém as prioridades das funcionalidades a serem implementadas. Isso garante que as prioridades do cliente sejam atendidas de acordo com sua expectativa.

b) Sprint: Ciclo de desenvolvimento no qual a equipe atua com a construção efetiva do sistema. Deve ter duração de 15 a 30 dias. 
É possível observar que o SCRUM possui particularidades, mas as principais diretrizes em muito se assemelham ao XP. Existem ainda outros modelos ágeis, entretanto as diretrizes expostas no manifesto ágil se mantêm. 


\section{Gerenciamento de projetos}

Um projeto é definido como uma série de atividades relacionadas que visam gerar uma saída principal e necessitam de um período para sua realização (AQUILANO; CHASE; DAVIS, 2001). Cada projeto é único, temporário, necessita de recursos e visa atender a um cliente com determinada entrega (GUIMARÃES; MATTOS, 2005). Pode ser dividido em qualquer número de fases, sendo que cada fase é um conjunto de atividades relacionadas com o intuito de concluir uma entrega. As fases podem ser relacionadas entre si de diferentes formas, conforme exposto abaixo (PMI, 2013):

a) Relação sequencial: Indica que uma fase é seguida por outra, sendo que a primeira deve ser totalmente concluída antes do início da próxima.

b) Relação sobreposta: Indica que a atividade iniciada mais tarde pode iniciar antes do término da atividade anterior, criando uma sobreposição nas fases.

Quando relacionadas, as fases formam uma cadeia de processos a serem seguidos para o andamento do projeto. Este conjunto de fases é conhecido como ciclo de vida de projeto e existem diferentes tipos, conforme segue:

a) Preditivos: São aqueles nos quais o escopo, o tempo e o custo exigidos para a entrega do projeto são definidos o mais cedo possível. Este ciclo de vida é preferível quando o produto a ser entregue é bem compreendido e só é efetivo quando completo.

b) Iterativos e incrementais: São aqueles em que fases do projeto repetem atividades do projeto, conforme evolução do entendimento do produto. Cada iteração (repetição de atividade) adiciona funcionalidades ao produto final do projeto e durante cada uma delas todas as atividades do gerenciamento de projetos são executadas, concluindo uma entrega ao final. Entre cada iteração há a incorporação de lições aprendidas na iteração anterior e há um detalhamento maior do produto a ser entregue, de forma a adicionar funcionalidades significativas em cada uma das iterações. Esta abordagem traz vantagens em casos nos quais o escopo não é totalmente conhecido desde o início do projeto ou quando entregas parciais representem retornos.

c) Adaptativos: São projetados para reagir a altos níveis de mudança e envolvimento contínuo das partes interessadas. Estes ciclos são iterativos e incrementais, mas com iterações muito rápidas (normalmente levam de 2 a 4 semanas), mantendo-se fixos 
os recursos e o tempo. Todas as características esperadas do produto a ser entregue são listadas em um documento, utilizado como base para priorizar o que deverá ser entregue a cada iteração. Ao final de cada iteração, o usuário deve validar a entrega (não necessariamente aceita-la) para conduzir a próxima iteração, dizendo quais são as próximas funcionalidades a serem incluídas, sempre baseado no que está documentado.

O gerenciamento de projetos é o conjunto de ações para estabelecer um plano que guiará o andamento do projeto e, em seguida, executá-lo (CLEMENTS; GIDO, 2007). É muito estudado e aplicado amplamente nas organizações, principalmente na área de TI. Sua utilização em empresas proporciona melhores resultados e custos reduzidos (AMARAL; CONFORTO, 2007).

Realizar o gerenciamento de projetos, entretanto, requer alto grau de atenção a diversas componentes do projeto, conhecimento prévio a respeito e disciplina (MERHI, 2007). Seguir práticas no gerenciamento de projetos faz-se necessário de forma a garantir uma uniformidade no trabalho de diferentes profissionais.

Há ainda a preocupação com o tipo de projeto que será gerenciado. Projetos de desenvolvimento de SI, por exemplo, possuem um teor técnico relacionado aos sistemas em construção, fazendo com que o gerenciamento de tais projetos esteja diretamente relacionado à técnica utilizada, como por exemplo, os modelos de desenvolvimento de SI (SENE, 2010). A figura 4 ilustra o relacionamento entre processos de gerenciamento de projetos (ilustrativamente baseado em PMBOK) e processos de modelo de desenvolvimento de SI (ilustrativamente baseado no modelo cascata).

Figura 4 - Modelo cascata e PMBOK

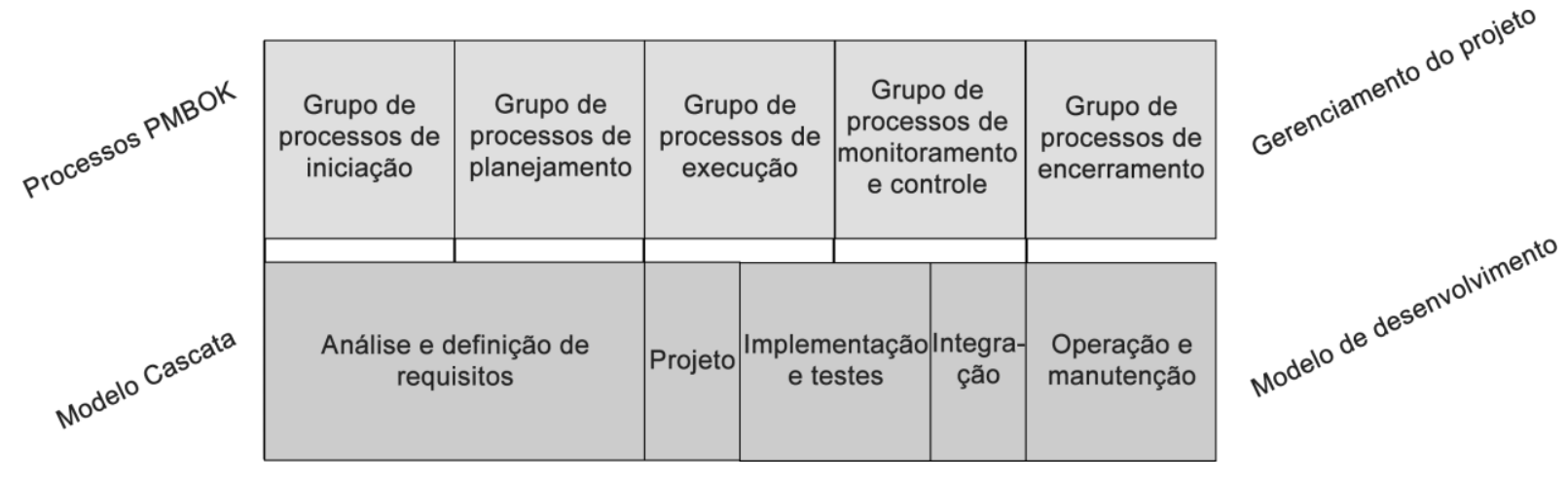

Fonte: Adaptado de Hossenlopp (2005) 
Com esse relacionamento entre processos para a construção do SI e processos de gerenciamento de projetos, deve-se aplicar formas de gerenciamento condizentes com as necessidades e tipo dos projetos a se gerenciar. Nas seções seguintes são apresentadas duas diferentes abordagens para gerenciamento de projetos: tradicional e ágil.

Cada organização efetua o gerenciamento de seus projetos de forma que mais se enquadre de acordo com a história e expectativa da organização, criando o ciclo de vida mais coerente para cada projeto e instituindo os procedimentos que julguem mais pertinentes. $\mathrm{O}$ importante, entretanto, é que haja uma organização no gerenciamento dos projetos e que práticas recomendadas sejam seguidas para tal. Existem diversos modelos propostos para o gerenciamento de projetos, apresentados a seguir.

\subsection{ICB}

O ICB (IPMA Competence Baseline) foi apresentado em uma publicação do IPMA (International Project Management Association) que surgiu em 1999 com o objetivo inicial de fornecer informações técnicas sobre gerenciamento de projetos, mas, com o passar do tempo, agregou mais informações sobre, por exemplo, habilidades interpessoais necessárias a um gerente de projetos (IPMA, 2006).

É dividido em três grandes grupos de competências: contextuais, comportamentais e técnicas:

a) Contextuais: Apresentam conceitos sobre a empresa e o negócio que o projeto visa atender. Nesta competência há fatores fundamentais, como o alinhamento estratégico do projeto para com a organização e seu portfólio.

b) Comportamentais: São as competências de habilidade interpessoal do gestor de projetos, como liderança, motivação, negociação, ética, entre outras.

c) Técnicas: Essas competências tratam mais especificamente dos aspectos do projeto, como partes interessadas, objetivos e requisitos, riscos, qualidade, tempo, recursos, custos, aquisições, contratos, comunicação, controle e acompanhamento do projeto.

\subsection{PRINCE2}

O PRINCE2 (Projects in controlled environments 2) é um modelo para o gerenciamento de projetos, apresentando planejamento, delegação, acompanhamento e controle de todos os 
aspectos do projeto e da motivação das pessoas envolvidas, a fim de atingir objetivos de desempenho esperado para o tempo, custo, qualidade, escopo, riscos e benefícios. Surgiu em 1996, como evolução do modelo PRINCE (Projects in controlled environments), apresentado em 1989 pela ACCT (agência de computação central e telecomunicações) do governo do Reino Unido e rapidamente disseminado, contribuindo com mais de 150 organizações europeias (OGC, 1996).

O modelo se baseia em temas e processos. Os temas guiam os processos, que definem quais atividades serão utilizadas em cada fase do projeto. Os temas são:

a) Business case: Forma de avaliar e apresentar viabilidade e vantagens do projeto, visando apoiar decisões de investimentos.

b) Organização: Estrutura organizacional para o projeto, definindo papéis e responsabilidades aos participantes do projeto.

c) Qualidade: Certificação de que os produtos entregues pelo projeto estão de acordo com a solicitação inicial.

d) Plano: Facilitação do controle e comunicação no projeto. Define o produto a ser entregue, atividades relacionadas e como devem ser realizadas. Define ainda os recursos, tempo e envolvidos em cada atividade. Identifica sinergia entre diferentes atividades e indica pontos de monitoramento e controle.

e) Risco: Controle dos riscos que podem influenciar negativa ou positivamente o projeto.

f) Mudança: Análise e avaliação de impactos causados por mudanças no decorrer do projeto.

g) Progresso: Acompanhamento de todo o progresso do projeto, com previsão de alterações e controle de desvios.

Os processos guiados por tais temas são:

a) Starting up a project: Prevenção do início de projetos mal concebidos e garantia de início de projetos com bom retorno de investimento.

b) Dirigindo o projeto: Delegação das atividades e autorizações para a evolução do projeto. Atividades relacionadas a este processo são: autorizar o início do projeto, o projeto em si, o plano de estágio e execução e autorizar o fechamento do projeto

c) Iniciando o projeto: Estabelecimento da estrutura do projeto, deixando claro qual trabalho tem de ser realizado para que seja concluído. As atividades relacionadas 
são: preparar a estratégia de gerenciamento da qualidade e gerenciamento de comunicação, configurar o controle de projetos e criar o plano do projeto.

d) Controlando estágios: Distribuição e divisão do trabalho, monitoramento do projeto e tomada de ações corretivas conforme necessário. As atividades são: autorizar pacotes de trabalho, rever o estado destes pacotes periodicamente, receber pacotes concluídos e emitir relatórios a respeito.

e) Gerenciamento da entrega do produto: Controle da ligação entre o gerente de projetos e o gerenciamento das equipes envolvidas no projeto.

f) Gerenciamento do limite de estágios: Comunicação do andamento do projeto, identificando o término e início de fases para todos os envolvidos.

g) Fechamento do projeto: Reconhecimento dos resultados, identificando se as solicitações iniciais do projeto foram atendidas. É o ponto final de confirmação da aceitação do projeto. As atividades relacionadas são: avaliar o projeto, entregar os produtos e preparar o encerramento do projeto.

\subsection{PMBOK}

O PMBOK (Project Management Body of Knowledge) é um guia que apresenta uma série de práticas recomendadas na área de gerenciamento de projetos. Foi apresentado em 1981 pelo PMI (Project Management Institute), uma entidade internacional sem fins lucrativos, que reúne diversos profissionais da área de gerenciamento de projetos em todo o mundo. No PMBOK há as principais diretrizes para o gerenciamento de projetos, sendo este constantemente atualizado. Importante salientar que o PMBOK não apresenta um modelo para realizar o gerenciamento de projetos, como o faz, mas sim práticas gerais que podem ser aplicadas em qualquer modelo (PMI, 2013).

O PMBOK é dividido em dez áreas de conhecimento que são necessárias no gerenciamento de projetos. Cada uma das áreas trata do gerenciamento de:

a) Integração: é a área do conhecimento responsável pela conexão de todos os elementos do projeto de forma que tudo se desenvolva de forma organizada e conforme planejado.

b) Escopo: tema central deste trabalho, é a área de conhecimento que garante que todo o trabalho exigido, e somente este, seja aplicado para a completude do projeto. 
c) Tempo: trata do cumprimento de atividades para atendimento do prazo estipulado para o projeto. É importante definir atividades, sequenciá-las, estimar recursos para executá-las, estimar duração de cada uma das atividades, desenvolver e controlar o cronograma.

d) Custos: agrega processos de planejamento, estimativa, orçamento e controle de custos, de modo que o projeto possa ser terminado dentro do orçamento aprovado. O gerenciamento de custos é possibilitado através de planejamento, estimação dos custos, determinação do orçamento e controle.

e) Qualidade: é importante para garantir que as expectativas em relação ao projeto sejam atendidas e pode utilizar diversas normas para estabelecer um padrão. Deve haver um planejamento de qualidade, além de garantia e controle da qualidade.

f) Recursos humanos: pessoas são essenciais para o sucesso do projeto e seu gerenciamento é fundamental para uma devida definição de funções, responsabilidades e relações hierárquicas do projeto em relação a tais recursos, criando um plano de gerenciamento de pessoal.

g) Comunicação: garante que todos os principais envolvidos e processos troquem informações de forma a garantir a integração e esclarecimentos necessários para o sucesso do projeto.

h) Riscos: podem representar ameaças ou oportunidades que, quando ocorrem, influenciam de forma negativa ou positiva o projeto. Para lidar com os riscos há o gerenciamento de riscos, que envolve planejamento, identificação de quais são esses riscos, análise quantitativa e qualitativa destes, planejamento de resposta, monitoramento e controle. Riscos podem se repetir em um mesmo projeto ou aparecerem igualmente em projetos diferentes. Pinto (2002) apresenta em seu trabalho uma lista com os principais riscos identificados durante o gerenciamento de projetos, com suas formas de mensuração e possíveis medidas mitigatórias.

i) Aquisições: descreve a área de conhecimento que trata de compras e aquisições de produtos, serviços ou resultados importantes para a realização do projeto. Deve haver um planejamento de compras, aquisições e contratações, seleção de fornecedores, administração e encerramento de contratos.

j) Partes interessadas: garante que sejam mapeadas todos as pessoas que possuam interesse no projeto e seus resultados. 
Para cada uma das áreas de conhecimento apresentadas o PMBOK estabelece alguns grupos de processos padronizados, através dos quais o projeto pode evoluir em cada uma das áreas de conhecimento. Os grupos de processos são:

a) Iniciação: preparação para andamento da fase do projeto em questão.

b) Planejamento: definição e refinamento de objetivos, definindo como o projeto deve seguir.

c) Execução: garantia de que o planejamento realizado na fase anterior ocorra conforme esperado, integrando os recursos necessários para tal.

d) Monitoramento e controle: identificação de variações do gerenciamento, providenciando ações corretivas ou replanejamentos conforme necessário.

e) Encerramento: formalização da aceitação, concluindo uma fase, iniciando uma próxima, caso exista, ou até mesmo concluindo o projeto como um todo.

O PMBOK apresenta entradas, ferramentas e as saídas de cada grupo de processos, para cada área de conhecimento. Esta forma de apresentar as áreas de conhecimento faz com que fique especificado o relacionamento entre os diferentes processos e facilita o entendimento da relação entre as diferentes fases do projeto (SALADIS, 2006).

Essa abordagem para o gerenciamento de projetos ficou conhecida como "tradicional", por ter sido amplamente utilizada em diversas áreas e tipos de projetos, por muito tempo. É baseada em uma visão processual e propõe grande enfoque em planejamento, sendo uma abordagem preditiva na qual se espera algum conhecimento prévio do que virá a acontecer ao longo do projeto.

A pessoa responsável por realizar o gerenciamento do projeto conforme proposto é o gerente do projeto, que se torna responsável pelo sucesso ou insucesso do projeto. O gerente do projeto deve ser reconhecido como tal pelos demais envolvidos no projeto, mas não necessita de conhecimento técnico aprofundado, tendo em vista que suas competências devem ser direcionadas para uma visão mais geral e não específica (PMI, 2013).

O gerenciamento de projetos em projetos de desenvolvimento de SI está presente ao longo de todo o ciclo de vida do desenvolvimento de tal SI. As práticas apresentadas pelo PMBOK podem ser aplicadas neste tipo de projeto, sendo recomentadas principalmente quando o modelo cascata de desenvolvimento de SI é utilizado. O objeto de pesquisa utilizado neste trabalho, inclusive, utilizava embasamento no PMBOK para o gerenciamento de projetos. Desta forma, o PMBOK foi selecionado para maior exploração na pesquisa bibliográfica. 
Com o aparecimento de novos modelos, como os ágeis, a adoção das orientações do PMBOK apresentou algumas incompatibilidades (SENE; 2010).

Um exemplo disso pode ser observado comparando as próprias características de modelos ágeis com as de gerenciamento de projetos, conforme apresentado no PMBOK. Modelos ágeis propõem adaptabilidade frequente às incertezas dos projetos, com ferramentas que podem se adequar às mudanças e aos riscos que podem surgir frequentemente. Isso já não acontece com as técnicas de gerenciamento de projetos tradicionais (SENE; 2010). Além disso, todas as áreas de conhecimento citadas anteriormente são importantes no gerenciamento do projeto, mas são apresentadas pelo PMBOK principalmente considerando um projeto que tenha um ciclo de vida preditivo ou iterativo e incremental com grandes entregas, que justifiquem um esforço empreendido em cada um dos processos presentes nas dez áreas do conhecimento.

Dado os ambientes de grande dinamicidade nos quais os projetos de SI estão envolvidos, há inclusive menção de que o gerenciamento tradicional de projetos não se mostrou plenamente efetivo para projetos de desenvolvimento de SI (DIAS, 2005). Muitas vezes os projetos precisam de uma dinâmica mais flexível, a exemplo daqueles com ciclo de vida adaptativo. Projetos de SI que lidem com modelos ágeis de desenvolvimento se enquadram nesta categoria e é importante observar que alterações no gerenciamento de tais projetos se fazem necessárias. Com isso, os modelos ágeis que surgiram para o desenvolvimento de SI se estenderam para o gerenciamento de projetos, dando origem ao gerenciamento ágil de projetos (SENE; 2010), como será apresentado a seguir.

\subsection{Gerenciamento ágil de projetos}

Considerando-se os modelos ágeis de desenvolvimento de SI, é necessário que se façam adaptações no modelo de gerenciamento de projetos de forma a atender a flexibilidade de tais projetos.

A abordagem ágil de gerenciamento de projetos tem foco no objetivo final do projeto e auxilia no gerenciamento de projetos que envolvam alto grau de incertezas (HIGHSMITH, 2004). Ela traz flexibilidade, simplicidade e entregas em períodos menores de tempo, resultando em um produto final construído iterativamente (COHN; FORD, 2003). 
Assim, o gerenciamento de projetos para desenvolvimentos com modelos ágeis permite adaptações nas formas de trabalho propostas pelo gerenciamento tradicional de projetos, principalmente no que diz respeito ao GE (ANGIONI et al., 2006).

A equipe deve trabalhar em grupos reduzidos e próximos ao cliente final, de forma que os requisitos a serem incluídos nas entregas parciais sejam avaliados em conjunto e as decisões a respeito sejam tomadas de forma colaborativa entre todos os envolvidos; conforme diretrizes dos métodos ágeis de desenvolvimento de SI. O gestor do projeto, neste momento, atua como facilitador (NERUR; MAHAPATRA; MANGLARAJ, 2005).

É importante ressaltar que o PMBOK é um guia de práticas, sendo estas também aplicáveis em métodos ágeis.

Highsmith (2004) apresenta como as diretrizes do manifesto ágil se aplicam ao gerenciamento de projetos:

a) Respostas às mudanças mais importantes que o seguimento de um plano: esse valor é importante pois no gerenciamento ágil de projetos, mais do que absorver alterações pontuais nos projetos, é importante haver uma completa aceitação de mudança seja de qual aspecto for (CHIN, 2004).

b) Entrega de produtos acima de documentação: A documentação não deve ser desvalorizada no gerenciamento ágil de projetos, mas a entrega concreta é aquilo que pode ser avaliado pelo cliente e por toda a equipe do projeto, portanto é mais importante e deve ser priorizada. A documentação, entretanto, é importante para apoiar o processo e garantir o gerenciamento do conhecimento da equipe e da instituição como um todo.

c) Priorização da colaboração do cliente à negociação de contratos: Considerando o cliente como aquele que utilizará as entregas do projeto para efetivamente agregar valor à instituição, é importante que haja um relacionamento direto, claro e bem estabelecido entre o cliente e a equipe do projeto, sem que isso ocorra pela obrigatoriedade de arranjos contratuais, por exemplo.

d) Mais indivíduos e interações do que processos e ferramentas: Processos e ferramentas devem ser utilizados para guiar e aumentar a eficiência do gerenciamento de projetos, entretanto o essencial é que haja pessoas qualificadas para utilizá-los. Assim, é importante que haja grande auto-organização das pessoas 
envolvidas no projeto, além de autodisciplina e garantia de que utilizarão as ferramentas e processos conforme necessário.

Além de diretrizes, importante observar que há características importantes (HIGHMSITH, 2004) para que haja um bom processo de exploração, que possibilita o desenvolvimento da visão do futuro, importante para o gerenciamento ágil de projetos (CHIN, 2004):

a) Inovação contínua: Entregas que agreguem valor ao negócio de forma diferenciada, atendendo aos requisitos dos clientes;

b) Adaptabilidade do produto: As entregas devem estar preparadas para atender necessidades futuras com pouco ou nenhum esforço adicional;

c) Tempo de entrega reduzido: Maior velocidade nas entregas realizadas é importante para manter a agilidade nesta forma de gerenciamento de projetos;

d) Capacidade de adaptação de processo e pessoas: As características dos modelos ágeis envolvem mudanças em ambientes dinâmicos, que têm de ser compreendidas e aceitas pelas equipes dos projetos, estabelecendo processos que sejam compatíveis com tais mudanças;

e) Resultados confiáveis: As entregas devem ser confiáveis, agregando valor conforme esperado e garantindo o crescimento da instituição.

É importante que o gerenciamento ágil de projetos tenha um ciclo de vida que suporte as orientações apresentadas anteriormente (CHIN, 2004). Para isso, um projeto típico de gerenciamento ágil de projetos deve possuir uma etapa inicial, seguida por vários ciclos nos quais são planejados escopo, tempo, custo e qualidade, resultando em entregas incrementais (UDO; KOPPENSTEINER, 2003).

Cruz (2013) apresenta uma abordagem de gerenciamento ágil de projetos na união de PMBOK com SCRUM. Trata-se de um exemplo sobre como projetos que utilizem os modelos ágeis de desenvolvimento de SI podem receber um gerenciamento embasado em práticas recomendadas, apesar de os processos serem flexibilizados e acompanharem a agilidade do modelo proposto; nesse caso, o SCRUM. 


\section{Gerenciamento de escopo}

O GE do projeto inclui processos para assegurar que o projeto inclui todo o trabalho necessário, e apenas o necessário, para terminar o projeto conforme esperado (PMI, 2013).

O SWEBOK (IEEE, 2004) apresenta uma área de conhecimento específica sobre requisitos de SI (requisitos da solução), que compõe o escopo como um todo. Os principais processos relacionados aos requisitos de SI, segundo o SWEBOK (IEEE, 2004), são: Fundamentos dos requisitos de SI, processos de requisitos, elicitação, especificação e validação dos requisitos. O SWEBOK (IEEE, 2004) possui foco em requisitos do produto, pois se trata de um guia de conhecimento a respeito de engenharia de SI.

O BABOK (IIBA, 2009) apresenta áreas de conhecimento específicas sobre requisitos: elicitação, análise, validação e gerenciamento e comunicação. O BABOK (IIBA, 2009) é um guia a respeito de análise de negócios, possuindo, portanto, foco em requisitos e alinhamento estratégico das organizações com suas áreas de SI.

O PMBOK, apresentado na subseção 3.1, sugere seis principais processos no GE: Planejamento do GE, coleta de requisitos, definição de escopo, criação da EAP, validação do escopo e controle do escopo.

Em seu trabalho, Hossenlopp (2005) apresenta, além do relacionamento entre o GE do PMBOK e o modelo de desenvolvimento cascata, conforme apresentado na seção 3, um relacionamento entre os processos com foco no projeto (PMBOK), no produto (SWEBOK) e no escopo (BABOK), conforme ilustrado pela figura 5.

É possível observar como estas abordagens são relacionadas ao gerenciamento tradicional de projetos; entretanto, há ainda outras propostas de GE. O gerenciamento ágil de projetos, por exemplo, aborda o GE considerando um ambiente mais dinâmico, no qual este escopo pode ser alterado e adaptado com maior frequência e liberdade.

De acordo com o modelo ágil aplicado no desenvolvimento de SI, por exemplo, o GE ocorre sob uma série de processos diferentes. No SCRUM, o escopo é definido gradativamente e a cada ciclo de vida do modelo, alguns requisitos determinados são entregues completamente e, no próximo ciclo, outros. Assim sucessivamente até completar a entrega do projeto. O modelo XP em muito se assemelha ao SCRUM no que tange aos conceitos de GE, pois propõe entregas parciais até a completude do projeto, com retornos do cliente a respeito da evolução que 
percebem, auxiliando na tomada de ações corretivas e até mesmo na redefinição escopo mediante tais percepções.

Figura 5 - Processos relacionados

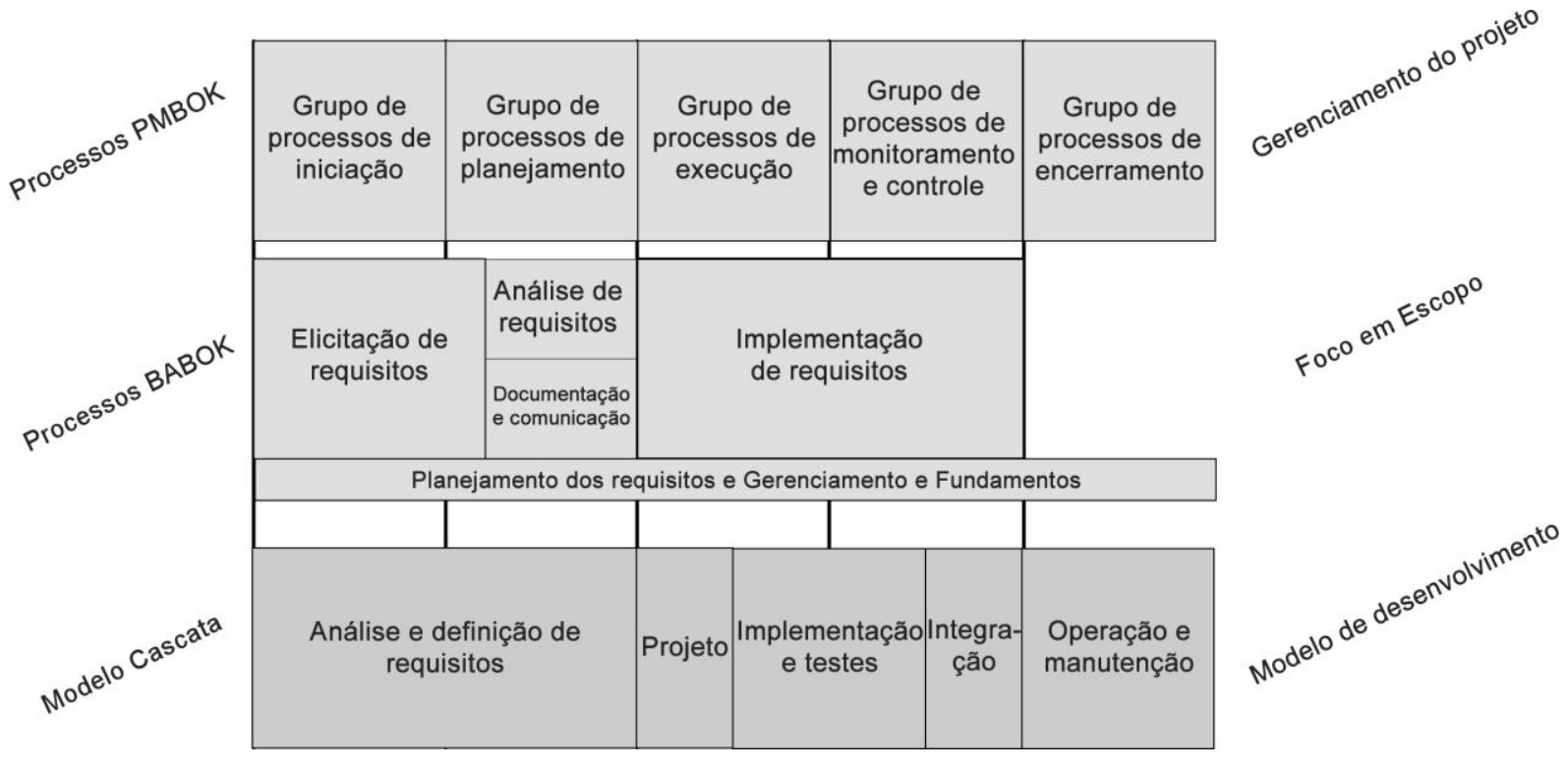

Fonte: Hossenlopp (2005)

Diversos autores também sugerem modelos específicos para o GE, ou até mesmo práticas específicas para tal. Pérez (2004) propõe a utilização de recursos gráficos para auxílio no GE, a exemplo de diagramas, matrizes, árvores de decisão, entre outros. De fato, como será apresentado a seguir, há diversos recursos realmente indicados, inclusive pelo PMBOK, para auxiliar na organização e comunicação durante todo o processo de GE. Dekkers (2010) apresenta modelos específicos de GE: southernSCOPE e northernSCOPE, que são baseadas nas práticas apresentadas no PMBOK, mas adicionam uma visão centrada no usuário e propõem quebras nas entregas realizadas, de forma parecida com o que ocorre no gerenciamento ágil de projetos.

Essas iniciativas para adaptar o GE, independente da forma de gerenciamento de projetos no qual está inserido ou do projeto que está atendendo, ilustram a possibilidade de flexibilizar os processos propostos pelo PMBOK como práticas para atender mais diretamente e com maior eficiência as necessidades de cada instituição. 
Os processos apresentados pelo PMBOK podem estar presentes como um guia inicial sujeito a quaisquer adaptações ou até mesmo em gerenciamento ágil de projetos, portanto as subseções seguintes se destinam à apresentação destes processos.

A figura 6 apresenta uma visão geral do GE do projeto, de acordo com as práticas propostas pelo PMBOK.

Figura 6 - Gerenciamento de escopo

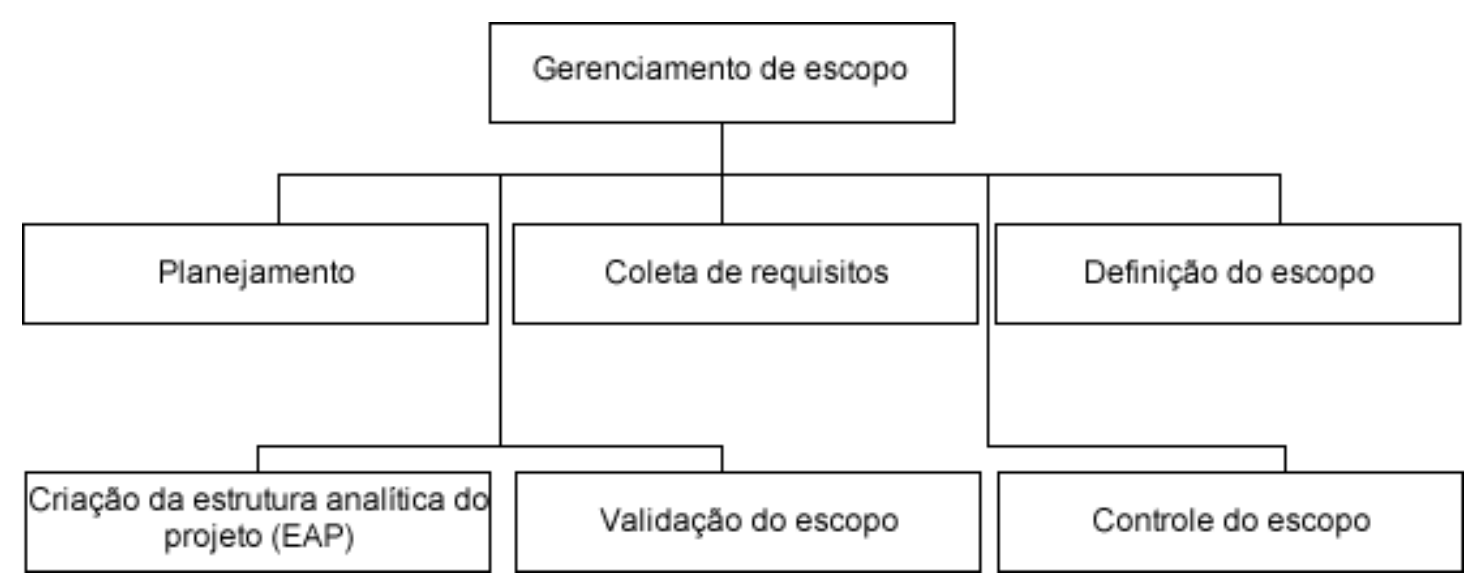

Fonte: PMI (2013)

Os processos de GE apresentados na figura 6 estão inseridos nos grupos de processos de "Planejamento" e "Monitoramento e controle" do PMBOK, conforme exposto pela tabela 1.

Tabela 1 - Processos do GE

Grupo de processos do GE

Planejamento

\section{Processos do GE}

Planejamento do GE;

Coleta de requisitos;

Definição do escopo;

Criação da estrutura analítica do projeto (EAP).

Monitoramento e controle

Validação do escopo;

Controle do escopo. 
Santos (2010) apresenta um instrumento para avaliar o quanto o GE está adequado ao que o PMBOK apresenta, separadamente por processos do GE. Cada um dos processos do GE serão detalhados nas subseções seguintes.

\subsection{Planejamento do GE}

O planejamento do projeto é de grande importância e quanto mais planejamento houver, maior chance de sucesso haverá (WANG; GIBSON, 2008). Isso também se aplica ao GE do projeto.

Planejar o GE é o processo de criar um "plano de gerenciamento do escopo", um documento responsável por ditar como o escopo do projeto será definido, desenvolvido, monitorado, controlado e verificado (PMI, 2013). O plano de GE descreve quais são as entregas finais de forma que o cliente possa entender e realizar suas considerações a respeito, possuindo também definições do que está e do que não está incluso no escopo do projeto, delimitando seus limites. Possui ainda descrição dos riscos do escopo, critérios de aceite das entregas e do projeto como um todo, ao final (MARTIN; TATE, 2000).

Para a formulação do plano de GE é importante levar em consideração as características do projeto e da empresa que o está realizando, como por exemplo, fatos históricos de sucesso ou insucesso de outros projetos, utilizando o gerenciamento de conhecimento realizado na empresa em questão (ALP; STACK, 2012). Utilizando informações como essa, os principais envolvidos no projeto realizam reuniões para discussão e definição da forma de trabalho, utilizando-as para embasar discussões, além de outros documentos como a requisição de projeto oficial apresentada pelo cliente e o plano de gerenciamento do projeto, por exemplo.

Há ainda um documento gerado nesse processo, que é de grande importância para o GE: o plano de gerenciamento dos requisitos (PMI, 2013). Esse documento é um descritivo de como os requisitos serão analisados, documentados e gerenciados. Ter essa visão de como tratar os requisitos no GE é importante pois não somente proporciona previsibilidade dos processos que seguirão, como também ajuda a comunicação do projeto, fazendo com que todos tenham conhecimento uniforme a respeito de como os requisitos serão tratados (HOSSENLOPP, 2005). 


\subsection{Coleta de requisitos}

Após o planejamento do GE, os requisitos são coletados, determinando, documentando e gerenciando as necessidades e requisições das partes interessadas. O principal benefício da fase de coleta de requisitos é a definição a respeito das expectativas dos interessados, para que os objetivos a serem atingidos com o projeto estejam esclarecidos e acordados entre todos (KUMAR, 2006).

Segundo o SWEBOK (IEEE, 2004) o processo denominado "elicitação de requisitos" tem como foco identificar a origem dos requisitos e como é possível coletá-los. Como fonte dos requisitos, cita objetivos do sistema, área de conhecimento, envolvidos, ambiente operacional e o próprio ambiente da organização. Como técnicas possíveis para coleta de requisitos, cita entrevistas, montagem de cenários e protótipos, dinâmicas de trabalho e observação. As mesmas técnicas são citadas pelo BABOK (IIBA, 2009), que apresenta a "elicitação de requisitos", assim como o SWEBOK (IEEE, 2004).

Como apresentado pelo SWEBOK (IEEE, 2004), há diversas técnicas para coleta de requisitos. Destacam-se a utilização de questionários, entrevistas estruturadas e análise de documentação (JONASSON, 2007). A seguir apresenta-se uma comparação entre estas técnicas de coleta, apresentando sua descrição, pontos fortes e pontos fracos (HOSSENLOPP, 2005):

a) Entrevista: Forma sistemática de coletar informações de uma pessoa ou grupo de pessoas utilizando de uma conversa formal ou informal na qual são apresentadas perguntas previamente formuladas. Pode ser complementada com acompanhamento das atividades do entrevistado, visitação em seu local de trabalho e análise de suas atividades.

- Pontos fortes:

- Permite o entrevistador e o participante a terem uma entrevista que pode ser guiada, proporcionando a possibilidade de uma interpretação consistente dos resultados, dado que existe a possibilidade de explorar novas informações que surjam.

○ Encoraja participação, estabelecendo contato e engajamento dos participantes.

○ Possibilita observação de linguagem não verbal. 
○ Permite confirmação das informações imediata, evitando erros de interpretação.

- Pontos fracos:

○ Exige disponibilidade e comprometimento dos envolvidos.

○ É importante haver treinamento e preparação para uma condução eficaz de entrevista.

○ Entrevistas não estruturadas exigem habilidades especiais para garantir a coleta de requisitos.

- A transcrição e análise das entrevistas podem ser complexas e trabalhosas.

○ O resultado da entrevista está sujeito à interpretação do entrevistador.

- Os envolvidos dificilmente conseguem discutir como as coisas deveriam ser, se limitando a dizer a respeito de como são.

b) Questionário: Administração de perguntas escritas para coletar informações a respeito dos clientes, trabalhos, práticas e atitudes. As respostas são analisadas para coletar os requisitos, interesses e posicionamento dos respondentes.

- Pontos fortes:

○ Exige pouco tempo dos respondentes.

○ Efetivo para contornar problemas de localização geográfica.

- Pode ser aplicado em diferentes escalas de público.

○ Relativamente rápido e prático de se administrar.

○ Evita subjetividade.

- Pontos fracos:

○ Em média há uma taxa baixa de respostas.

○ Incentivos para que as pessoas respondam podem ser caros.

○ Uso de questões abertas requer mais análises.

- Impossibilidade de melhor entendimento das respostas.

- Necessário treinamento de ferramenta e conhecimento do domínio de respostas.

- Perguntas ambíguas podem prejudicar o projeto, causando um desvio das informações reais. 
c) Análise de documentação: Administração de perguntas escritas aos envolvidos para coletar informações a respeito dos clientes, trabalhos, práticas e atitudes. As respostas são analisadas para coletar os requisitos, interesses e posicionamento dos respondentes.

- Pontos fortes:

○ Esta técnica auxilia no mapeamento do "cenário atual".

- Pontos fracos:

○ Documentação existente pode estar desatualizada.

○ Exige um conhecimento técnico e de negócios para determinar se a documentação representa o processo atual.

Como é possível observar, cada uma das técnicas para coleta de requisitos possui particularidades, cabendo ao responsável pela coleta de requisitos fazer a escolha mais adequada para cada projeto. Há ainda técnicas específicas de levantamento de requisitos criadas por empresas com o intuito de facilitar o processo de acordo com suas necessidades. Um exemplo é JAD (Joint Application Design), criada pela IBM mas rapidamente expandida para outras organizações devido à sua efetividade na coleta de requisitos.

JAD apresenta uma proposta de dinâmica de trabalho com regras, papéis e estrutura prédefinidos (BURNETT et al., 2010). Este modelo foi criado pela IBM em 1977 com o objetivo de facilitar a obtenção de um consenso entre usuários a respeito de requisitos. De forma sucinta, consiste em uma dinâmica de trabalho em grupo na qual cada participante possui um papel bem definido, com responsabilidades atribuídas. Há o condutor, que deve mediar as dinâmicas; o analista de sistemas, que é geralmente a pessoa responsável por efetuar o desenvolvimento do SI em questão; o patrocinador, com poder supremo a respeito das funcionalidades do sistema a desenvolver, resolvendo conflitos durante as sessões, apresentando visões estratégicas e fornecendo os recursos necessários para o andamento do projeto; usuários do sistema, que devem apresentar as necessidades e auxiliar nas tomadas de decisão; o documentador que deve fazer todas as anotações necessárias, auxiliando o líder. É possível incluir participantes adicionais conforme necessário, mas se adequando às dinâmicas propostas pelo modelo.

Além de papéis bem definidos, propõe algumas reuniões fixas para a dinâmica. A primeira reunião destina-se à abertura dos trabalhos, definindo escopo do sistema, objetivos, problemas, limites, pessoas envolvidas nos levantamentos de requisitos e data da próxima reunião. Em seguida, há a reunião de levantamento de dados e análise, executada pelo analista 
de sistemas, com a apresentação de diagramas que facilitem a comunicação, demonstrando os fluxos atuais baseado nas informações da reunião anterior. Na reunião que se segue, pode haver somente a presença do condutor e do analista de sistemas, para o planejamento da sessão de desenho. Nesta reunião o analista de sistemas apresenta para o condutor a proposta do sistema que será debatido na reunião seguinte, para que o condutor possa auxiliar com sugestões e aprimoramentos. $\mathrm{O}$ analista deve preparar o material a ser exibido na seção seguinte, de desenho. A seção de desenho é a mais importante para o JAD, pois é o momento em que todos poderão debater sobre a proposta apresentada pelo analista de sistemas responsável.

Para controle dos requisitos, o PMBOK orienta a utilização de uma matriz de rastreabilidade de requisitos, um documento que relaciona cada um dos requisitos coletados com as entregas previstas e objetivos do projeto. Neste documento podem haver, por exemplo: necessidades e oportunidades de negócio, objetivos do projeto, entregas do projeto, desenho do produto a ser entregue, desenvolvimento deste produto, estratégia de testes e cenário de testes para os requisitos coletados e os próprios requisitos (PMI, 2013). A figura 7 apresenta um modelo proposto de matriz de rastreabilidade.

Figura 7 - Matriz de rastreabilidade de requisitos

\begin{tabular}{|c|c|c|c|c|c|c|c|c|}
\hline \multicolumn{9}{|c|}{ Nome do projeto: } \\
\hline \multicolumn{9}{|c|}{ Descrição do projeto: } \\
\hline ID & $\begin{array}{c}\text { ID } \\
\text { associado: }\end{array}$ & \begin{tabular}{|c|}
$\begin{array}{c}\text { Descrição dos } \\
\text { requisitos }\end{array}$ \\
\end{tabular} & $\begin{array}{c}\text { Necessidades } \\
\text { do negócio }\end{array}$ & $\begin{array}{l}\text { Objetivos } \\
\text { do projeto }\end{array}$ & \begin{tabular}{|} 
Entregas da \\
EAP
\end{tabular} & $\begin{array}{c}\text { Desenho do } \\
\text { produto }\end{array}$ & $\begin{array}{c}\text { Desenvolvimento } \\
\text { do produto }\end{array}$ & $\begin{array}{l}\text { Casos de } \\
\text { teste }\end{array}$ \\
\hline \multirow{4}{*}{1} & 1.0 & & & & & & & \\
\hline & 1.1 & & & & & & & \\
\hline & 1.2 & & & & & & & \\
\hline & 1.2 .1 & & & & & & & \\
\hline \multirow{3}{*}{2} & 2.0 & & & & & & & \\
\hline & 2.1 & & & & & & & \\
\hline & 2.2 & & & & & & & \\
\hline \multirow{3}{*}{3} & 3.0 & & & & & & & \\
\hline & 3.1 & & & & & & & \\
\hline & 3.1 .1 & & & & & & & \\
\hline
\end{tabular}

Fonte: PMDOCUMENT (2013)

\subsection{Definição do escopo}

Sabendo o que será contemplado no escopo é possível organizar e detalhar os requisitos, o que pode ser feito iterativamente até que o detalhamento seja o suficiente para o 
desenvolvimento do projeto sem dúvidas ou duplas interpretações das necessidades declaradas (KUMAR, 2006). Sabendo o que não será contemplado no escopo é possível estabelecer os limites do projeto, explanando aos envolvidos o que não será entregue.

Kayed (2013) propõe sete passos para uma definição completa e adequada de escopo. O primeiro passo está relacionado a analisar o ambiente do projeto, incluindo os interessados e influências. Isso ajuda a garantir uma integração com os demais projetos em andamento, se for o caso, ou analisar impactos e percepções acerca dos requisitos coletados anteriormente. $\mathrm{O}$ segundo passo é alinhar o escopo do projeto com os objetivos estratégicos e desafios de negócios. Para isso, é necessário compreender tais desafios, tentando propor soluções simples para resolvê-los. Em seguida, no terceiro passo, é importante determinar como agregar valor aos negócios, com soluções endereçadas para as principais funcionalidades. Aqui é importante atentar para o retorno sobre investimento, determinando quais requisitos podem trazer maior retorno. O quarto passo é o estudo do fluxo de processos entre as unidades de negócios, para auxiliar nas estimativas de impactos do escopo proposto, mesmo em áreas que não estejam inseridas no projeto, por participarem de algum fluxo em comum com outras áreas contempladas no projeto. No quinto passo, desenvolve-se uma estratégia de comunicação eficiente, através da qual serão resolvidos conflitos de interesse ou dúvidas a respeito do entendimento de como os requisitos irão funcionar, impactar ou agregar valor aos negócios. No sexto passo, é estabelecida uma abordagem do projeto, na qual aparecem aspectos mais técnicos do escopo, apresentando esforços por conta dos requisitos e esclarecendo o que será feito. Por fim, o sétimo passo trata-se da coordenação do novo projeto com outras iniciativas já em andamento. Nesta etapa é importante integrar satisfatoriamente o escopo do projeto que está sendo definido com outros que eventualmente estejam em andamento, verificando se há conflitos, sinergias ou outros tipos de impacto a serem administrados.

A figura 8 representa o fluxo apresentado para uma adequada definição do escopo. 
Figura 8 - Sete passos para definição do escopo

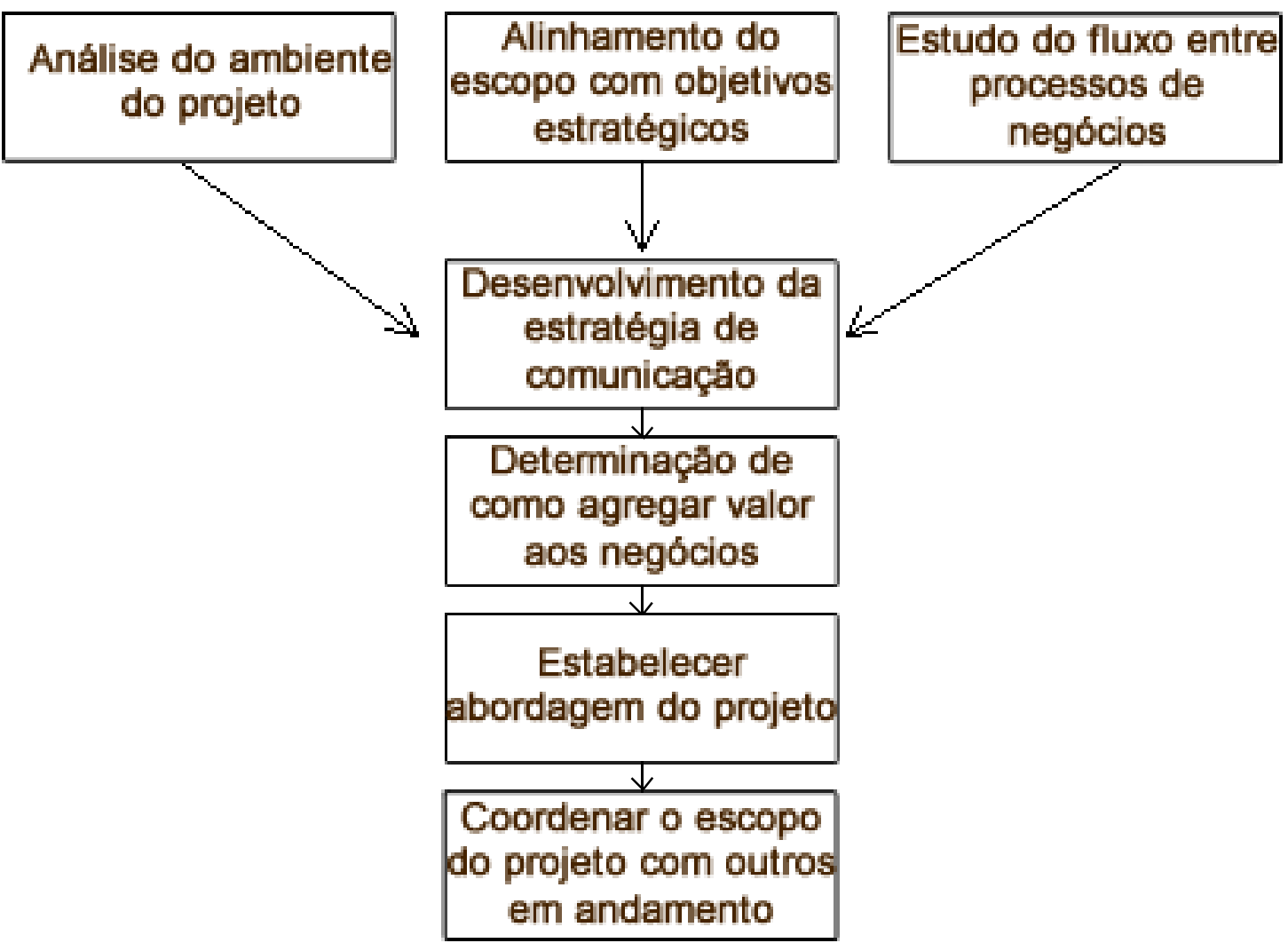

Fonte: Kayed (2013)

Com a definição do escopo também é importante apresentar quais são os critérios de aceite que serão utilizados para aprovar ou recusar os requisitos entregues ao final do projeto, quais são as limitações presentes no projeto para a entrega final do acordado e quais são as premissas, que são assumidas em comum acordo por todos os envolvidos (PMI, 2013).

Segundo o SWEBOK (IEEE, 2004) os processos de análise de requisitos são capazes de detectar e resolver conflitos entre requisitos e delimitar os limites dos requisitos. Os processos de especificação de requisitos visam os documentar de forma estruturada no projeto, garantindo rastreabilidade, acompanhamento e compartilhamento de conhecimento a respeito dos requisitos. Este conjunto de processos do SWEBOK (IEEE, 2004) se referem à definição do escopo, que apresenta os mesmos objetivos. 


\subsection{Criação da EAP}

Com o escopo fechado, é possível criar a EAP, que significa "Estrutura Analítica do projeto". Trata-se de um documento no qual as entregas do projeto são decompostas de forma a facilitar o gerenciamento de cada entrega, apresentando-as de forma hierárquica (BUREK, 2013). Cada nível inferior máximo da hierarquia representa um "pacote de trabalho", que diz respeito a uma entrega atômica, que não deve ser mais segmentada (PMI, 2013). As entregas devem ser descritas por substantivos, e não por verbos, como ocorre no cronograma do projeto, para descrever as atividades. A figura 9 apresenta um exemplo de modelo para a EAP.

Figura 9 - Exemplo de modelo da EAP

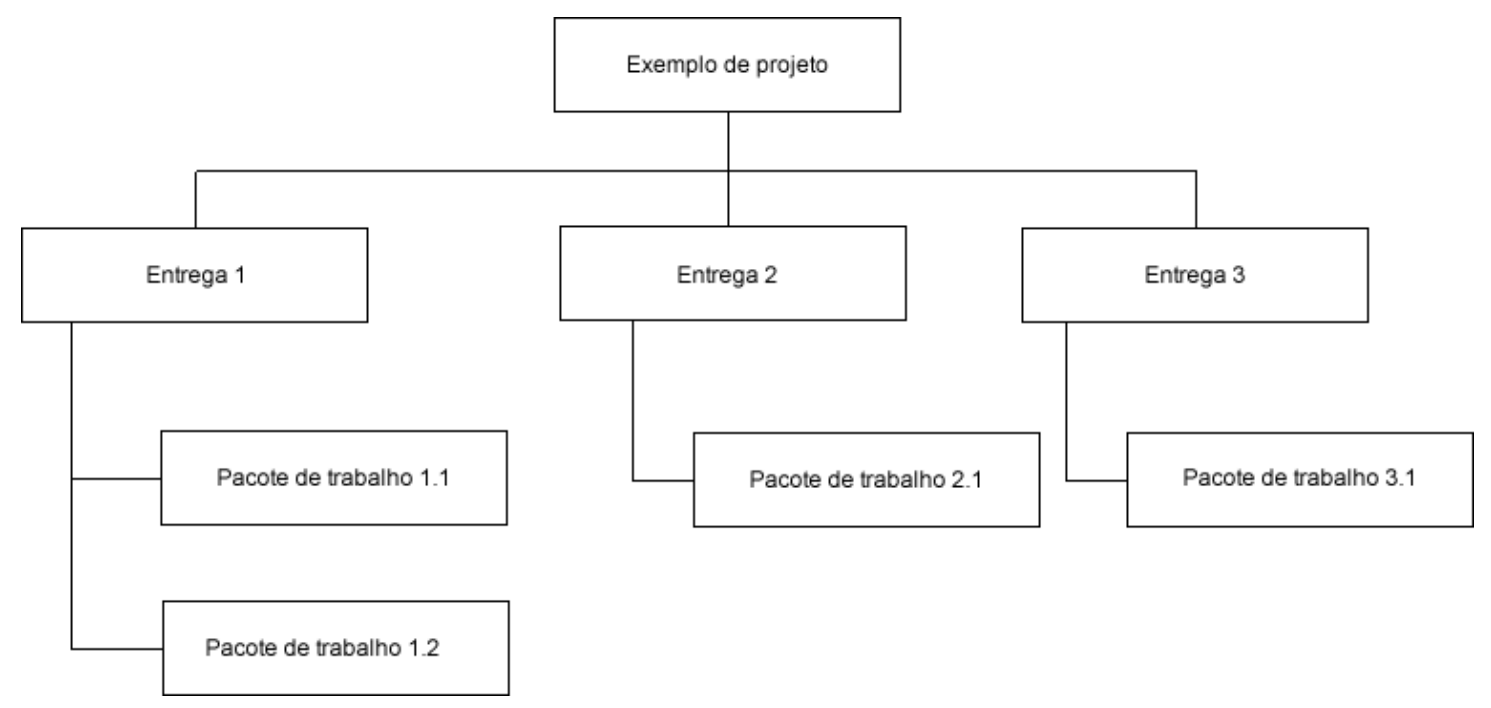

Fonte: Adaptado de PMDOCUMENTS (2013)

A EAP representa todas as entregas a serem produzidas pelo projeto e pode auxiliar na estimativa de custos, atribuição de recursos e definição de dependência entre atividades. Assim, trata-se de um importante documento do projeto (BUREK, 2011).

Não há uma única forma correta de se construir uma EAP, o importante é que a EAP final faça sentido e seja aceita por todos os envolvidos no projeto, além de representar tudo que será entregue como solução do projeto (BUREK, 2011).

Além da EAP em si, nesta fase é criado também o dicionário da EAP, que detalha cada uma das entregas apresentadas na EAP, contendo sua descrição, estimativa de custo, principais prazos de entrega, premissas e restrições, critérios de aceite, dentre outros detalhes pertinentes 
a cada entrega (WARD, 2001). Com o dicionário é possível entender, através de uma descrição, do que se trata cada um dos itens apresentados na EAP. É possível aumentar a efetividade do dicionário, incluindo, para cada entrega: dependências e impactos, comentários de progresso, principal pessoa responsável, data de início, percentual de completude, término previsto, lista de problemas e riscos e estado da entrega (um sinalizador que indica o estado geral de cada entrega) (WARD, 2001).

A figura 10 apresenta um modelo simples de estrutura que pode compor um dicionário da EAP (PMDOCUMENTS, 2014).

Figura 10 - Exemplo de dicionário EAP

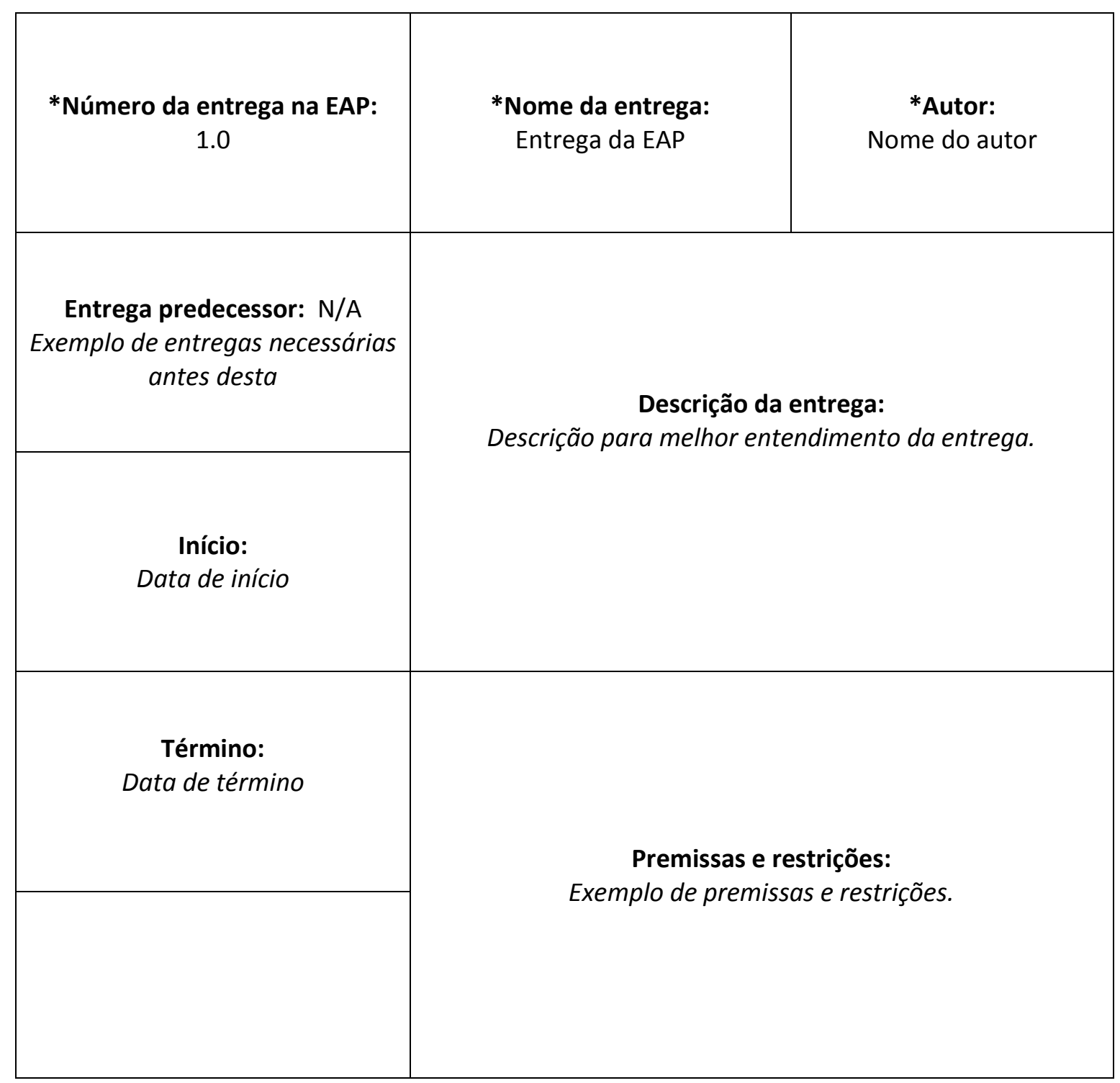




\subsection{Validação do escopo}

Com as entregas bem definidas e cada critério de aceite estabelecido é possível validar o escopo. Na fase de validação de escopo, as entregas são apresentadas aos requisitantes do projeto, que devem fornecer o "aceite" oficial às entregas (PMI, 2013).

Nessa fase também é possível colaborar com gerenciamento de conhecimento, documentando os aprendizados do projeto. O gerenciamento de conhecimento é importante para a organização, pois além de deter os aprendizados originados por cada um dos projetos, utilizando disto para formar pessoas e disseminar conhecimento; também será utilizado como insumo em processos do gerenciamento de projetos (GASIK, 2011).

O SWEBOK (IEEE, 2004) apresenta a importância da validação dos requisitos, garantindo que foram compreendidos, e a importância da verificação dos requisitos, garantindo que os requisitos sejam documentados de acordo com os padrões da instituição, de forma objetiva, consistente e completa. A validação dos requisitos é parte importante da validação do escopo.

\subsection{Controle do escopo}

Mudanças de escopo em projetos muitas vezes são inevitáveis, sendo que o GE não deve tentar bloquear tais mudanças, mas sim gerenciá-las de forma adequada (MILLHOLLAN, 2008).

A fase de controle do escopo verifica o que está sendo realizado, em relação ao que foi inicialmente planejado, acompanhando a evolução do escopo do projeto (PMI, 2013). O controle do escopo permite a realização de mudanças através de requisições de mudança, que podem acontecer ao longo de todo o projeto e devem ser acordadas entre todos os envolvidos, avaliando-se os impactos que poderão causar no projeto. Essas requisições de mudanças podem ser armazenadas, por exemplo, em ferramentas de apoio que possibilitam rastreabilidade e criação de histórico (CANFORA; CERULO, 2005).

Requisições de mudanças aparecem em todas as fases do ciclo de vida do projeto de SI. A figura 11 ilustra como se distribuem as requisições de mudanças ao longo das fases do projeto durante seu ciclo de vida. 
Figura 11 - Mudanças solicitadas por fase no projeto

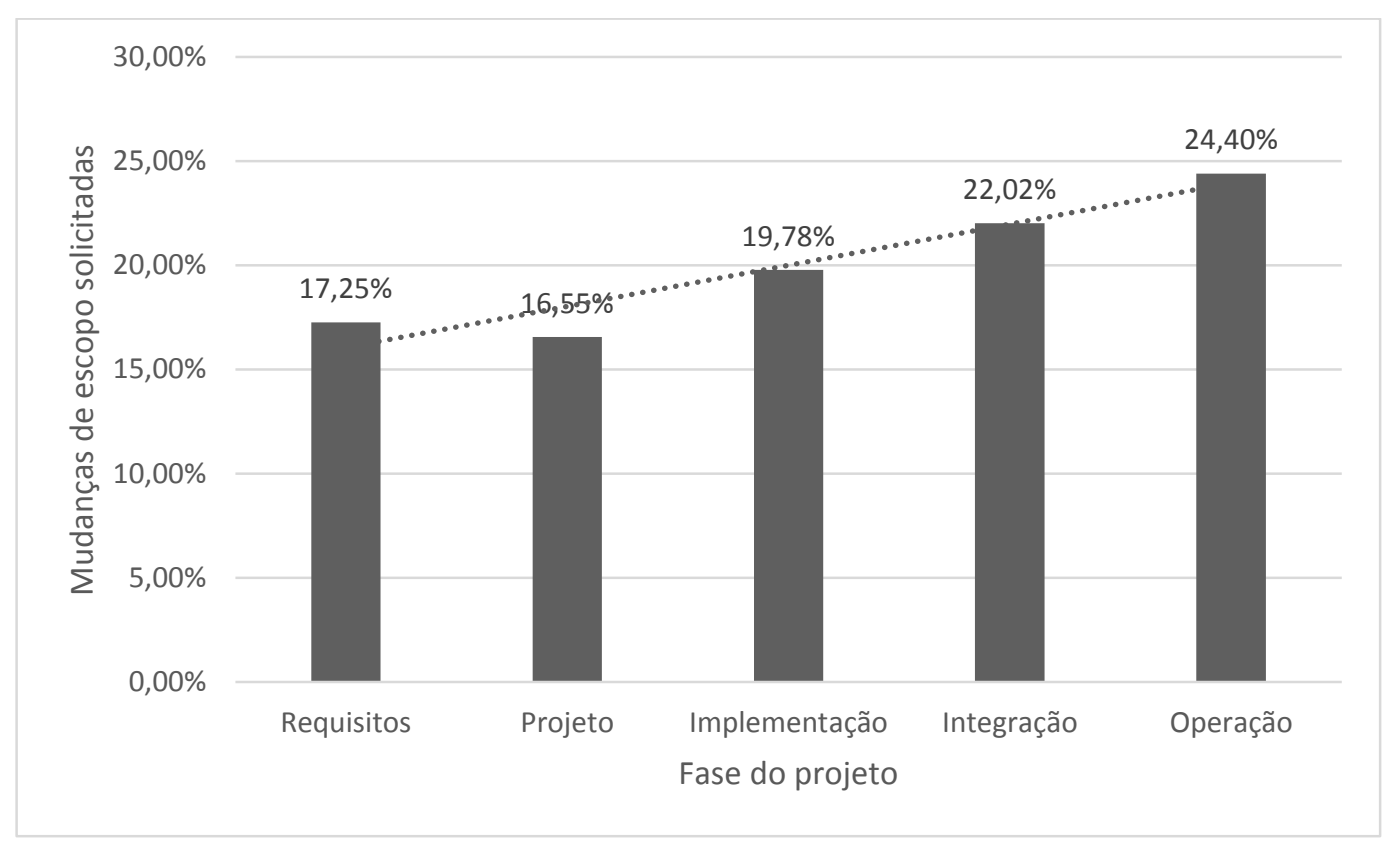

Fonte: Ahmed et al. (2010)

Como é possível se observar, as requisições de mudanças aparecem com maior frequência conforme o projeto evolui. Esse é um fator relevante pois o custo dessas mudanças também se eleva com a evolução do projeto (IBBS; WONG; KWAK, 2001). A figura 12 ilustra como o custo se eleva com o passar do tempo no projeto.

Figura 12 - Custo das mudanças ao longo do projeto

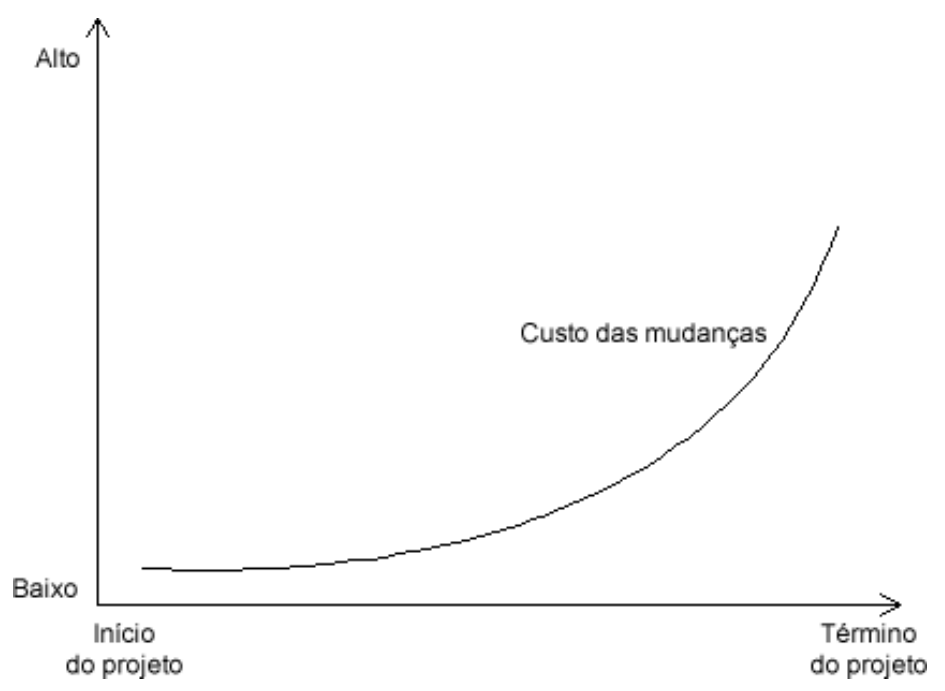

Fonte: Adaptado de PMI (2013) 
Com estas informações é possível entender melhor a necessidade de controlar o escopo do projeto, pois quanto mais o projeto se aproxima de seu término, mais aparecem mudanças, e mais caro elas custam.

O controle de escopo inclui controlar as mudanças, que devem ser analisadas, discutidas e gerenciadas. Sempre que houver uma mudança necessária no projeto, seja por uma necessidade do cliente, por uma determinação legal ou até mesmo por conta de solução técnicas, essa mudança deve ser discutida em comitês específicos com a representatividade dos principais envolvidos no projeto.

Para mudanças externas ao projeto (solicitações do cliente, determinações legais ou da instituição, por exemplo), sugere-se os seguintes passos para controlar o escopo (ABRAMOVICI, 2000):

- Garantir que o escopo esteja fechado e que tenha sido validado junto ao cliente, verificando-se requisito a requisito.

- Estabelecer regras para o envolvimento do cliente no projeto.

- Definir como trabalhos decorrentes de solicitações fora do escopo inicial serão validados, aceitos e executados. É importante estabelecer quem pode iniciar propostas de mudanças no escopo e como essas propostas têm de ser formalizadas. Os custos de preparar e formalizar propostas, além de análise dos custos de mudanças, têm de ser assumidos pelo solicitante, ainda não impactando o orçamento do projeto.

Caso as mudanças sejam internas do projeto, como por exemplo, melhorias no processo que está sendo alterado ou alterações na solução técnica que possam impactar o escopo inicialmente definido, há passos específicos a se atentar (ABRAMOVICI, 2000):

a) Reforçar com a equipe do projeto que é importante fazer aquilo que é necessário, e somente aquilo que é necessário, para atender às solicitações realizadas pelo cliente no escopo acordado.

b) Definir como adições ao escopo inicial, a exemplo de melhorias, serão tratados em caso de necessidade. Uma prática sugerida é a implementação de uma "caixa de sugestões", que pode ser visitada em determinados marcos do projeto e apresentada aos clientes para alinhamento do benefício de mudanças.

c) Simplificações ou remoções devem ser olhadas sempre como benéficas, desde que não reduzam qualidade ou tragam impactos às funcionalidades que devem ser entregues. No caso de existirem tais sugestões, deverá haver uma análise de 
impactos cuidadosa para garantir que as entregas do projeto não serão comprometidas.

Há formas sugeridas de fazer o gerenciamento das mudanças no GE. O controle por um comitê, por exemplo, garante que as mudanças necessitem de análise e aprovação para que se possa implementá-las. Um comitê de controle de mudanças deve ser formado por membros do projeto que sejam impactados pelas mudanças, mas também pode conter partes interessadas que não estejam diretamente envolvidas na execução do projeto. As tarefas do comitê são de analisar, organizar e tomar decisões a respeito de solicitações de mudança (HU; LIU, 2008). A figura 13 apresenta um modelo possível para o controle de mudanças.

Figura 13 - Processo de controle das mudanças

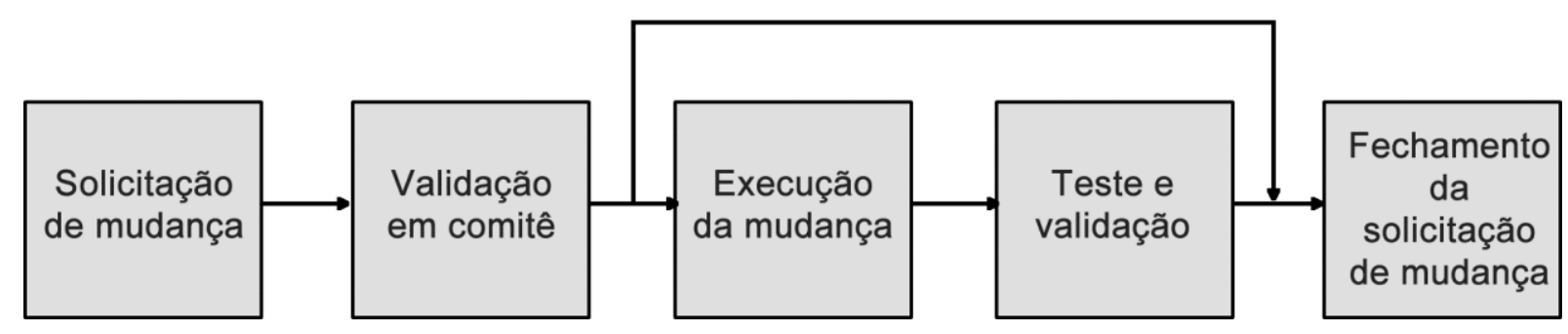

Fonte: Hu e Liu (2008)

É importante haver um formulário padrão para se fazer solicitações de mudanças, contendo quem requisitou a mudança, data, título, projeto, funcionalidade afetada, tipo de mudança, criticidade, prioridade, responsável pela mudança e descrição; por exemplo (AHMED et al., 2010). Além disso, é importante armazenar a documentação das mudanças realizadas para referências futuras.

\subsection{Riscos que influenciam custo e tempo dos projetos}

Segundo Davis (2000), o GE já vinha sendo discutido desde aproximadamente 1985, sendo que se tornou mais complexo com o passar do tempo. Surgiu para simplificar o desenvolvimento de produtos, reduzir custos e riscos associados ao desenvolvimento de SI. Em vez disso, o GE e, especificamente, atividades relacionadas ao gerenciamento de requisitos, tornaram-se atividades propensas a erros e considerados uma das maiores causas de falhas de 
produtos entregues pelos projetos. Em tal contexto, é importante analisar os riscos dos projetos e, principalmente, aqueles que de fato ocorreram, identificando sua relação com o GE.

Pinto (2002) realizou um estudo acerca dos principais fatores de risco que influenciam o sucesso de projetos de SI.

Nakashima e Carvalho (2004) apresentam que o PMBOK (PMI, 2013) mostrou-se adequado para o gerenciamento de riscos em um estudo de caso realizado em uma rede de acesso de âmbito nacional, com clientes como provedores de acesso à internet e bancos. $\mathrm{O}$ principal risco identificado no estudo foi o fechamento de escopo do projeto estudado.

Segundo Vezzoni (2011), a preparação para enfrentar riscos é significativa para aumento de probabilidade de alcance de sucesso em projetos, sendo que tal sucesso estaria relacionado a alguns fatores, dentre os quais, a eficiência do projeto.

Com elevada importância no gerenciamento de projetos, a área de conhecimento de riscos, entretanto, é a segunda de maior dificuldade no gerenciamento segundo gerentes de projetos entrevistados no estudo de Bomfin, Nunes e Hastenreiter (2012).

Ao abordar os modelos de desenvolvimento de SI, Pinto (2002) apresentou uma lista de dez riscos que podem impactar qualidade, custo e tempo destes projetos, conforme a tabela 2.

Tabela 2 - Principais riscos e impactos

\begin{tabular}{llll}
\hline & \multicolumn{2}{c}{ Impactos } \\
\cline { 2 - 4 } & Qualidade & Custo & Tempo \\
\hline Identificação tardia de mudanças e retrabalho excessivo & $\bullet$ & $\bullet$ & $\bullet$ \\
\hline Conflitos entre membros da equipe de desenvolvimento & $\bullet$ & $\bullet$ & $\bullet$ \\
\hline Recursos de desenvolvimento inadequados & $\bullet$ & $\bullet$ \\
\hline Conflitos entre áreas envolvidas no projeto & $\bullet$ \\
\hline Inserção de tecnologia necessária & $\bullet$ \\
\hline Lentidão e falta de objetividade no levantamento de & $\bullet$ \\
requisitos & & $\bullet$ \\
\hline
\end{tabular}


Principais riscos

\section{Impactos}

Qualidade Custo Tempo

Interrupções na fase de análise

Desempenho inadequado da aplicação

Ênfase excessiva em documentação, em forma de texto e burocracia de aprovação

Desenvolvimento de funcionalidades inadequadas

Fonte: Adaptado de Pinto (2002)

Segundo o autor, conhecer os riscos que podem impactar resultados dos projetos pode ser fundamental para a devida prevenção, correção e minimização de problemas e falhas que possam se apresentar ao longo dos projetos. Pinto (2002) faz ainda um levantamento mais profundo acerca das características de riscos durante sua pesquisa, explorando fatores de sucesso que considerou relevantes e apresentando relações entre as variáveis de riscos e sucesso dos projetos. Para o atual trabalho, no qual o que se está medindo é o desempenho de custo e tempo, consideraremos os riscos de forma mais generalizada, para um levantamento acerca daqueles que se manifestaram em fato como problemas nos projetos avaliados.

\subsection{Critérios para avaliação do GE}

Os processos do gerenciamento de projetos podem ou não seguir as práticas apresentadas na literatura. Saber em quais práticas projetos se baseiam pode proporcionar uma forma de avaliar se os processos foram executados conforme esperado, e se há ainda adaptações necessárias ou quanto aprendizado ainda há para atingir melhores resultados na execução dos processos.

Observando as práticas sugeridas pelo PMBOK, por exemplo, é possível analisar se todas as saídas esperadas dos processos foram geradas com sua execução. Santos (2010) propôs uma lista de verificação baseada em questionário para a realização da inspeção de documentação do GE para projetos que seguem as práticas apresentadas pelo PMBOK. 
Segundo a pesquisa realizada, a lista de verificação proposta minimiza problemas identificados nos casos analisados, complementa informações sugeridas pelo PMBOK para a verificação do escopo e pode prevenir os impactos de problemas legais desde as fases iniciais dos projetos. Segundo Santos (2010), a utilização de inspeção de documentação pode detectar de $30 \%$ a $90 \%$ de erros existentes em documentação gerada no desenvolvimento de SI, por exemplo.

Santos (2010) baseou-se no PMBOK e em literatura acadêmica adicional para identificar quais eram os principais fatores a serem avaliados no GE. Utilizando de decomposição para remover a subjetividade presente no método de inspeção utilizado, estruturou tais fatores em características, aspectos e questões.

Segundo as análises realizadas com embasamento em seu referencial teórico, propôs que as informações relevantes encontradas envolviam as características:

a) Informações do grupo de processos de planejamento do GE do projeto.

b) Informações de requisitos.

c) Cuidados com os requisitos.

d) Informações de escopo.

e) Informações da EAP.

O instrumento elaborado no trabalho leva em consideração as entradas, técnicas e saídas dos processos apresentados no PMBOK, avaliando se foram adequadamente documentados e utilizados da forma indicada. Foi estruturado por um conjunto de cinco características, subdivididas, por sua vez, em aspectos. Cada aspecto foi composto por um conjunto de questões que deviam obter o maior número possível de respostas positivas para garantir uma especificação adequada para a característica e o aspecto proposto. As respostas possíveis para cada questão eram: "Sim", "Não" e "Não se aplica".

Cada "Não" indicado era relacionado a uma "não conformidade" e o tipo de erro identificado. Caso fosse indicado um "Não se aplica", o mesmo era devidamente justificado. 


\section{Trabalhos correlatos}

Este capítulo apresenta trabalhos relacionados aos temas centrais abordados na pesquisa, visando contribuir com a compreensão e do que tem sido pesquisado na literatura.

\subsection{Problemas no gerenciamento de projetos}

Filho (2013) apresentou uma pesquisa na qual analisou e discutiu os cinco problemas mais frequentes nos projetos das organizações brasileiras. Estes problemas estiveram associados ao GE, gerenciamento de tempo, gerenciamento de custo e gerenciamento de comunicação; segundo pesquisa anterior sobre gerenciamento de projetos Brasil. Como resultados da pesquisa utilizada como base pelo autor, o principal problema no gerenciamento de projetos, apontado por $60,2 \%$ das organizações participantes, foi não cumprimento de prazos. Em seguida, apresenta-se o gerenciamento de escopo, sendo por mudanças de escopo constantes (43\%) e escopo não definido adequadamente (39,5\%). Em terceiro lugar, apresentam-se os problemas de comunicação (40,1\%), seguidos, por fim, dos problemas de gerenciamento de custos $(28,3 \%)$.

A respeito do gerenciamento de tempo, o autor apresenta oito diferentes grupos de causas potenciais: escopo mal definido, prazos mal estimados, recursos humanos insuficientes, atrasos na execução de atividades, atrasos nas entregas de fornecedores, qualidade verificada está aquém da planejada, excesso de burocracia na organização e riscos que se tornam realidade.

Sobre o gerenciamento de escopo, são apresentados diferentes perfis de gerentes de projetos: os mais rígidos quanto a mudanças no escopo original do projeto, utilizando-se de comitês de aprovação para negociação de prazos e custos decorrentes das mudanças de escopo; e os mais flexíveis, menos exigentes quanto às mudanças solicitadas, pois entendem que as organizações estão inseridas em contextos dinâmicos e que mudanças fazem parte da vida do projeto. Apresenta que quanto mais detalhado for o planejamento do escopo, mais preciso será o cronograma do projeto e melhores serão os resultados de custos e qualidade. $\mathrm{O}$ autor afirma que quanto mais criteriosa e responsável for o GE do projeto, maior será a possibilidade de sucesso.

O problema de comunicação é apresentado como causa de comunicação em projetos ser complexa e exigir um efetivo planejamento. São apresentadas ferramentas que podem auxiliar 
o gerente de projetos a alcançar comunicação mais efetiva com os envolvidos, como reuniões de projetos e atenção à comunicação visual.

Como proposta de atenuação de problemas relacionados aos principais fatores apresentados anteriormente, o autor apresenta a utilização de indicadores para mensurar e controlar variáveis envolvidas em tais problemas.

\subsection{Aumento de sucesso em projetos de TI por conta do GE}

Dekkers (2007) apresentou o GE como principal área de conhecimento do PMBOK. Ainda mais para projetos de TI, que se desenvolvem em um contexto mais recente e com gestores de projetos menos experientes.

Considerando como fatores de sucesso para os projetos aqueles apresentados pelo CHAOS REPORT, sendo custo, tempo e qualidade; o autor apresenta que um processo bem estruturado para GE pode auxiliar em otimização dos resultados.

Foram apresentadas cinco características essenciais para o sucesso em implementação de novas iniciativas, relacionados ao GE:

a) Predisposição, referente ao desejo, motivação, ambição e comprometimento na implementação de iniciativas (como um novo sistema, por exemplo).

b) Perspectiva, referente ao que se considera sucesso para a implementação de novas iniciativas, devendo-se considerar o que é esperado com a entrega do projeto.

c) Meios, referindo-se às possibilidades de implementação das iniciativas propostas, englobando a maturidade das organizações e como desenvolvem seus projetos.

d) Avaliação, incluindo a validação das entregas dos projetos, através de medições e análise de dados.

e) Recursos, a respeito da alocação de recursos necessários para o desenvolvimento das novas iniciativas, sendo através de ferramentas automatizadas ou força de trabalho humano.

Segundo o autor, caso uma das características não seja contemplada no projeto, as chances de falhas no projeto aumentam. 


\subsection{Inspeção de documentos de GE por inspeção com lista de verificação}

Sayão, Staa e Leite (2003) apresentaram a importância do documento de requisitos no GE de projetos de SI, citando a importância da inspeção dos documentos.

Segundo os autores, diversas formas de inspeção são aplicáveis para documentos de requisitos, sendo as principais, leituras baseadas em:

a) Ad-Hoc: Técnica baseada no conhecimento e experiência do inspetor, não havendo suporte técnico para indicar quais informações checar e como avalialas. As características que podem ser verificadas por esta técnica são: clareza, completude, consistência, corretude, funcionalidade, testabilidade e detalhamento.

b) Listas de verificação: Técnica já consolidada na indústria, através da utilização de uma lista padrão para leitura e análise dos artefatos, a ser utilizada por todos os inspetores. Estas listas podem ser adaptadas, levando em consideração características particulares de cada documento ou projeto inspecionado.

c) Perspectivas: Técnica na qual se utilizam diversas perspectivas (ou pontos de vista) de diferentes envolvidos nos projetos. Ao contrário da técnica de leitura baseada em lista de verificação, na qual as listas são padrões para todos os inspetores, na técnica de leitura baseada em perspectivas, são utilizadas diferentes listas para avaliação, por diferentes inspetores.

Segundo os autores, sem um documento de requisitos que atenda às características de qualidade de requisitos, não há como dizer que um projeto atingiu seus objetivos.

Com esta definição, as técnicas de inspeção apresentadas se tornam fundamentais para garantir que a qualidade esperada seja alcançada nas documentações e, consequentemente, nos resultados dos projetos. 


\section{Método de pesquisa}

Este capítulo apresenta os procedimentos metodológicos utilizados na pesquisa. Eles estão apresentados em seis seções: estratégia da pesquisa, objeto de estudo, desenho da pesquisa, coleta de dados, tratamento dos dados e limitações da pesquisa.

A pesquisa se caracteriza como um estudo qualitativo, que visa descrever a complexidade de uma determinada situação e compreender seus processos dinâmicos (SAMPIERI; COLLADO; LUCIO, 2006). Como consequência, esse tipo de pesquisa se mostra adequado à proposta, pois se busca analisar a relação entre variáveis específicas relacionadas dos projetos, sendo este um ambiente de estudo complexo e com diversos fatores envolvidos. Para este tipo de pesquisa o pesquisador deve manter contato direto com o ambiente e objeto de estudo em questão.

Esta pesquisa se caracteriza também como descritiva, pois visa registrar, analisar e ordenar dados gerando informações com o objetivo de identificar características e relações entre fatos (FREITAS; PRODANOV, 2013).

Para sua realização foi realizado um estudo de caso, utilizando pesquisa bibliográfica e documental.

\subsection{Estratégia da pesquisa}

A estratégia de pesquisa selecionada foi o estudo de caso, que consiste em coletar e analisar informações sobre determinado indivíduo grupo ou comunidade, a fim de estudar aspectos relacionados ao assunto pesquisado (YIN, 2011).

Durante um estudo de caso é comum haver muito mais variáveis de interesse do que pontos de dados, e, como resultado, baseia-se em várias fontes como evidências. Para chegar ao resultado, os dados devem convergir de forma triangulada, a ser devidamente planejada para a análise de dados. A obtenção de dados por diferentes fontes de evidências reforça a confiabilidade do estudo de caso, principalmente se coletados de formas distintas (MARTINS, 2006).

Trata-se ainda de um estudo de caso único e incorporado, por haver a análise de diversos projetos de uma organização, justificando-se sua aplicação por conta de o objeto de estudo analisado se tratar de uma das maiores empresas de seu setor, com alto investimento em TI e 
ampla atuação com projetos de SI. A pesquisa apresenta um propósito revelador como objetivo, sendo que o pesquisador possui acesso a informações não disponíveis abertamente ao público.

\subsection{Objeto de estudo}

O objeto de estudo desta pesquisa foi representado por projetos de SI realizados em uma instituição bancária brasileira de grande porte. Essa instituição foi selecionada de acordo com os seguintes critérios:

a) É uma das maiores instituições bancárias do Brasil com elevado investimento em tecnologia de informação.

b) Apresenta projetos de grande porte na área de SI, que exigem um gerenciamento eficaz com métodos formais e baseados em práticas recomendadas de gestão.

c) Tem uma área de desenvolvimento de SI própria, facilitando o alinhamento entre os projetos desenvolvidos e as estratégias de negócios da organização.

d) Possibilidade de acesso às informações dos projetos da organização em estudo, viabilizando a execução da pesquisa.

A instituição BANCO, assim denominada de forma ilustrativa, possuía nove diretorias distintas de desenvolvimento de SI. Cada diretoria é composta por superintendências, gerências e coordenações. A figura 14 apresenta um exemplo do modelo da estrutura hierárquica da instituição BANCO.

Para o presente trabalho, foram selecionados projetos desenvolvidos pela superintendência de sistemas de cobrança e renegociação e solicitados pela diretoria de cobrança e renegociação PF. Essa seleção permitiu que os projetos fossem similares em relação a:

a) Alinhamento estratégico por terem sido originados pela mesma área solicitante.

b) Características técnicas similares por terem sido desenvolvidos pela mesma área de desenvolvimento de SI.

c) Levantamentos realizados em um mesmo contexto e ambiente para todos os projetos. 
Foram selecionados projetos concluídos em 2012, 2013 ou 2014, visando analisar um contexto recente e possibilitar o resgate de informações a respeito dos projetos, tanto em documentações e base de dados, como com participantes dos projetos.

Inicialmente foram selecionados, desta forma, 60 projetos, dos quais 50 apresentaram documentação armazenada para atender as necessidades da pesquisa, formando a amostra selecionada da pesquisa.

Figura 14 - Estrutura organizacional da instituição BANCO

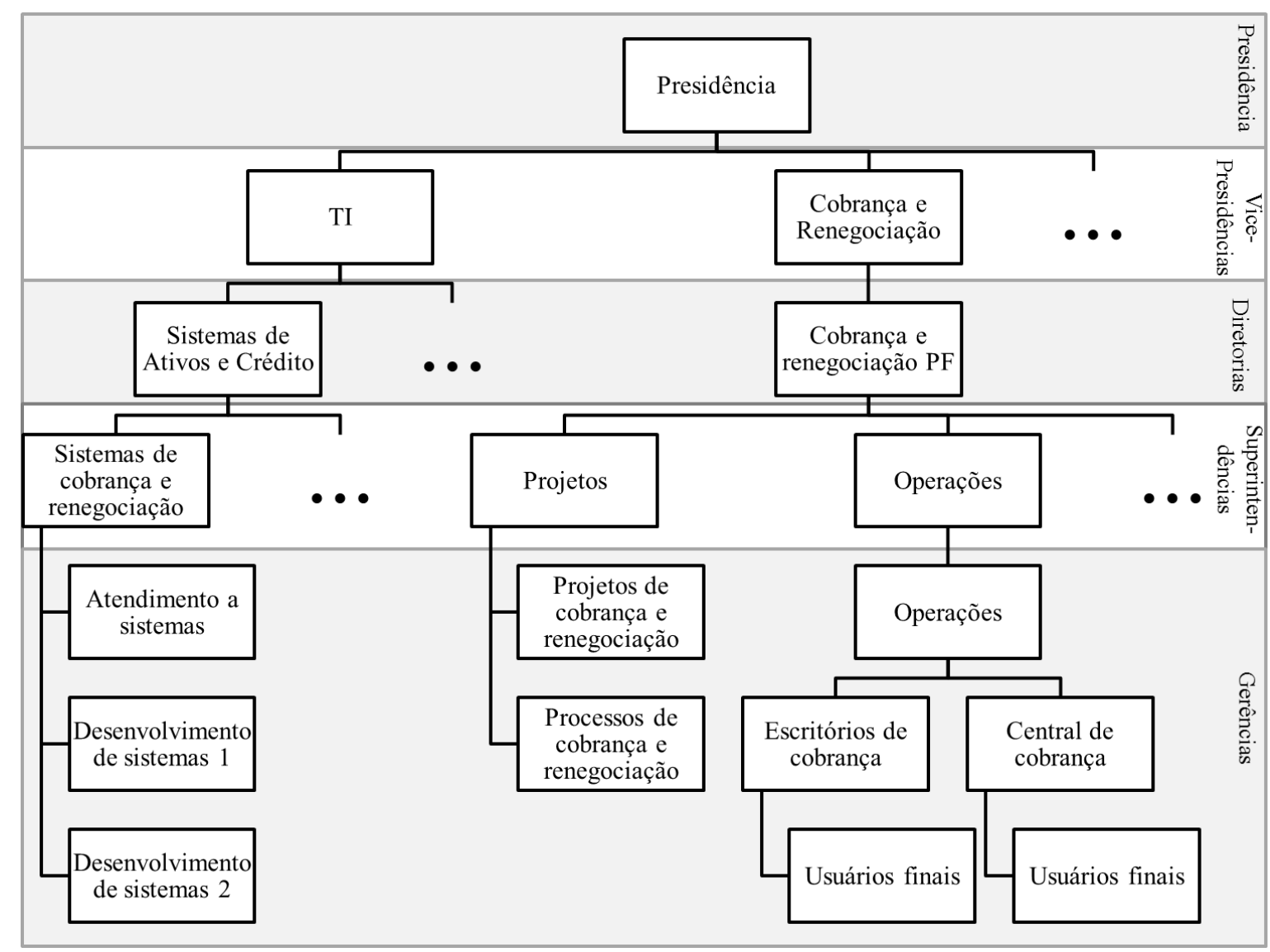

Fonte: próprio autor

\subsection{Etapas da pesquisa}

A pesquisa foi dividida em quatro etapas com objetivos e instrumentos bem definidos. Esta seção visa descrever as etapas que foram executadas e esclarece a importância de cada uma delas para os objetivos finais da pesquisa. 
A primeira etapa teve como objetivo avaliar o grupo de processos de planejamento do GE (GPPGE) executados nos cinquenta projetos selecionados, analisando a documentação armazenada na base de dados de projetos do BANCO. Para tal avaliação foi utilizada uma lista de verificação, averiguando a aderência do projeto às práticas de GE apresentadas na literatura (APGEL) (PMI, 2013).

Na segunda etapa foi realizado um levantamento a respeito do desempenho dos projetos, levando-se em consideração as informações existentes na base de dados de projetos do BANCO. Foi verificada a variação entre o planejamento e a execução do projeto quanto ao tempo de duração e ao custo.

Em seguida, na terceira etapa, visando identificar as influências especificamente dos processos de GE, houve uma avaliação em relação a outros tipos de influências que possam ter ocorrido, através de um questionário aplicado aos gerentes dos projetos avaliados.

Por fim, na quarta etapa, foi possível identificar causas e motivadores para as conclusões obtidas através das fases anteriores. Com entrevistas realizadas junto aos clientes solicitantes dos projetos, foi possível explorar em profundidade as conclusões obtidas até então.

A figura 15 apresenta a abordagem proposta de forma ilustrativa e nas seções seguintes os instrumentos para a coleta de dados em cada uma das etapas são apresentados de forma detalhada.

Figura 15 - Abordagem empregada

\begin{tabular}{|c|c|c|c|}
\hline 1․ fase & $2^{a}$ fase & 3ㅁ fase & 4 a fase \\
\hline $\begin{array}{l}\text { Avaliar: Aderência do } \\
\text { gerenciamento do } \\
\text { escopo às práticas } \\
\text { apresentadas na } \\
\text { literatura. }\end{array}$ & $\begin{array}{l}\text { Avaliar: Desempenho do } \\
\text { projeto (custo e tempo); }\end{array}$ & $\begin{array}{l}\text { Avaliar: Influência do } \\
\text { planejamento do } \\
\text { gerenciamento do } \\
\text { escopo no desempenho } \\
\text { dos projetos. }\end{array}$ & $\begin{array}{c}\text { Avaliar: Como ocorreram } \\
\text { as influências identificada } \\
\text { nas fases anteriores da } \\
\text { pesquisa. }\end{array}$ \\
\hline $\begin{array}{l}\text { Instrumentos: Lista de } \\
\text { verificação e } \\
\text { documentação do } \\
\text { projeto. }\end{array}$ & $\begin{array}{c}\text { Instrumentos: } \\
\text { Documentação do } \\
\text { projeto. }\end{array}$ & $\begin{array}{c}\text { Instrumentos: } \\
\text { Questionário aplicado } \\
\text { aos gerentes de } \\
\text { projetos. }\end{array}$ & $\begin{array}{c}\text { Instrumentos: Entrevistas } \\
\text { realizadas com clientes } \\
\text { solicitantes dos projetos } \\
\text { avaliados. }\end{array}$ \\
\hline
\end{tabular}




\subsection{Coleta de dados e instrumentos}

Para cada etapa da pesquisa foram planejadas as formas de coleta de dados, selecionando o público adequado e abordagem mais indicada para atingir cada objetivo proposto. Foram elaborados instrumentos de coleta de dados de acordo com o propósito de cada uma das etapas.

\subsubsection{Avaliação dos processos de GE}

A lista aplicada para a realização da pesquisa foi composta por vinte e cinco (25) diferentes critérios para avaliação do GE a serem verificados. A figura 16 representa o relacionamento entre as seções apresentadas na revisão bibliográfica e os itens sobre os processos do GPPGE, a serem avaliados através da lista de verificação.

Figura 16 - Itens da lista de verificação

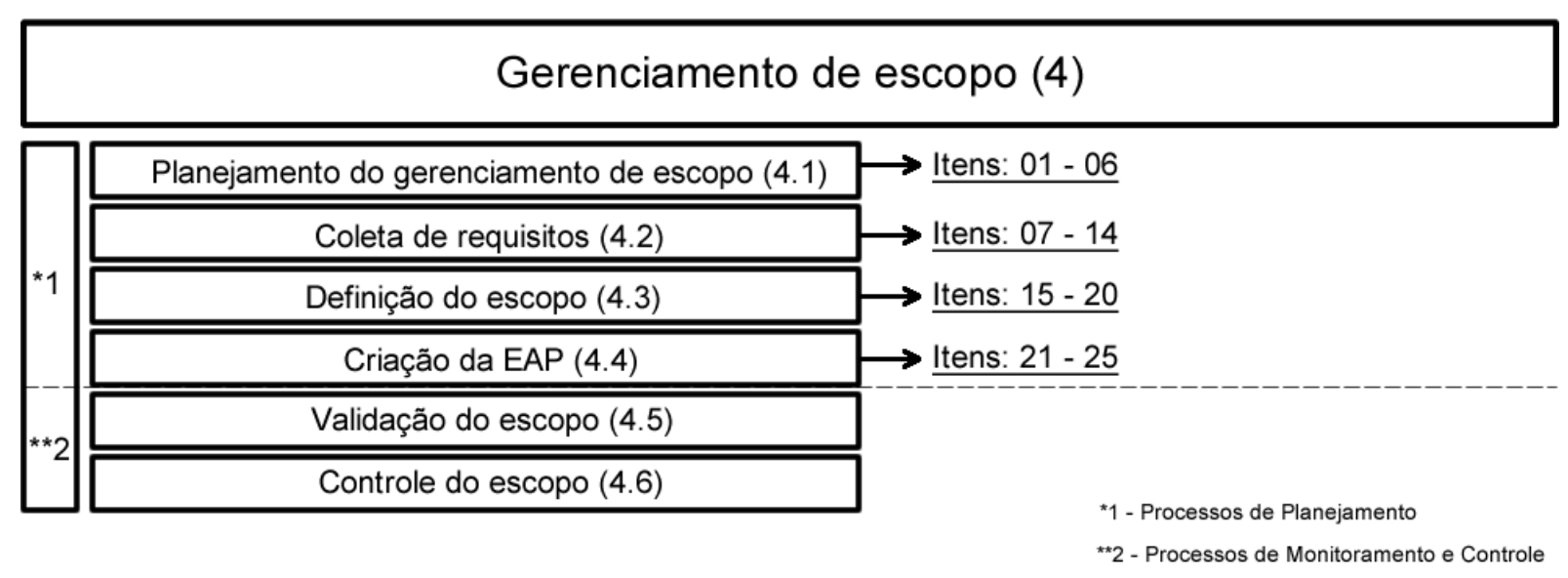

Fonte: próprio autor

O apêndice A apresenta a lista de verificação aplicada e a quais processos cada critério da lista esteve relacionado. Os critérios foram agrupados conforme os processos do GPPGE:

a) Planejamento do GE: este grupo de critérios verifica se o escopo do projeto foi previamente planejado de forma adequada, contendo em sua documentação descrições a respeito dos passos a serem seguidos nos próximos processos.

b) Coleta de requisitos: verifica se os requisitos do projeto foram bem coletados, analisados e documentados, envolvendo diversos tipos de requisitos (funcionais, não-funcionais, de tecnologia e organizacionais). 
c) Definição do escopo: verifica se o escopo do projeto está bem definido, com restrições, premissas, fronteiras e entregáveis bem declarados e documentados.

d) Criação da EAP: verifica se há uma EAP construída conforme indicado nas práticas recomendadas.

Para cada projeto verificado, foi obtida a documentação completa armazenada na base de dados de projetos do BANCO. Nesta base encontravam-se documentos anexos referentes ao GE de cada um dos projetos selecionados, sendo em formatos digitais no padrão estabelecido pela instituição. Observou-se tal documentação para assinalar respostas aos critérios apresentados na lista de verificação, podendo ser uma resposta "Sim" ou "Não" para cada critério.

\subsubsection{Problemas que impactam o desempenho dos projetos}

Com o objetivo de identificar os problemas que acarretaram em queda nos desempenhos de custo e tempo, bem como quais destes problemas estariam relacionados aos processos do GPPGE, foi elaborado um questionário com base nos riscos que influenciam custo e tempo do projeto. Foram selecionados oito riscos, conforme apresentado no apêndice B. Quatro deles estão diretamente relacionados ao escopo do projeto e, consequentemente, ao GE do projeto:

a) Identificação tardia de mudanças e retrabalho: Identificar necessidades de mudança tardiamente pode estar relacionado a levantamentos ineficientes de requisitos no projeto. Um escopo que não tenha as necessidades especificadas terá de ser revisto com frequência durante o desenvolvimento do projeto, acarretando em retrabalho e possíveis atrasos e/ou aumento de custos.

b) Lentidão e falta de objetividade no levantamento de requisitos: Este risco é propriamente um risco relacionado a problemas no levantamento de requisitos do projeto. Lentidão e falta de objetividade fazem com que este processo seja maior do que deveria ser, aumentando o tempo do projeto como um todo e exigindo maior esforço de todos envolvidos, e consequentemente, aumentando o custo.

c) Interrupções na fase de análise: Caso o escopo não esteja bem definido, a fase de análise será dificultosa por necessidade de entendimentos adicionais ao longo de sua execução. Se os objetivos do projeto não forem conhecidos na análise, pode haver 
inclusive erros na entrega do projeto por uma interpretação incorreta ou julgamentos equivocados dos responsáveis pela análise.

d) Ênfase excessiva em documentações em forma de texto e burocracia de aprovação: O PMBOK apresenta em suas práticas diversas sugestões de modelos de documentação a serem seguidos visando uniformidade no trabalho de diversos gerentes de projetos e uma redução de modelos ineficientes que possam surgir em cada projeto. Documentos do GE que sejam utilizados para finalidades inadequadas, como acordos contratuais, por exemplo, podem resultar em burocratização e ocasionar atrasos desnecessários.

Cada respondente foi instruído a preencher, no questionário, o impacto de cada problema, caso tenha ocorrido, nos desempenhos de custo e tempo. O questionário possuía ainda um campo aberto possibilitando que os respondentes incluíssem problemas além dos oito apresentados.

Foi realizado um pré-teste para a aplicação do questionário, sendo selecionados como respondentes dois gerentes de projetos responsáveis por projetos contemplados na pesquisa. $\mathrm{O}$ pré-teste suscitou em algumas alterações no formato e instruções do questionário, mas demonstraram que o instrumento estava satisfatório.

O público selecionado para responder os questionários foram os gerentes de projetos, totalizando vinte e dois respondentes, tendo em vista que alguns destes atuaram em mais de um dos projetos selecionados.

Os gerentes de projetos foram selecionados como respondentes dos questionários por acompanharem todo o projeto, sendo responsáveis pelo GE e estarem informados a respeito dos fatores que podem ter influenciado os desempenhos estudados.

\subsubsection{Desempenhos de custo e tempo dos projetos}

Para cada projeto selecionado foram verificadas as informações a respeito de seu planejamento e execução, a fim de analisar o desempenho em termos de tempo e custo.

No BANCO, o custo dos projetos é mensurado em quantidade de horas trabalhadas e o tempo pela data de término do projeto (prazo). 
Tais informações estavam presentes no banco de dados de projetos do BANCO, em campos específicos com data de início e término planejados e realizados, custo estimado inicialmente e custo real após a realização do projeto.

As informações foram extraídas através de planilhas eletrônicas para tratamento posterior.

\subsubsection{Investigação a respeito de como ocorreram as influências}

As entrevistas foram elaboradas levando-se em consideração as informações coletadas nas fases anteriores. Os entrevistados foram informados previamente a respeito dos projetos que seriam discutidos, entretanto não foram apresentadas as motivações e os objetivos da pesquisa, evitando que pudessem direcionar suas respostas por conta de tais fatores.

Foram selecionados os clientes solicitantes de cada projeto analisado, totalizando doze entrevistados, já que cada solicitante da área de negócios era responsável por mais de um projeto. Os entrevistados tinham cargos, gêneros e idades distintas, entretanto possuíam a mesma responsabilidade e executaram as mesmas atividades nos projetos selecionados.

Os clientes foram selecionados como respondentes por conta de acompanharem o projeto junto ao gestor de projetos responsável durante toda sua execução, com um interesse particular nos resultados dos projetos, buscando se informar a respeito de interferências em desempenhos que possam causar atrasos ou aumento de custos.

O roteiro de entrevista foi organizado de forma em que os primeiros questionamentos fossem a respeito do envolvimento dos entrevistados nos projetos avaliados e como ocorreram os processos, principalmente aqueles relacionados ao GE, explorando as percepções dos respondentes. Em seguida discutir-se-ia o desempenho dos projetos a respeito de tempo, custo e percepções gerais dos entrevistados quanto às entregas.

As respostas seriam confrontadas com as informações coletadas nas etapas anteriores da pesquisa e a discussão poderia se aprofundar em torno destes resultados.

Segundo o planejamento realizado para a entrevista, haveria espaço para discussões gerais dos projetos no BANCO, de forma a ampliar o conhecimento sobre a instituição e situações particulares que pudessem ser relevantes à pesquisa, de forma independente aos projetos questionados. 
Todas as entrevistas foram gravadas com o consentimento dos participantes, a fim de auxiliar nas análises de resultados. Definiu-se que seria declarado aos respondentes que as informações seriam utilizadas exclusivamente para o objetivo da pesquisa realizada e de forma confidencial.

Ao final das entrevistas, a pesquisa seria explanada em maiores detalhes, com explicação a respeito do contexto das perguntas e apresentação da contribuição das respostas para a pesquisa como um todo.

\subsection{Limitações da pesquisa}

A principal limitação da pesquisa refere-se à existência de certo nível, ainda que baixo, de subjetividade ao responder a lista de verificação de escopo. A abordagem proposta para identificar as influências específicas do GE sobre os desempenhos de custo e tempo também se mostrou suscetível à subjetividade dos gerentes de projetos como respondentes.

Além disso a pesquisa propõe a avaliação do desempenho do projeto baseando-se nas variáveis custo e tempo somente, não sendo essas as únicas significantes para tal.

Por se tratar um estudo de caso em uma única instituição, de um setor específico da economia no Brasil, os resultados da pesquisa não podem ser generalizados para qualquer efeito, apesar de não ter sido a proposta inicial. 


\section{Contextualização do estudo de caso}

A área de desenvolvimento de SI para cobrança e renegociação, analisada nesta pesquisa, executou projetos nos anos de 2012, 2013 e 2014 para a diretoria de cobrança e renegociação PF. Para realização de projetos de SI, a área seguia dois modelos desenvolvidos internamente: modelo de gerenciamento de projetos (MGP), baseado no PMBOK; e modelo de desenvolvimento de sistemas (MDS), baseado no modelo cascata.

Em 2012 as atividades de gerenciamento de projetos foram incentivadas pela alta administração do BANCO. Diversos profissionais da área de TI foram treinados e obtiveram certificação em gerenciamento de projetos pelo PMI, passando a atuar como gerentes de projetos. O conhecimento a respeito do papel e das atividades exercidas pelo gerente de projetos não era homogêneo, gerando discussões sobre a forma de atuação e objetivos dessa carreira.

Naquele ano, o MGP foi disseminado com o objetivo de definir as práticas de gerenciamento de projetos para os desenvolvedores e clientes. O MGP teve embasamento no PMBOK, apresentando orientações aos gerentes de projetos a respeito das dez áreas de conhecimento e dos cinco grupos de processos. Foi implantado um SI automatizado para gerenciamento de projetos, até então inexistente.

Em 2013, o BANCO aprimorou o MGP, com a divulgação da versão 2.0 do modelo. Incluiu documentações com exemplos práticos da aplicação e apresentou formatos padrões para utilização nos processos, como o formato da EAP, por exemplo. Ocorreram treinamentos para gerentes de projetos e clientes, tanto sobre o MGP quanto sobre o SI utilizado para o gerenciamento de projetos.

Em 2014, mais uma vez, o BANCO atualizou as informações do MGP, gerando a versão 3.0, vigente até o momento da realização desta pesquisa. Com a prática de gerenciamento de projetos melhor disseminada no BANCO, foram estabelecidos indicadores para avaliar a qualidade do gerenciamento de projetos. Tais indicadores avaliavam variações do planejamento em relação à execução nos projetos, existência de documentos obrigatórios, aprovações obrigatórias de clientes ou demais envolvidos, entre outros quesitos.

O MDS tinha embasamento no modelo cascata de desenvolvimento de SI, apresentando da mesma forma que o MGP, orientações aos gerentes de projetos e desenvolvedores de sistemas. Contemplava todas as fases do modelo cascata e estabelecia normas oficiais a serem seguidas no desenvolvimento e manutenção de SI. 
Em 2012 o MDS foi muito difundido principalmente na área de tecnologia. Houve um grande esforço do BANCO para que os desenvolvedores de SI conhecessem o MDS e o aplicassem no seu dia a dia. Nesse período todos os desenvolvedores realizavam atividades relacionadas ao MDS, mas nem todos exerciam o papel de gerente de projetos, o que levou à disseminação mais acelerada do MDS em relação ao MGP.

O MDS teve uma evolução constante, com atualizações das diretrizes e normas ao longo dos três anos analisados. Foram definidos documentos com exemplos e padrões de documentação, algumas das quais também eram produzidos pelas áreas de negócios, levando à necessidade de expandir o conhecimento do MDS para essas áreas. O modelo proporcionou maior alinhamento entre as áreas de negócio e tecnologia no BANCO, apresentando processos comuns entre tais áreas e atividades que envolviam tanto os clientes quanto os desenvolvedores. O gerente de projetos era responsável por garantir que o MDS fosse seguido pelos envolvidos no projeto, enquanto executava os processos do MGP.

Em 2013 o contato entre as áreas de TI e negócios era mais próximo e as discussões de projetos aconteciam com maior interação presencial entre clientes e desenvolvedores. Durante o processo de coleta de requisitos do MGP, coincidente ao processo de análise e definição dos requisitos do MDS, os clientes apresentavam suas necessidades para o gerente de projetos e, muitas vezes, para os desenvolvedores em conjunto. Nestes casos, os desenvolvedores analisavam as solicitações do ponto de vista técnico, realizando análises a respeito e sugerindo alterações nos requisitos para possibilitar maior agilidade no desenvolvimento que seria realizado posteriormente.

Com a definição de solução (equivalente à fase de projeto do modelo cascata) sendo realizada ao mesmo tempo que a fase de coleta de requisitos, os analistas faziam com que houvesse uma adaptação no MDS, que propõe fases sequenciais.

Foi possível analisar as informações fornecidas sobre o MDS relacionando-as ao MGP conforme apresentado na figura 4. No modelo cascata a fase de análise e definição de requisitos está relacionada aos processos pertencentes aos grupos de iniciação e planejamento do gerenciamento de projetos. Já a fase de projeto do modelo cascata possui processos relacionados ao grupo de processos de execução do gerenciamento de projetos.

Quando o MDS era adaptado por conta da atuação dos desenvolvedores nas discussões de requisitos, havia uma alteração na equivalência das fases do MDS com os processos do MGP, fazendo com que a fase de projeto do MDS se sobrepusesse à fase de análise e definição 
de requisitos. Essa adaptação pode ser ilustrada conforme a figura 17 considerando-se a relação do modelo cascata (equivalente ao MDS) com o PMBOK (equivalente ao MGP).

Figura 17 - Modelo de desenvolvimento de sistemas adaptado

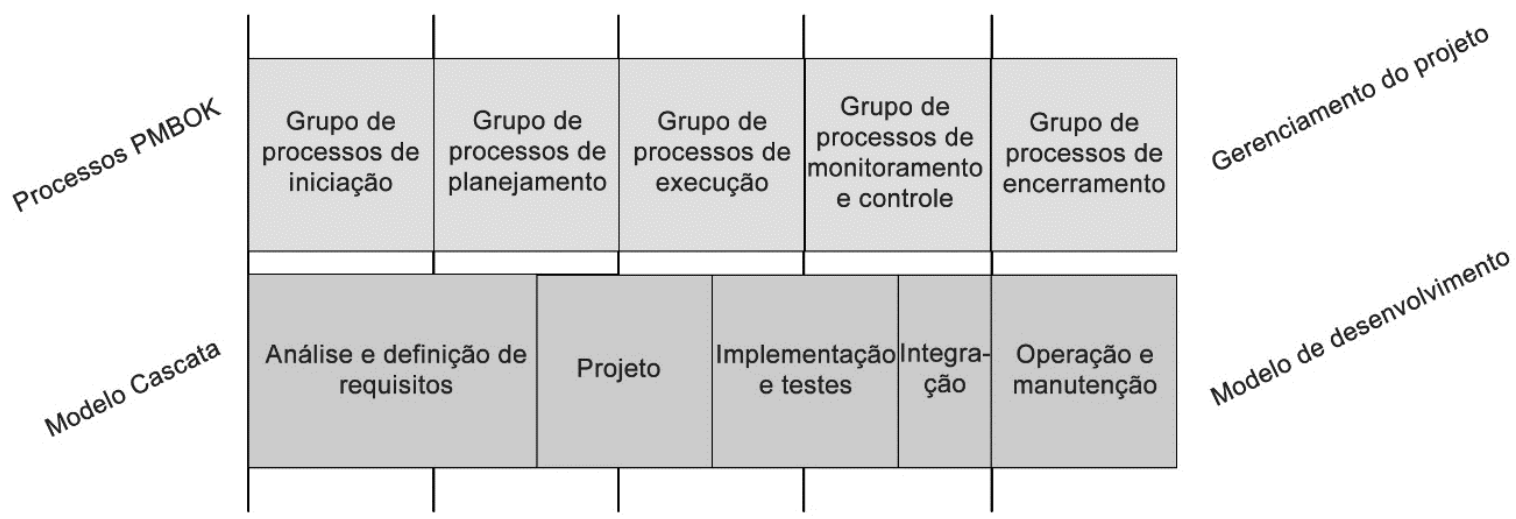

Fonte: próprio autor

Em 2014 o BANCO realizou uma avaliação do período de implantação do MGP e do MDS, e propôs mudanças organizacionais, tentando manter as vantagens e reduzir os problemas da condução adaptada do MDS que vinha acontecendo. Para isso foi criada uma nova área de tecnologia de negócio, com atividades específicas de contato com os clientes para coleta de requisitos e discussão das necessidades. Isso proporcionou aos desenvolvedores uma forma de manter o enfoque no desenvolvimento de SI.

Foram selecionados desenvolvedores com interesse e perfil para atuar com atividades menos técnicas e mais ligadas à definição e gerenciamento de requisitos, criando a função de analistas de tecnologia do negócio, responsável por realizar os alinhamentos com clientes, coletar os requisitos e definir o escopo; atuando como apoio ao gerente de projetos na área de conhecimento do GE.

\section{Apresentação dos resultados}

A aplicação dos instrumentos de coleta de dados propostos possibilitou a obtenção de dados referentes à APGEL, de acordo com a documentação dos projetos na base de dados do 
BANCO, sobre os desempenhos dos projetos em relação ao custo e tempo de cada um deles e problemas que possam ter ocorrido no projeto, relacionados a tais desempenho e ao GE.

Os resultados obtidos são apresentados nas subseções a seguir.

\subsection{Aderência do GE às práticas apresentadas na literatura}

Os primeiros dados coletados eram a respeito da APGEL, a partir da avaliação da documentação de GE dos projetos.

A tabela 3 apresenta os critérios da lista de verificação com os respectivos resultados obtidos, considerando-se os cinquenta projetos analisados.

Tabela 3 - Lista de verificação

\begin{tabular}{|c|c|c|c|c|c|}
\hline \multirow{3}{*}{$\begin{array}{l}\text { Processo do } \\
\text { GPPGE }\end{array}$} & \multirow[t]{3}{*}{ Critério } & \multicolumn{4}{|c|}{ Frequência } \\
\hline & & \multicolumn{2}{|c|}{ Absoluta } & \multicolumn{2}{|c|}{ Relativa } \\
\hline & & Sim & Não & Sim & Não \\
\hline \multirow{13}{*}{$\begin{array}{c}\text { Planejamento } \\
\text { do GE }\end{array}$} & (C1) $\mathrm{O}$ documento apresenta as informações sobre o & 3 & 47 & $6 \%$ & $94 \%$ \\
\hline & processo "coletar os requisitos"? & & & & \\
\hline & (C2) O documento apresenta as informações sobre o & 33 & 17 & $66 \%$ & $34 \%$ \\
\hline & processo "criar a EAP"? & & & & \\
\hline & (C3) $\mathrm{O}$ documento apresenta as informações sobre o & 7 & 43 & $14 \%$ & $86 \%$ \\
\hline & processo "definir o escopo"? & & & & \\
\hline & (C4) O documento apresenta como será obtida a aceitação & 22 & 28 & $44 \%$ & $56 \%$ \\
\hline & formal das entregas do projeto concluídas? & & & & \\
\hline & (C5) O documento apresenta o processo de priorização dos & 1 & 49 & $2 \%$ & $98 \%$ \\
\hline & requisitos? & & & & \\
\hline & (C6) O documento apresenta os processos para controlar & 1 & 49 & $2 \%$ & $98 \%$ \\
\hline & como as solicitações de mudança de escopo serão & & & & \\
\hline & processadas? & & & & \\
\hline $\begin{array}{l}\text { Coleta de } \\
\text { requisitos }\end{array}$ & $\begin{array}{l}\text { (C7) O campo "justificativa" especifica o benefício de se } \\
\text { fazer os requisitos? }\end{array}$ & 18 & 32 & $36 \%$ & $64 \%$ \\
\hline
\end{tabular}




\begin{tabular}{|c|c|c|c|c|c|}
\hline \multirow{14}{*}{$\begin{array}{l}\text { Processo do } \\
\text { GPPGE }\end{array}$} & \multirow[t]{3}{*}{ Critério } & \multicolumn{4}{|c|}{ Frequência } \\
\hline & & \multicolumn{2}{|c|}{ Absoluta } & \multicolumn{2}{|c|}{ Relativa } \\
\hline & & Sim & Não & Sim & Não \\
\hline & (C8) As situações atuais foram especificadas? & 22 & 28 & $44 \%$ & $56 \%$ \\
\hline & (C9) O campo importância está preenchido de forma a & 17 & 33 & $34 \%$ & $66 \%$ \\
\hline & possibilitar diferenciação? & & & & \\
\hline & $\begin{array}{l}\text { (C10) O documento apresenta os requisitos de suporte e } \\
\text { treinamento? }\end{array}$ & 12 & 38 & $24 \%$ & $76 \%$ \\
\hline & (C11) O documento apresenta os requisitos funcionais? & 34 & 16 & $68 \%$ & $32 \%$ \\
\hline & (C12) O documento apresenta os requisitos não- & 18 & 32 & $36 \%$ & $64 \%$ \\
\hline & funcionais? & & & & \\
\hline & (C13) O documento apresenta os requisitos & 24 & 26 & $48 \%$ & $52 \%$ \\
\hline & organizacionais? & & & & \\
\hline & (C14) Os requisitos deixam claro o que está sendo & 30 & 20 & $60 \%$ & $40 \%$ \\
\hline & solicitado? & & & & \\
\hline \multirow{7}{*}{$\begin{array}{l}\text { Definição do } \\
\text { escopo }\end{array}$} & (C15) O documento define as restrições do projeto? & 5 & 45 & $10 \%$ & $90 \%$ \\
\hline & (C16) O documento descreve o escopo do produto? & 15 & 35 & $30 \%$ & $70 \%$ \\
\hline & (C17) O documento descreve os critérios de aceitação do & 20 & 30 & $40 \%$ & $60 \%$ \\
\hline & ( & & & & \\
\hline & (C18) O documento descreve os entregáveis do projeto? & 40 & 10 & $80 \%$ & $20 \%$ \\
\hline & (C19) O documento lista as premissas do projeto? & 7 & 43 & $14 \%$ & $86 \%$ \\
\hline & (C20) Tem o quadro de volumetria preenchido? & 9 & 41 & $18 \%$ & $82 \%$ \\
\hline \multirow{3}{*}{$\begin{array}{l}\text { Criação da } \\
\text { EAP }\end{array}$} & (C21) A EAP tem decomposição do trabalho a ser & 20 & 30 & $40 \%$ & $60 \%$ \\
\hline & realizado durante todo o projeto? & & & & \\
\hline & $\begin{array}{l}\text { (C22) A EAP tem um pacote de trabalho que se refere a } \\
\text { entregáveis identificados do projeto? }\end{array}$ & 21 & 29 & $42 \%$ & $58 \%$ \\
\hline
\end{tabular}




\begin{tabular}{|c|c|c|c|c|c|}
\hline \multirow{6}{*}{$\begin{array}{l}\text { Processo do } \\
\text { GPPGE }\end{array}$} & \multirow[t]{3}{*}{ Critério } & \multicolumn{4}{|c|}{ Frequência } \\
\hline & & \multicolumn{2}{|c|}{ Absoluta } & \multicolumn{2}{|c|}{ Relativa } \\
\hline & & Sim & Não & Sim & Não \\
\hline & $\begin{array}{l}\text { (C23) Foi criada uma estrutura gráfica de decomposição } \\
\text { para representar a EAP? }\end{array}$ & 34 & 16 & $68 \%$ & $32 \%$ \\
\hline & (C24) Há um detalhamento/dicionário da EAP & 12 & 38 & $24 \%$ & $76 \%$ \\
\hline & $\begin{array}{l}\text { (C25) Os pacotes de trabalho são decompostos o suficiente } \\
\text { para estabelecer tempo e recursos necessários para sua } \\
\text { entrega? }\end{array}$ & 12 & 38 & $24 \%$ & $76 \%$ \\
\hline
\end{tabular}

Fonte: próprio autor

$\mathrm{O}$ critério que apresentou maior aderência às práticas recomendadas foi o $\mathrm{C} 18$, do processo de definição do escopo, indicando que os projetos apresentam na documentação, em sua maioria, os entregáveis que serão apresentados como resultado final.

Os critérios C2, C11, C14 e C23 também apresentaram mais de 60\% de APGEL, mostrando que os processos de coleta de requisitos e criação da EAP também possuíram ao menos um critério com mais de $50 \%$ de respostas positivas. Isso não ocorreu para o processo de planejamento do GE, grupo ao qual pertencem os critérios C1, C5 e C6, que apresentaram aderência menor do que $10 \%$.

Considerou-se a APGEL de acordo com os seguintes grupos de resultados:
a) Inferior a 50\%: Baixa.
b) Entre $50 \%$ e $75 \%$ : Regular.
c) Superior a $75 \%$ : Alta.

A tabela 4 apresenta os critérios agrupados por processo do GPPGE e a média de APGEL para cada processo.

Tabela 4 - APGEL por processo

\begin{tabular}{ccccccc}
\hline Processo & Critérios & \multicolumn{4}{c}{ APGEL média do processo (\%) } & APGEL \\
\cline { 3 - 6 } & & $\mathbf{2 0 1 2}$ & $\mathbf{2 0 1 3}$ & $\mathbf{2 0 1 4}$ & Total & Total \\
\hline Planejamento do GE & C1 - C6 & $29,2 \%$ & $22,0 \%$ & $19,0 \%$ & $22,3 \%$ & Baixa \\
\hline Coleta de requisitos & C7 - C14 & $42,2 \%$ & $48,7 \%$ & $34,8 \%$ & $43,8 \%$ & Baixa \\
\hline
\end{tabular}




\begin{tabular}{ccccccc}
\hline Processo & Critérios & \multicolumn{4}{c}{ APGEL média do processo (\%) } & APGEL \\
\cline { 3 - 5 } & & $\mathbf{2 0 1 2}$ & $\mathbf{2 0 1 3}$ & $\mathbf{2 0 1 4}$ & Total & Total \\
\hline Definição do escopo & C15 - C20 & $31,3 \%$ & $31,5 \%$ & $33,3 \%$ & $32,0 \%$ & Baixa \\
\hline Criação da EAP & C21 - C25 & $50,0 \%$ & $37,1 \%$ & $38,6 \%$ & $39,6 \%$ & Baixa \\
\hline Total & C1 - C25 & $38,0 \%$ & $35,9 \%$ & $31,4 \%$ & $35,0 \%$ & Baixa \\
\hline
\end{tabular}

Fonte: próprio autor

A média geral de $35,0 \%$ de respostas afirmativas em relação ao total que se poderia obter indicou baixa aderência no BANCO às práticas de GE apresentadas pela literatura. Nenhum dos processos recebeu uma avaliação com mais de $50 \%$ de respostas positivas, sendo todos classificados com baixa APGEL.

A queda de APGEL média geral dos processos do GPPGE indica que o GE piorou no BANCO.

\subsection{Problemas no gerenciamento de projetos relacionados ao GE}

Conforme a coleta de dados proposta, os questionários apresentaram o impacto de problemas relacionados ao GE nos desempenhos de custo e tempo dos projetos. As respostas de cada questionamento foram posteriormente convertidas para um número, sendo "1" relacionado a "muito baixo" e "5" relacionado a "muito alto".

$\mathrm{O}$ apêndice $\mathrm{C}$ apresenta os resultados consolidados dos questionários para cada um dos projetos avaliados. A tabela 5 apresenta a relação de problemas com o nível de impacto de cada um no grupo total dos cinquenta projetos analisados, com a indicação de relacionamento com o GE e impactos em custo e tempo, conforme apresentado no instrumento de coleta.

Tabela 5 - Problemas e nível de ocorrência

\begin{tabular}{|c|c|c|c|c|c|}
\hline \multirow[t]{2}{*}{ Problema } & \multirow{2}{*}{$\begin{array}{l}\text { Nível em relação ao } \\
\text { total de impactos }(\%)\end{array}$} & \multicolumn{2}{|c|}{ Relacionado ao GE* } & \multicolumn{2}{|c|}{ Impacto em } \\
\hline & & Diretamente & Indiretamente & Custo & Tempo \\
\hline $\begin{array}{l}\text { Interrupções na fase de } \\
\text { análise }\end{array}$ & 15,1 & $\bullet$ & & & $\bullet$ \\
\hline $\begin{array}{l}\text { Identificação tardia de } \\
\text { mudanças }\end{array}$ & 14,9 & $\bullet$ & & $\bullet$ & $\bullet$ \\
\hline $\begin{array}{l}\text { Conflitos entre áreas } \\
\text { envolvidas no projeto }\end{array}$ & 13,8 & & $\bullet$ & $\bullet$ & $\bullet$ \\
\hline
\end{tabular}




\begin{tabular}{|c|c|c|c|c|c|}
\hline \multirow[t]{2}{*}{ Problema } & \multirow{2}{*}{$\begin{array}{l}\text { Nível em relação ao } \\
\text { total de impactos }(\%)\end{array}$} & \multicolumn{2}{|c|}{ Relacionado ao GE* } & \multicolumn{2}{|c|}{ Impacto em } \\
\hline & & Diretamente & Indiretamente & Custo & Tempo \\
\hline $\begin{array}{l}\text { Ênfase excessiva em } \\
\text { documentações com } \\
\text { burocracia de aprovação }\end{array}$ & 13,5 & • & & & $\bullet$ \\
\hline $\begin{array}{l}\text { Lentidão e falta de } \\
\text { objetividade no } \\
\text { levantamento dos } \\
\text { requisitos }\end{array}$ & 12,8 & $\bullet$ & & $\bullet$ & $\bullet$ \\
\hline $\begin{array}{l}\text { Conflitos entre membros } \\
\text { da equipe de } \\
\text { desenvolvimento }\end{array}$ & 10,8 & & $\bullet$ & $\bullet$ & $\bullet$ \\
\hline $\begin{array}{l}\text { Recursos de } \\
\text { desenvolvimento } \\
\text { inadequados }\end{array}$ & 9,9 & & $\bullet$ & $\bullet$ & $\bullet$ \\
\hline $\begin{array}{l}\text { Inserção de tecnologia } \\
\text { necessária }\end{array}$ & 9,4 & & $\bullet$ & $\bullet$ & $\bullet$ \\
\hline
\end{tabular}

* Definição da relação em 5.4.2

Fonte: próprio autor

$56,3 \%$ dos impactos ocorreram por problemas relacionados diretamente ao GE. Considerando-se o valor total observado para o grupo de impactos que afetaram desempenho de custo e tempo, foi possível observar que $32 \%$ dos impactos em custo e $56 \%$ dos impactos em tempo estiveram diretamente relacionados ao GE, de acordo com o ponto de vista dos gerentes dos projetos.

\subsection{Desempenho dos projetos em termos de custo e planejamento do GE}

Com os dados coletados a respeito dos custos de cada projeto, foi realizada uma comparação entre a variação das horas realizadas no projeto e as horas planejadas inicialmente. A variação permitida segundo as práticas de GE apresentadas pelo PMI (2013) e pelo OGC (1996), por exemplo, é de (-5)\% a (+10)\%. Assim, foi possível classificar os projetos em três grupos distintos para custo: aqueles que tiveram desempenho adequado, os que tiveram desempenho inadequado por variar acima de $(+10) \%$ do esperado e os que tiveram desempenho 
inadequado por variar abaixo de $(-5) \%$ do esperado. A tabela 6 apresenta a quantidade de projetos em cada grupo, considerando o ano de término dos projetos avaliados.

Tabela 6 - Desempenho de custo

\begin{tabular}{ccccc}
\hline \multirow{2}{*}{ Variação de custo } & \multicolumn{4}{c}{ Frequência Relativa (\%) } \\
\cline { 2 - 5 } & $\mathbf{2 0 1 2}$ & $\mathbf{2 0 1 3}$ & $\mathbf{2 0 1 4}$ & Total \\
\hline Acima de $10 \%$ & 12,5 & 28,6 & 7,1 & 20,0 \\
\hline Entre $-5 \%$ e $+10 \%$ & 25,0 & 50,0 & 21,4 & 38,0 \\
\hline Abaixo de $-5 \%$ & 62,5 & 21,4 & 71,4 & 42,0 \\
\hline
\end{tabular}

Fonte: próprio autor

A figura 18 apresenta um gráfico que demonstra a quantidade de projetos em cada grupo de desempenho de custo de acordo com os anos de término dos projetos.

Figura 18 - Gráfico de desempenho de custo

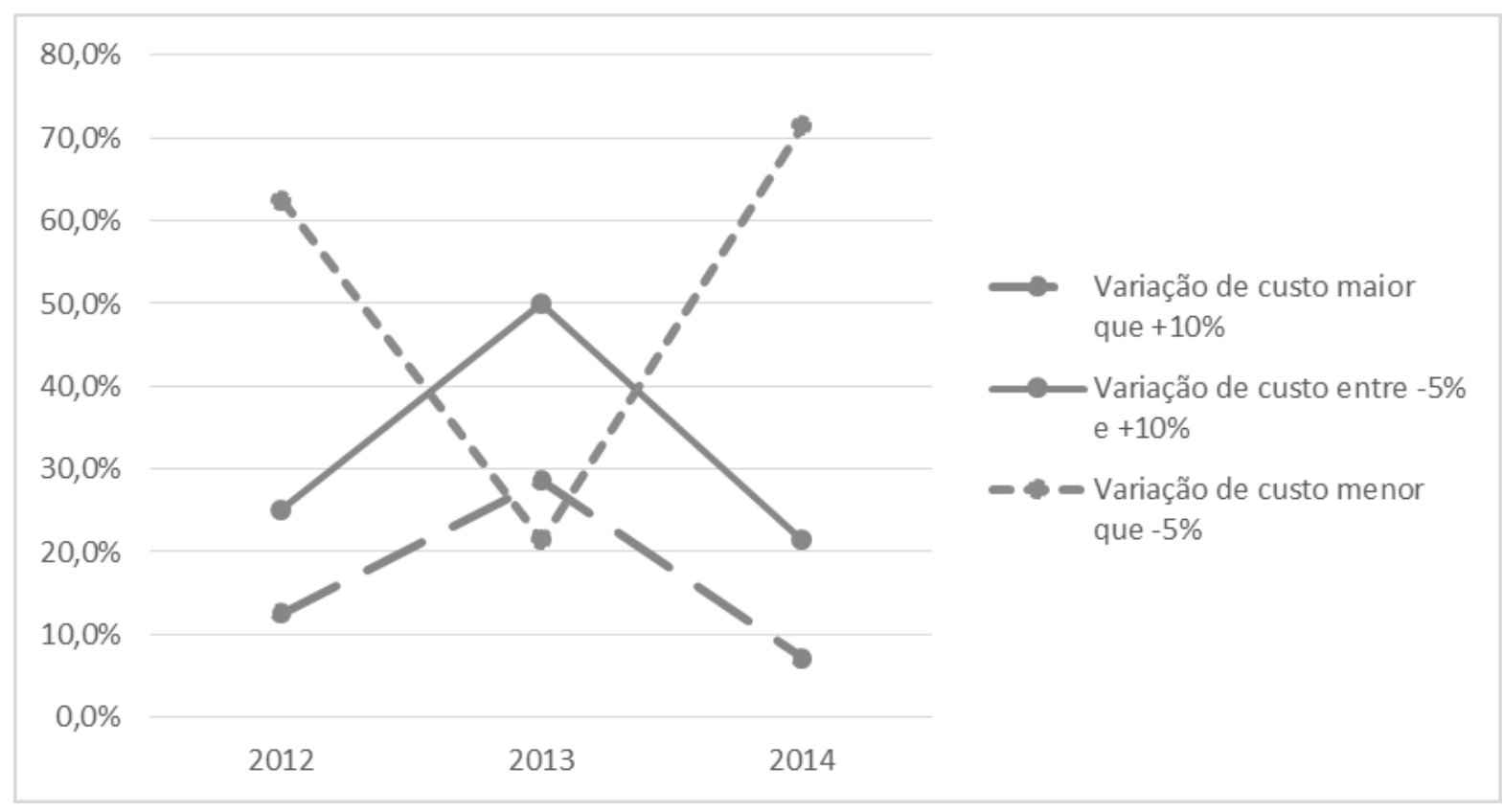

Fonte: próprio autor

$42 \%$ dos projetos custaram menos do que planejado inicialmente e $20 \%$ custaram acima do esperado. $38 \%$ dos projetos tiveram um desempenho adequado de custo.

As análises realizadas a respeito dos desempenhos de custo dos projetos foram relacionadas com as informações sobre a APGEL identificadas na primeira etapa de pesquisa. 
A tabela 7 apresenta as informações dos níveis de desempenho e os respectivos percentuais médios de APGEL para cada grupo, por processo do GPPGE.

Tabela 7 - Desempenhos de custo e nível de APGEL

\begin{tabular}{|c|c|c|c|c|c|}
\hline \multirow{2}{*}{$\begin{array}{c}\text { Processo do } \\
\text { GPPGE }\end{array}$} & \multirow{2}{*}{$\begin{array}{c}\text { Faixas de variação } \\
\text { de custo }\end{array}$} & \multicolumn{3}{|c|}{ Nível de APGEL (\%) } & \multirow{2}{*}{$\begin{array}{l}\text { APGEL } \\
\text { média por } \\
\text { faixa }(\%)\end{array}$} \\
\hline & & Baixa & Regular & Alta & \\
\hline \multirow{3}{*}{$\begin{array}{c}\text { Planejamento } \\
\text { do GE }\end{array}$} & Maior que $+10 \%$ & 90,0 & 10,0 & 0,0 & 25,0 \\
\hline & Entre $-5 \% \mathrm{e}+10 \%$ & 94,7 & 5,3 & 0,0 & 23,7 \\
\hline & Menor que $-5 \%$ & 85,7 & 9,5 & 4,8 & 19,8 \\
\hline \multirow{3}{*}{$\begin{array}{l}\text { Coleta de } \\
\text { requisitos }\end{array}$} & Maior que $+10 \%$ & 50,0 & 40,0 & 10,0 & 46,3 \\
\hline & Entre $-5 \%$ e $+10 \%$ & 31,6 & 42,1 & 26,3 & 52,0 \\
\hline & Menor que $-5 \%$ & 47,6 & 47,6 & 4,8 & 35,1 \\
\hline \multirow{3}{*}{$\begin{array}{c}\text { Definição de } \\
\text { escopo }\end{array}$} & Maior que $+10 \%$ & 60,0 & 30,0 & 10,0 & 41,7 \\
\hline & Entre $-5 \%$ e $+10 \%$ & 73,7 & 21,1 & 5,3 & 29,8 \\
\hline & Menor que $-5 \%$ & 71,4 & 23,8 & 4,8 & 29,4 \\
\hline \multirow{3}{*}{$\begin{array}{l}\text { Criação da } \\
\text { EAP }\end{array}$} & Maior que $+10 \%$ & 70,0 & 20,0 & 10,0 & 36,0 \\
\hline & Entre $-5 \%$ e $+10 \%$ & 63,2 & 15,8 & 21,1 & 46,3 \\
\hline & Menor que $-5 \%$ & 66,7 & 4,8 & 28,6 & 35,2 \\
\hline \multirow{3}{*}{ Total } & Maior que $+10 \%$ & 90,0 & 10,0 & 0,0 & 38,0 \\
\hline & Entre $-5 \%$ e $+10 \%$ & 78,9 & 15,8 & 5,3 & 38,7 \\
\hline & Menor que $-5 \%$ & 71,4 & 19,1 & 9,5 & 30,1 \\
\hline
\end{tabular}

Fonte: próprio autor

Observando o total, é possível identificar que apenas 5,3\% dos projetos com desempenho adequado de custo tiveram APGEL alta. A maioria dos projetos deste grupo de desempenho teve APGEL baixa.

Buscando identificar diferenciações e compreender melhor as relações, os resultados foram agrupados considerando-se os processos do GPPGE:

a) Planejamento do GE: foi possível observar que dos projetos com desempenho adequado de custo, 94,7\% tiveram baixa APGEL. O grupo com variação menor que 
$(-5) \%$ apresentou a menor APGEL. Apesar de o grupo com variação maior que $(+10) \%$ apresentar o maior percentual de projetos com APGEL regular, nenhum dos projetos do grupo teve APGEL alta.

b) Coleta de requisitos: Os dados apresentados demonstraram que dos projetos com desempenho de custo adequado, 26,3\% tiveram APGEL alta. A média de APGEL do grupo de variação de custo adequada foi $52,0 \%$, representando uma aderência regular, superior à APGEL dos outros grupos (46,3\% e 35,1\%). Com uma melhor APGEL, o desempenho de custo se apresentou maior, com o processo de coleta de requisitos apresentando influência sobre o desempenho de custo dos projetos.

c) Definição do escopo: O grupo de projetos que apresentou variação de custo acima de $(+10) \%$ teve melhor APGEL, com $10 \%$ de projetos com APGEL alta. Para os grupos de variação adequada e variação abaixo de (-5)\% a APGEL média foi similar, bem como a distribuição entre APGEL baixa, regular e alta.

d) Criação da EAP: Maior APGEL no processo de criação da EAP esteve relacionada com melhor desempenho de custo. O grupo de variação adequada de custo teve a maior APGEL (46,3\%). Além disso é possível verificar que há uma distribuição de projetos com maior APGEL no grupo de variação adequada de custo.

\subsection{Desempenho dos projetos em termos de tempo e planejamento do GE}

Com os dados coletados a respeito dos prazos de cada projeto, foi realizada uma comparação a quantidade de dias planejados para a realização do projeto e a quantidade de dias efetivamente utilizados. As quantidades foram obtidas através da contagem de dias entre as datas de início e término planejadas e realizadas, obtidas na coleta de dados da pesquisa.

Assim como para custo, foi possível classificar os projetos em três grupos distintos para tempo: aqueles que tiveram desempenho adequado, os que tiveram desempenho inadequado por variar acima de $(+10) \%$ do esperado e os que tiveram desempenho inadequado por variar abaixo de (-5)\% do esperado. A tabela 8 apresenta os dados de acordo com esta classificação. 
Tabela 8 - Desempenho de tempo

\begin{tabular}{ccccc}
\hline \multirow{2}{*}{ Variação de tempo } & \multicolumn{4}{c}{ Frequência Relativa (\%) } \\
\cline { 2 - 5 } & $\mathbf{2 0 1 2}$ & $\mathbf{2 0 1 3}$ & $\mathbf{2 0 1 4}$ & Total \\
\hline Acima de 10\% & 25,0 & 57,1 & 42,9 & 48,0 \\
\hline Entre -5\% e +10\% & 0,0 & 25,0 & 50,0 & 28,0 \\
\hline Abaixo de -5\% & 75,0 & 17,9 & 7,1 & 24,0 \\
\hline
\end{tabular}

Fonte: próprio autor

A figura 19 apresenta um gráfico que demonstra a quantidade de projetos em cada grupo de desempenho de tempo de acordo com os anos de término dos projetos.

Figura 19 - Gráfico de desempenho de tempo

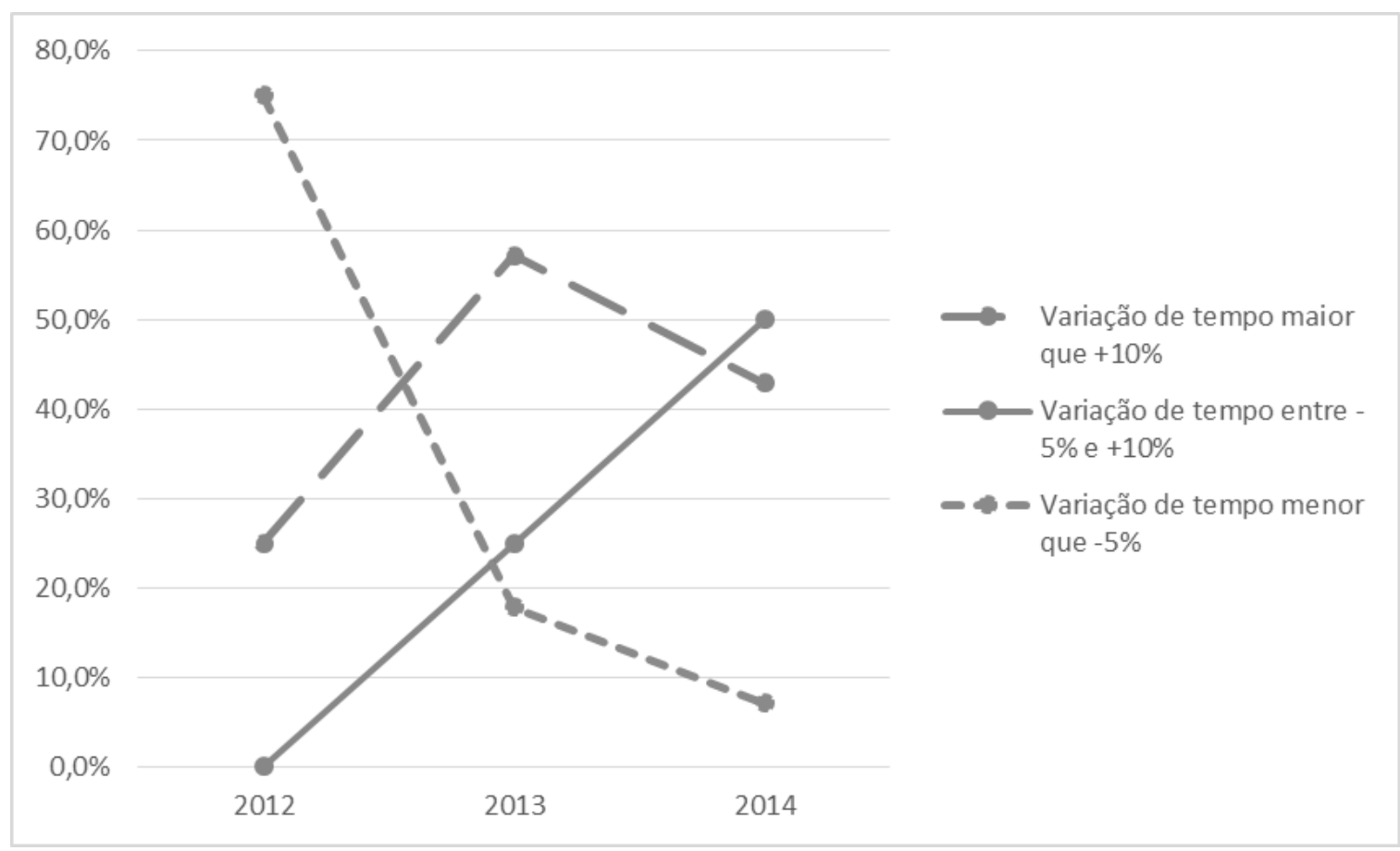

Fonte: próprio autor

Apenas $28,0 \%$ dos projetos apresentaram desempenho adequado de tempo. A tabela 9 apresenta as relações entre a APGEL e desempenho de tempo, por processo do GPPGE. 
Tabela 9 - Desempenho de tempo e nível de APGEL

\begin{tabular}{|c|c|c|c|c|c|}
\hline \multirow{2}{*}{$\begin{array}{c}\text { Processo do } \\
\text { GPPGE }\end{array}$} & \multirow{2}{*}{$\begin{array}{c}\text { Faixas de variação } \\
\text { de tempo }\end{array}$} & \multicolumn{3}{|c|}{ Nível de APGEL (\%) } & \multirow{2}{*}{$\begin{array}{l}\text { APGEL } \\
\text { média por } \\
\text { faixa }(\%)\end{array}$} \\
\hline & & Baixa & Regular & Alta & \\
\hline \multirow{3}{*}{$\begin{array}{c}\text { Planejamento } \\
\text { do GE }\end{array}$} & Maior que $+10 \%$ & 83,3 & 12,5 & 4,2 & 25,7 \\
\hline & Entre $-5 \%$ e $+10 \%$ & 92,9 & 7,1 & 0,0 & 20,2 \\
\hline & Menor que $-5 \%$ & 100,0 & 0,0 & 0,0 & 18,1 \\
\hline \multirow{3}{*}{$\begin{array}{l}\text { Coleta de } \\
\text { requisitos }\end{array}$} & Maior que $+10 \%$ & 41,7 & 54,2 & 4,2 & 39,6 \\
\hline & Entre $-5 \%$ e $+10 \%$ & 42,9 & 21,4 & 35,7 & 50,0 \\
\hline & Menor que $-5 \%$ & 41,7 & 50,0 & 8,3 & 44,8 \\
\hline \multirow{3}{*}{$\begin{array}{c}\text { Definição de } \\
\text { escopo }\end{array}$} & Maior que $+10 \%$ & 66,7 & 25,0 & 8,3 & 33,3 \\
\hline & Entre $-5 \%$ e $+10 \%$ & 71,4 & 21,4 & 7,2 & 33,3 \\
\hline & Menor que $-5 \%$ & 75,0 & 25,0 & 0,0 & 27,8 \\
\hline \multirow{3}{*}{$\begin{array}{c}\text { Criação da } \\
\text { EAP }\end{array}$} & Maior que $+10 \%$ & 54,2 & 12,5 & 33,3 & 46,7 \\
\hline & Entre $-5 \%$ e $+10 \%$ & 64,3 & 14,3 & 21,4 & 38,6 \\
\hline & Menor que $-5 \%$ & 91,7 & 8,3 & 0,0 & 26,7 \\
\hline \multirow{3}{*}{ Total } & Maior que $+10 \%$ & 75,0 & 16,7 & 8,3 & 36,2 \\
\hline & Entre $-5 \%$ e $+10 \%$ & 78,6 & 14,3 & 7,1 & 36,6 \\
\hline & Menor que $-5 \%$ & 83,3 & 16,7 & 0,0 & 30,7 \\
\hline
\end{tabular}

Fonte: próprio autor

Considerando o total dos processos, a média de APGEL para cada faixa de prazo teve pouca diferença $(36,2 \%, 36,6 \%$ e 30,7\%). Por outro lado, a média de APGEL dos processos de planejamento do GE $(22,3 \%)$ e coleta de requisitos $(43,8 \%)$ tiveram diferença em relação à média geral $(35,0 \%)$. O primeiro ficou abaixo da média enquanto o segundo ficou acima. Isso indica que o processo de coleta de requisitos recebeu maior atenção das equipes de projeto do BANCO do que os demais processos. Ao contrário, o processo de planejamento do GE recebeu menos atenção que os demais processos. Os resultados foram então agrupados por processo do GPPGE, assim como feito para custo:

a) Planejamento do GE: Os resultados do processo de planejamento foram similares para os grupos de desempenho de tempo. O grupo com variação acima de $(+10) \%$ 
apresentou alguns projetos com alta APGEL, entretanto a APGEL média, apesar de maior do que dos demais grupos $(25,7 \%)$, não apresentou diferença relevante.

b) Coleta de requisitos: $35,7 \%$ dos projetos com desempenho adequado de tempo tiveram APGEL alta, contra 12,5\% (4,2\% e 8,3\%) para grupos com desempenho inadequado de tempo. Com 50\% de média de APGEL, o grupo de projetos com desempenho adequado de tempo se apresentou com aderência superior às dos outros grupos de desempenho $(39,6 \%$ e $44,48 \%)$.

c) Definição do escopo: O grupo com variação menor do que (-5)\% de tempo teve baixa APGEL (26,7\%). Os demais grupos tiveram resultados iguais.

d) Criação da EAP: $21,4 \%$ dos projetos que tiveram variação adequada de tempo tiveram APGEL adequada. Em contrapartida, dos projetos com variação acima do esperado, $40 \%$ apresentaram APGEL igualmente adequada. 


\section{Análises e discussão}

Os resultados apresentados foram analisados, avaliando-se a APGEL identificada para os projetos, os problemas apresentados pelos gerentes de projetos e os desempenhos de custo e tempo.

As análises foram realizadas considerando-se os quatro processos do GPPGE e complementadas por informações obtidas nas entrevistas com os clientes.

\subsection{Aderência do GE às práticas apresentadas na literatura}

Foi constatado uma APGEL média de apenas 35,0\% para os projetos selecionados no BANCO. Considerando os processos do GPPGE, o processo com maior aderência foi coleta de requisitos $(43,8 \%)$, seguido por criação da EAP $(39,6 \%)$. O processo de definição do escopo ficou abaixo dos anteriores $(32,0 \%)$ e o processo de planejamento do GE apresentou a pior aderência $(22,3 \%)$. Todos os processos tiveram, portanto, aderência baixa às práticas de GE apresentadas na literatura.

Por se tratar de uma instituição que realiza investimentos elevados em projetos de SI, esperava-se que houvesse maior aderência às práticas de gerenciamento de projetos propostas pelo PMI, considerando-se que o MGP foi elaborado com embasamento no PMBOK.

A APGEL média dos projetos sofreu queda ao longo do tempo ao se observar os projetos de acordo com seu ano de execução. Os modelos MGP e MDS foram alterados no mesmo período, propondo melhorias que deveriam ter levado à maior APGEL nos projetos.

\subsubsection{Análise por período}

Em 2012, quando o MDS e o MGP surgiram, a APGEL foi a melhor dentre os três anos analisados $(38,0 \%)$. Nesse período não havia conhecimento uniforme a respeito dos modelos, fazendo com que houvesse variações na forma de condução dos projetos pelos gerentes de projetos. Em contrapartida, o BANCO apresentava uma valorização do gerenciamento de projetos e da importância de conhecimento a respeito. Segundo entrevistados, foi possível identificar que muitos desenvolvedores buscaram tal conhecimento e o aplicaram com dedicação a fim de, provavelmente, serem reconhecidos como bons gerentes de projetos. $\mathrm{O}$ 
processo do GPPGE com maior APGEL em 2012 foi criação da EAP (50,0\%), indicando que havia uma preocupação em apresentar documentações aderentes às práticas propostas e registrar de forma eficiente as entregas e trabalho a ser realizado nos projetos.

Como o MGP ainda não apresentava, em 2012, documentos com exemplos e padrões a serem seguidos, os gestores de projetos tinham que elaborar a documentação sem formato padrão ou a partir de projetos anteriores com adaptações. Acabavam por construir documentos mais detalhados e que representavam melhor os projetos.

Em 2013 os modelos eram mais conhecidos e detalhados, havendo formatos padrões de documentos e exemplos a serem seguidos. Segundo os clientes entrevistados, desenvolvedores passaram a participar mais ativamente de atividades junto aos clientes, antes mesmo do desenvolvimento do SI. Foi possível observar um aumento na APGEL do processo de coleta de requisitos (de 42,2\% para 48,7\%). De forma diferente, o planejamento do GE e a criação da EAP apresentaram reduções (de 29,2\% para 22,0\% e de 50,0\% para 37,1\%, respectivamente).

Os documentos de coleta de requisitos, arquivos eletrônicos de texto conforme padrão do MDS, apresentavam preenchimento adequado, com detalhamentos e imagens, por exemplo, auxiliando no entendimento das solicitações. Muitas EAP's, entretanto, eram o padrão proposto pelo MGP sem alterações que representassem o trabalho e entregáveis específicos dos projetos. Nesse mesmo período havia menor quantidade de documentos indicando quais seriam os processos a serem executados pelos gerentes de projetos durante o GE. Os processos padronizados fizeram com que os gestores de projetos interpretassem que podiam utilizar as orientações como planejamento geral para todos os projetos da mesma forma, sem realizar a documentação das especificidades de seus projetos.

De acordo com tal ponto de vista, o MDS auxiliou a aproximar as áreas de tecnologia e de negócios, além de propor um documento de coleta de requisitos que foi efetivo e proporcionou maior APGEL. De forma diferente, o MGP causou uma queda no esforço dos gerentes de projetos com redução de APGEL para os outros processos do GPPGE, gerando maior burocracia nos processos e não aumentando a eficiência conforme esperado.

Em 2014 foi proposto um novo modelo para organizar melhor a interação entre as áreas durante o processo de coleta de requisitos. Com maior enfoque no MDS, os clientes e analistas de tecnologia de negócio discutiam e documentavam os requisitos, em um novo padrão estabelecido pelo MDS. De forma contraditória ao que se esperava como resultado de tais 
adaptações, o processo de coleta de requisitos apresentou uma queda de APGEL (de 48,7\% para $34,8 \%$ ).

O documento de coleta de requisitos do MDS deixou de ser um documento eletrônico de texto (anexo B), passando a ser uma planilha eletrônica para listagem dos requisitos (anexo A) nesse período, sendo parte das mudanças por conta da nova estrutura e forma de interação entre as áreas. Através das entrevistas, foi possível identificar que os clientes e analistas de tecnologia de negócio demonstraram insatisfação com o novo padrão de documento, utilizando de recursos adicionais, como e-mails e apresentações eletrônicas para documentar os requisitos, não compondo a documentação oficial do projeto e justificando a redução de APGEL apresentada.

Outro fator que influenciou tal resultado foi a adaptação necessária para a nova forma de trabalho, fazendo com que a condução realizada pelos gerentes de projetos tivesse que ser diferente, garantindo a comunicação sobre os modelos para todos os envolvidos. Para isso, o mesmo acabava por utilizar de reuniões presenciais e e-mails, não produzindo devidamente todas as documentações dos projetos.

\subsubsection{Análise por processo do GPPGE}

O processo de planejamento do GEteve redução de APGEL (de 22,0\% para 19,0\%), pois os gerentes de projetos seguiam os processos estabelecidos pelos modelos e não realizavam documentações mais detalhadas a respeito de como executariam os processos de GE. Os clientes citaram que durante a fase de coleta de requisitos os analistas de tecnologia do negócio já discutiam em conjunto e acabavam por selecionar os requisitos a serem incluídos ou não no escopo final do projeto. Além disso os envolvidos já discutiam o trabalho necessário para atender os requisitos coletados. Assim, o processo de definição do escopo não era executado conforme as práticas da literatura, sendo que suas atividades eram realizadas no processo de coleta de requisitos.

O processo de criação da EAP também apresentou menor aderência em relação ao ano anterior (de 48,7\% para 34,8\%), indicando que a qualidade da documentação continuou reduzindo com a utilização dos padrões do MGP, já que o documento era obrigatório mas seu conteúdo não era verificado ou avaliado. 
No período foram estabelecidos indicadores do MGP, avaliando os projetos do BANCO, obrigando os gerentes de projetos a cumprirem certas diretrizes e serem mais assertivos em suas estimativas. Os gerentes de projetos passaram a realizar processos em função dos indicadores, diminuindo a motivação de executá-los pelo objetivo final do projeto e das práticas propostas. Com isso o resultado foi contrário ao esperado, com a redução de APGEL dos processos.

Considerando-se a APGEL média total obtida ao final da coleta de dados, foram realizadas análises comuns aos três anos e execução dos projetos, por processo do GPPGE, executados conforme o MGP.

Com relação ao processo de planejamento do GE, foi possível identificar que não havia foco dos gestores de projetos nesse momento. Nem sempre aconteciam reuniões para alinhamento sobre como ocorreriam os processos do GPPGE e foi identificado que havia falta de comunicação a respeito para os envolvidos.

Muitas vezes não eram estabelecidos os critérios de aceite no planejamento do GE, como proposto pelas práticas apresentada na literatura e pelo MGP. De acordo com a lista de verificação aplicada na documentação dos projetos foi possível observar que o critério C4 (O documento apresenta como será obtida a aceitação formal das entregas do projeto concluídas?) apresentou 44,0\% de respostas positivas. É um baixo percentual de APGEL, apesar de ter sido o segundo maior dentre os critérios do processo de planejamento do GE, corroborando a percepção de ausência dos critérios de aceite em muitos dos projetos.

As técnicas que seriam utilizadas para a realização da coleta de requisitos não eram documentadas como parte do plano de GE do projeto e não havia comunicação a respeito para todos os envolvidos no projeto. O critério $\mathrm{C} 1$ (O documento apresenta as informações sobre o processo "coletar os requisitos"?) apresentou apenas 6,0\% de APGEL. Segundo entrevistado: “às vezes, a área de TI nos convocava para reuniões sobre os projetos, mas às vezes enviávamos apenas o documento e ficávamos aguardando respostas.", reforçando que havia falta de planejamento, ou da comunicação do planejamento, para o processo de coleta de requisitos; pois os clientes não sabiam como seria realizada a coleta de requisitos até que fossem convocados para tal.

Sobre o processo de coleta de requisitos do GPPGE, foi identificada baixa APGEL $(43,8 \%)$. Os requisitos eram elaborados inicialmente pela área de negócios e enviados para a área de TI através do preenchimento de um documento padrão, no qual eram listados os 
requisitos que os clientes julgavam necessários. O documento era então enviado à área de tecnologia para avaliação, questionamentos e melhor entendimento.

Os clientes demonstraram mais conhecimentos a respeito do MDS do que do MGP no BANCO, pois o principal processo em comum entre os modelos era coleta de requisitos, levando os clientes e a apresentarem maior conhecimento e facilidade de discussão nas entrevistas. Ainda referente ao GE realizado no MGP, cabe destacar que muito foi citado a respeito do escopo do produto, mas pouco sobre o escopo do projeto ou do trabalho que deveria ser realizado, reforçando o enfoque no processo de coleta de requisitos funcionais, realizada segundo o MDS.

Sobre o processo de definição do escopo, foi possível perceber que muitas discussões acerca do que seria ou não feito, negociações de requisitos e fechamentos de escopo eram na verdade realizadas em dinâmicas de coleta de requisitos e não ficavam devidamente documentadas ou seguiam práticas sugeridas nestes momentos. Os entregáveis na maioria dos casos eram listados de forma completa na documentação, mas outras informações como premissas, restrições, limites do escopo e critérios de aceite nem sempre eram definidos e documentados. A lista de verificação apresenta dados que corroboram essas análises. O critério C18 (O documento descreve os entregáveis do projeto?) do processo de planejamento do GE apresentou $80,0 \%$ de respostas positivas, enquanto todos os demais critérios deste processo apresentaram APGEL inferior a 50,0\%.

Segundo entrevistado: "Em um projeto que acompanhei, por exemplo, eu estava homologando enquanto a equipe estava testando em paralelo. Eles não faziam testes iguais aos meus, então eu pegava muitas coisas erradas de cara. Isso entendo que foi problema de planejamento.". Isso mostra que não houve definição de critérios de aceite para o caso apresentado, sendo uma atividade do processo de definição do escopo que não foi cumprida.

Os clientes entrevistados não conheciam ou utilizavam a EAP de seus projetos, mas sabiam se tratar de um documento obrigatório nos projetos no BANCO. Assim, as EAP's criadas foram utilizadas exclusivamente pelos gerentes de projetos. Por se tratar de um documento obrigatório para os gerentes de projetos, haviam muitas EAP's criadas, entretanto não continham muitas informações sobre os pacotes de entrega ou sobre o trabalho necessário para alcançar os objetivos. Na maioria dos casos também não havia dicionário da EAP junto ao documento. 
O critério C23 (Foi criada uma estrutura gráfica de decomposição para representar a EAP?) apresentou $68,0 \%$ de respostas positivas, indicando que a maioria das EAP's foram criadas para os projetos avaliados. Já os critérios C21 (A EAP tem decomposição do trabalho a ser realizado durante todo o projeto?) e C22 (A EAP tem um pacote de trabalho que se refere a entregáveis identificados do projeto?) apresentaram $40,0 \%$ e $42,0 \%$ respectivamente. O resultado reforçou a situação encontrada em 2013, na qual os gerentes de projetos anexavam apenas o formato padrão da EAP no projeto.

\subsection{Problemas no gerenciamento de projetos relacionados ao GE}

Durante as entrevistas foram coletadas as percepções dos clientes a respeito dos problemas listados pelos gerentes de projetos por meio dos questionários, realizando análises mais específicas a respeito:

a) Identificação tardia de mudanças: Esteve relacionado à falta de discussão dos requisitos. Segundo os clientes, eles mesmos podiam se dar conta de necessidades esquecidas ao longo do projeto, gerando retrabalho e postergação das entregas do projeto. Citaram ainda que a participação do pessoal da área de TI em discussões conjuntas a respeito do escopo mitigava este problema.

b) Interrupções na fase de análise: Com maior proximidade ao MDS do que ao MGP, os clientes citaram que durante a fase de análise do MDS, se a discussão do escopo ainda não estava finalizada, os analistas de TI demonstravam desconforto quando eram solicitadas mudanças nos requisitos, pois tinham de parar as análises, reiniciar as discussões de escopo e em seguida retomar as análises. Os clientes discordaram de que isso se tratava de um problema, pois entendiam que algumas análises permitiam que o escopo evoluísse de forma mais adequada, sendo um trabalho complementar. Considerando-se o MGP, esse é um problema que está relacionado à baixa APGEL dos projetos, pois interrupções oriundas de detalhamentos não finalizados no escopo tenderiam a não ocorrer caso o escopo estivesse bem definido e claro para todos os envolvidos.

c) Ênfase excessiva em documentações com burocracia de aprovação: Esse problema não foi identificado pelos clientes, que consideraram as documentações produzidas ao longo do projeto adequadas e pertinentes. Em contrapartida, os entrevistados 
declararam não ter conhecimento ou não participar de confecção e aprovação de documentos como EAP e seu dicionário, informações sobre requisitos não funcionais e de tecnologia, entre outros. Foi possível compreender que o problema sinalizado pelos gestores de projetos era maior para a área de desenvolvimento de SI analisada do que para os solicitantes dos projetos, já que não perceberam tal problema mas não estavam envolvidos em diversos processos de confecção de documentos.

d) Conflitos entre áreas envolvidas no projeto: Os clientes informaram que os conflitos aconteciam principalmente durante as validações dos projetos, quando identificavam que testes iniciais ainda não tinham sido realizados e perdiam muito tempo aguardando enquanto os responsáveis em TI tentavam corrigir erros ainda não identificados.

e) Lentidão e falta de objetividade no levantamento dos requisitos: Este problema apareceu em determinados projetos, sendo dependente da forma como o GE foi conduzido. Projetos nos quais os requisitos eram apresentados, enviados para análise e devolvidos juntamente com dúvidas e sugestões, exigiam maior esforço para alinhamento entre os participantes. Com reuniões e conversas entre todos os envolvidos o problema foi mitigado para alguns projetos.

f) Conflitos entre membros da equipe de desenvolvimento: Foram citadas situações nas quais ficaram evidentes conflitos de times de TI entre si, por divergências de opiniões sobre soluções técnicas ou níveis de conhecimento dos envolvidos. Muitas vezes as equipe de tecnologia do negócio e as equipes de desenvolvimento tinham pontos de vista diferentes e, no período de implantação do modelo, havia falta de definição dos papéis e responsabilidades. As áreas de negócios acompanhavam tais discussões muitas vezes presencialmente em reuniões de trabalho, mas também por trocas de e-mails nos quais estavam copiados.

g) Recursos de desenvolvimento inadequados: Os clientes não citaram problemas específicos das ferramentas de desenvolvimento utilizadas pela área de SI no BANCO, mas houve uma constatação interessante e comum a diversos projetos sobre os ambientes tecnológicos disponíveis para testes, validações e acompanhamento dos projetos pela área cliente. Durante as entrevistas foi possível constatar que era um dos principais problemas de validação dos projetos realizados. 
h) Inserção de tecnologia necessária: Problema não relatado pelos clientes e sem referências a ocorrências na área de TI a respeito.

O processo de projeto do MDS relacionado aos processos de planejamento e de execução do MGP gerou satisfação dos clientes, que citaram pontos positivos a respeito, exemplificando como mitigava alguns dos problemas relatados pelos gerentes de projetos:

a) Redução de problemas de comunicação: sem a interação presencial, ocorriam problemas de comunicação por interpretação incorreta dos requisitos apresentados pela área de negócios. Os clientes muitas vezes pensavam corretamente nos requisitos, mas ao escrevê-los nos documentos geravam descrições que possibilitavam entendimentos ambíguos, fazendo com que as áreas de tecnologia interpretassem a solicitação de forma equivocada.

b) Requisitos importantes foram menos "esquecidos": o fato de haver mais pessoas analisando as necessidades e discutindo os requisitos em conjunto fazia com que a responsabilidade de pensar em todas as situações necessárias para a especificação não fosse de uma única pessoa, evitando o esquecimento de requisitos a serem declarados.

c) Interação entre a área de negócios e a área de tecnologia: através da aplicação do MDS com a adaptação, as áreas adquiriram maior proximidade ao longo dos projetos, havendo negociações facilitadas e melhor compreensão do projeto, tanto do ponto de vista de requisitos, quanto de solução, por ambas as partes.

Contudo, alguns problemas também foram apresentados pelos clientes:

a) Forma de comunicação verbal: por diversas vezes os desenvolvedores utilizaram forma demasiada técnica de se comunicar, exigindo um nível de compreensão que não estava sob domínio dos clientes.

b) Inversão de papéis: por ter maior contato com as soluções técnicas e particularidades sistêmicas durante as análises para desenho da solução, os clientes passavam a compreender melhor os sistemas e sugerir soluções, muitas vezes não possíveis para as solicitações. Chegavam a imaginar se os requisitos eram possíveis tecnicamente antes mesmo de apresenta-los à TI, muitas vezes sequer evoluindo tais pedidos. Da mesma forma, desenvolvedores passavam a conhecer mais a respeito do negócio e 
passavam a sugestionar, muitas vezes de forma enfática, o que deveria ser solicitado nos projetos.

c) Redução da dedicação em atividades de desenvolvimento: desenvolvedores acabavam por aplicar demasiado esforço nas discussões com negócios e eram interrompidos em momentos posteriores para voltar a discutir assuntos nos quais havia participado anteriormente, não conseguindo se dedicar inteiramente ao desenvolvimento de SI.

Considerando-se os problemas identificados pelos gestores de projetos e pelos clientes, foi possível observar duas causas raízes principais: forma inadequada de interação entre áreas e burocracia demasiada em processos. Tais problemas motivaram o BANCO a realizar uma mudança organizacional para manter os benefícios do relacionamento próximo de TI com negócios, mas mitigando tais conflitos.

\subsection{Desempenho dos projetos em termos de custo e planejamento do GE}

Apenas 38,0\% dos projetos apresentaram desempenho adequado de custo. O baixo desempenho de custo reforça as informações apresentadas na literatura, de que a maioria dos projetos são entregues com variação inadequada de custo, tempo ou funcionalidades (STANDISH GROUP, 2014).

Analisando a evolução do desempenho do custo dos projetos ao longo do período analisado, observa-se que houve uma melhora em 2013, mas em seguida, no ano de 2014, houve um retrocesso para níveis inferiores ao de 2012.

Em 2012, 25,0\% dos projetos tiveram variação adequada de custo. Durante as entrevistas realizadas com os clientes foi possível compreender que os custos não eram acompanhados pelos próprios clientes ou pelos gestores de projetos. Por serem clientes internos do BANCO, o controle de custos associados à TI era realizado de forma agregada por meio do orçamento, mas sem acompanhamento individual de custos por projeto.

Nesse contexto, os gerentes de projetos tinham maior liberdade para aumentar as estimativas inicias de custo, reduzindo o risco de ter de lidar com problemas futuros de justificar gastos acima dos previstos. Projetos com baixa APGEL tinham essa situação agravada, pois um 
escopo com reconhecido problema de definição era uma oportunidade para o uso da prática de elevação da estimativa de custo.

Essa realidade é uma das explicações para 42,0\% de projetos terem apresentado variação de custo abaixo do esperado. Reforça essa justificativa o comentário de um dos clientes entrevistados: “...a área de TI sempre comenta, mesmo sem analisar as solicitações do cliente, que as coisas relacionadas à tecnologia são caras e de difícil implementação".

Em 2013 houve um aumento para 50,0\%, representando uma evolução quanto aos desempenhos dos projetos e representando bons resultados da aplicação do gerenciamento de projetos, que estava sendo fomentado no período. A participação mais ativa da equipe de sistemas auxiliando nas discussões proporcionou melhores estimativas de custo. Segundo os clientes, quando os analistas participavam se sentiam parte integrante do projeto e mais seguros para apresentar soluções. Isso melhorava, por consequência, as estimativas de custo.

Em 2014, a quantidade de projetos com desempenho adequado reduziu para $21,4 \%$, sendo que $71,4 \%$ dos projetos teve variação abaixo de (-5)\%. No período estava ocorrendo a implementação de um novo modelo de trabalho, especializando a atuação com GE, com segregação dos papéis de desenvolvedores de SI e analistas de tecnologia do negócio. Nesse período as estimativas se apresentaram maiores do que deveriam para a maioria dos casos, indicando que havia maior insegurança ou desconhecimento para estimar custos.

A implementação da nova área gerou custos com treinamentos, capacitação e consultorias para adequação da forma de trabalho e preparação dos analistas. Tais custos eram distribuídos nos projetos executados no período e os gerentes de projetos não conseguiam prever adequadamente tais valores, aumentando as estimativas em seu planejamento como forma de precaução diante do cenário com maior incerteza.

Os processos do GPPGE não apresentaram, no total, diferenciação relevante para os grupos de desempenho de custo. Fatores relacionados à estrutura organizacional, tais como, atribuição de responsabilidade e delegação de autoridade tiveram influência mais direta sobre o desempenho de custo do que o GE.

O processo de planejamento do GE não foi bem conduzido pela área de TI do BANCO. A grande maioria dos projetos apresentou um nível de APGEL insatisfatório em relação ao processo de planejamento do GE, independente da faixa de desempenho de custo. Os poucos projetos que obtiveram níveis de APGEL bom tiveram uma variação de custo menor que -5\%. 
Isso ficou mais evidente ao se observar o nível de APGEL dos critérios de avaliação desse processo na tabela 7. Somente o critério C2 (O documento apresenta as informações sobre o processo "criar a EAP"?) teve um nível regular. Isto porque a elaboração da EAP era um item obrigatório. Ou seja, o critério mais bem avaliado neste processo foi realizado para atender a requisitos burocráticos obrigatórios da instituição. Corrobora essa inferência a opinião dos clientes, que citaram na entrevista, que uma maior interação entre as áreas de negócios e de tecnologia teria contribuído para que esse problema fosse minimizado, ao invés de interações formais e documentações com finalidade apenas burocrática.

Um dos problemas mais impactantes para o custo dos projetos, segundo os gerentes de projetos através dos questionários, foi conflito entre áreas envolvidas no projeto. De acordo com os clientes, tais conflitos aconteciam principalmente durante as validações, nas quais encontravam muitos problemas não verificados previamente pelos desenvolvedores. Definir e documentar durante o planejamento do GE como ocorreriam as validações dos projetos auxiliava em tal contexto.

O processo de coleta de requisitos apresentou APGEL de 43,8\%. Para este processo, projetos com desempenho adequado de custo tiveram uma média APGEL regular (52\%), enquanto projetos com desempenho inadequado de custo tiveram baixa APGEL. Isso indicou que maior aderência do processo de coleta de requisitos contribuiu para maior desempenho de custo. Com uma melhor coleta de requisitos, os custos podiam ser estimados de forma mais adequada, pois os envolvidos podiam entender melhor as necessidades e prever os esforços necessários para a execução do projeto.

Este era o processo do GPPGE realizado com maior atenção pela instituição. Não só porque apresentou a maior APGEL entre todos, mas principalmente porque o MDS definia várias atividades relacionadas a coleta e definição de requisitos, que eram executadas pela área de TI. A preocupação com a coleta de requisitos foi percebida na instituição e isso teve associação positiva a projetos com melhor desempenho de custo.

O processo de definição do escopo apresentou APGEL de 32,0\% e o grupo de desempenho de custo por variação acima de $(+10) \%, 41,7 \%$. Maior aderência no processo de definição do escopo esteve relacionada, assim, a custos superiores aos estimados inicialmente no projeto. Tal constatação não era esperada, pois com uma melhor definição de escopo deveria se ter um melhor desempenho de custo. Entretanto, observando os critérios de avaliação desse processo e o ambiente de gerenciamento de projetos da instituição foi possível perceber essa 
associação negativa. Assim como no processo de planejamento do GE, boa parte da documentação encontrada na base de dados não atendia as recomendações das práticas de GE descritas na literatura. Muito tempo era gasto com documentações para atender a requisições burocráticas, com pouca contribuição para o bom andamento dos projetos, mas com gasto de tempo da equipe de projeto e consequentemente de custo.

Como atividades de definição do escopo eram executadas indevidamente no processo de coleta de requisitos, os gestores de projetos não se atentavam especificamente ao processo de definição do escopo e desconsideravam suas atividades no momento de estimar os custos, causando a variação para mais de $(+10) \%$ quando as atividades eram executadas.

O processo de criação da EAP apresentou APGEL de 39,6\% e o grupo de variação adequada de custo 46,3\%. De acordo com tais resultados, assim como no processo de coleta de requisitos, houve uma associação de melhores níveis de APGEL com desempenhos adequados de custo.

Conforme as práticas de gerenciamento de projetos descritas na literatura, a EAP é uma entrada importante para a estimativa de custos. Os dados de desempenho de custo dos projetos do BANCO corroboraram essa realidade. Destaca-se que apesar do baixo nível de APGEL do processo criação da EAP, esta se tornou obrigatória nos projetos, mostrando a importância atribuída pela instituição a esse processo.

\subsection{Desempenho dos projetos em termos de tempo e planejamento do GE}

Assim como para custo, a quantidade de projetos com desempenhos adequados de tempo foi inferior à metade da quantidade de projetos analisados (28\%). O baixo desempenho de tempo reforça, mais uma vez, os resultados apresentados pelo Standish Group (2014) de que a maioria dos projetos são entregues com variação inadequada de custo, tempo ou funcionalidades. Analisando a evolução do desempenho do tempo dos projetos ao longo do período analisado, observa-se que houve uma melhora contínua. Em 2012 nenhum projeto foi encerrado com desempenho de tempo adequado, mas em 2013 foram 25,0\% e 2014 50,0\%.

Em 2012 a maioria dos projetos $(75,0 \%)$ foi entregue antes do previsto, indicando que havia um problema de planejamento das entregas, com estimativas de tempo acima do que seria posteriormente realizado. 
Em 2013, mais projetos começaram a atrasar (57,1\%), sendo entregues após a previsão inicial. Por se tratar de um período no qual os processos estavam sendo instituídos de forma mais clara no BANCO, as estimativas começaram a ser ajustadas de acordo com as orientações do MGP, mas havendo ainda adequações necessárias.

Em 2014, poucos projetos foram entregues antes do previsto $(7,1 \%)$, mas metade dos projetos foram entregues conforme planejado. $42,9 \%$ dos projetos atrasou.

De acordo com os clientes entrevistados, o prazo era o fator de grande importância nos projetos. Além disso, muitas vezes, os projetos tinham que atender a demandas legais, ou seja, solicitações de órgãos governamentais que exigiam implementações específicas nos SI com prazos pré-determinados. Assim, nesses casos as datas de entrega eram definidas antes mesmo da área de TI conhecer as necessidades a serem atendidas pelos projetos. Ou seja, os processos do GPPGE eram executados não para obter uma estimativa de prazo, mas para atender às regras burocráticas da instituição. Nesses casos, nos quais os prazos dos projetos eram impostos por necessidades externas, o esforço em executar os processos superou os benefícios de fazê-lo.

O tempo era acompanhado constantemente ao longo da vida de todo o projeto pelos clientes, pois um atraso de um dia poderia significar postergar o projeto por um mês por conta dos processos de implantação de SI no BANCO.

Mesmo se os custos dos projetos fossem elevados visando atender os prazos de entrega solicitados, muitos atrasos ocorriam, pois a área de desenvolvimento de SI era interna no BANCO, fazendo com aumentos de custo para redução do tempo de execução, através de contratação de terceiros, por exemplo, não fosse uma solução viável.

Os processos do GPPGE não apresentaram, no total, diferenciação relevante para os grupos de desempenho de tempo, assim como aconteceu para custo.

O processo de planejamento do GE apresentou APGEL baixa (22,3\%). Analisando a APGEL por faixa não houve diferença entre as faixas, mostrando que não houve influência do processo de planejamento de GE no desempenho de tempo dos projetos.

O processo de coleta de requisitos apresentou APGEL de 43,8\% e a faixa de desempenho adequado de tempo apresentou 50,0\%. Um melhor APGEL no processo de coleta de requisitos esteve associado com desempenho adequado de tempo. Foi o processo que apresentou maior associação com desempenho de tempo.

Nas entrevistas foi constatado que durante a coleta de requisitos, estes eram adaptados para viabilizar as entregas nas datas impostas, sinalizando que algumas atividades do processo 
de definição do escopo eram executadas no processo de coleta de requisitos. Isso foi confirmado por um dos clientes entrevistados: “...conversávamos com a área de TI para mostrar o que precisávamos no projeto, e nessas conversas nós conseguíamos definir o que seria ou não feito no projeto para entregar a tempo. Às vezes, quebrávamos o projeto em mais de uma entrega para isso".

O processo de definição de escopo apresentou 32,0\% de APGEL, não havendo diferenciação entre as faixas de desempenho de tempo. Com baixa aderência, a definição de escopo não era um processo realizado adequadamente pelos gestores de projetos, pois parte das atividades eram executadas no processo de coleta de requisitos. Apesar de atividades como documentação dos entregáveis do projeto $(\mathrm{C} 18)$ e dos critérios de aceite do produto $(\mathrm{C} 17)$ terem sido realizadas, muitas informações sobre o escopo não foram apresentadas na maioria dos projetos, tais como, restrições, premissas e informações sobre volumetria das funcionalidades em SI a serem implementadas, entre outras.

O processo de criação da EAP apresentou 39,6\% de APGEL. Apesar de baixa, a média de APGEL esteve entre as maiores ao lado do processo de coleta de requisitos. Isto porque a EAP era um documento obrigatório na instituição. Entretanto, observando-se a tabela 9, percebe-se uma associação negativa com o desempenho de tempo, ou seja, níveis maiores de APGEL (46,7\%) foram associados a níveis maiores de atraso (faixa maior que $10 \%$ ). Assim, quanto mais tempo se investia na EAP no contexto apresentado, mais atrasos poderiam ocorrer nos projetos. 


\section{Conclusão}

O objetivo deste trabalho foi analisar, na área de TI de uma grande organização brasileira do setor financeiro, como os processos de planejamento do GE em projetos de desenvolvimento de SI podem influenciar o desempenho de custo e o desempenho de tempo de tais projetos.

Este objetivo foi atingido por meio de uma pesquisa qualitativa e descritiva, utilizando a estratégia de estudo de caso aplicada a uma instituição financeira brasileira de grande porte.

Cabe destacar que a pesquisa analisou 50 projetos de desenvolvimento de SI, e apesar de ter seguido com rigor o procedimento metodológico, apresenta limitações. Entre elas destacam-se: a abordagem proposta para identificar as influências do GE sobre os desempenhos de custo e tempo, que apresenta subjetividade associada à lista de verificação e aos gerentes de projetos e clientes como respondentes; e por se tratar um estudo de caso em uma única instituição, os resultados da pesquisa não podem ser generalizados.

Esta pesquisa contribuiu para a compreensão de que nem sempre o GE é o fator de maior importância para se obter melhores resultados de desempenho para custo e tempo, contudo os processos do GE apresentaram relacionamento com tais variáveis de resultado, principalmente coleta de requisitos. A pesquisa apresentou lições aprendidas do ambiente de projetos da instituição analisada. As contribuições estão apresentadas a seguir em função dos objetivos específicos da pesquisa:

a) Aderência dos projetos de SI: A APGEL dos projetos analisados foi baixa $(35,0 \%)$. Isso mostra que as questões envolvendo o GE em projetos de SI continuam a ter um papel relevante na área de TI. Entre as barreiras existentes à implantação de SI nas organizações, Prado, Castro e Albuquerque (2010) destacaram dois fatores: o primeiro denominado fator humano, relacionado ao envolvimento das partes interessadas; e o segundo denominado gerenciamento, relacionado a planejamento, monitoramento e uso de modelos. Ambos se aplicam na realidade constatada neste estudo, pois estão relacionados aos problemas que dificultaram a obtenção de um bom desempenho de custo e de tempo nos projetos de SI avaliados no BANCO. Somente o processo coleta de requisitos, que foi o que teve maior APGEL, foi executado com maior cuidado pelo BANCO. Os demais apresentaram problemas relacionados à burocracia ou interação entre áreas. Ou seja, tempo e custo 
gastos com excesso de documentações que não agregaram valor ao projeto, mas com a finalidade de atender às normas institucionais. Essa realidade foi percebida pela instituição, que analisou a possibilidade de mudança no MDS, que adotava o modelo cascata. A instituição iniciou projeto piloto para a adoção de modelo alternativo, baseado em modelos ágeis. Entre os objetivos da escolha dessa alternativa estão os relacionados a duas diretrizes do manifesto ágil (HIGHSMITH, 2004):

- Entrega de produtos está acima da documentação. Esta diretriz se adequa bem a constatação do excesso de documentação e burocracia que impactou os desempenhos de custo e tempo, mas não agregou valor aos projetos da instituição.

- Mais indivíduos e interações do que processos e ferramentas. Esta diretriz vai ao encontro da constatação dos clientes, que perceberam um melhor andamento dos projetos quando ocorriam mais interações presenciais entre os envolvidos no projeto do que o uso de normas e ferramentas definidas nos modelos de gerenciamento de projetos da instituição.

b) Problemas relacionados ao GE: De acordo com clientes e gestores de projetos, foram levantados problemas e ações que mitigaram alguns deles. Foram identificadas duas causas principais para os problemas: forma inadequada de interação entre áreas e burocracia demasiada nos processos. O MDS e o MGP apresentaram relação com estas duas causas, sendo que o MDS vinha sendo adaptado por conta da condução dos envolvidos nos projetos para uma melhor interação durante os projetos, enquanto o MGP apresentou processos burocráticos que visavam melhor acompanhamento dos projetos, mas suscitou em resultados contrários, com motivação de atuação em prol de indicadores e cumprimento de regras acima de alcançar os objetivos dos projetos.

c) Influência do GPPGE no desempenho de custo: $\mathrm{O}$ desempenho dos projetos em relação a custo não foi bom. Apenas $38.0 \%$ dos projetos foram concluídos com desempenho adequado. Além disso, não houve uma evolução do desempenho ao longo do tempo, ou seja, no ano de 2013 houve uma melhora no desempenho $(50,0 \%)$, mas no ano seguinte o desempenho caiu para o pior nível do período analisado $(21,4 \%)$. Parte desse problema pode ser explicado pela falta de acompanhamento dos custos de cada projeto por parte dos clientes e dos gerentes de 
projeto. O acompanhamento era feito de forma agregada pelo orçamento. Isso mostra que mesmo em instituições na qual a TI desempenha um papel estratégico e na qual os investimentos em tecnologia são elevados, o gerenciamento dos custos se faz necessário. Uma alternativa para melhorar a eficiência dos custos seria avaliar o desempenho operacional de todas as unidades organizacionais envolvidas. Outra alternativa, já em curso na instituição, é a adoção de modelos ágeis para endereçar problemas de excesso de burocracia e falta de maior interação com as partes interessadas. Todos os quatro processos que pertencem ao GPPGE tiverem baixo nível de APGEL e somente dois deles tiveram associação com melhores níveis de desempenho de custo. Um desses processos foi coleta de requisitos. Os bons resultados deveram-se ao MDS existente na instituição, que promovia a realização mais cuidadosa da coleta de requisitos. MDS, orientações sobre coleta e definição clara de requisitos são preocupações antigas da área de TI e não foi diferente na instituição analisada. Mesmo assim, o fraco desempenho de custo não passou desapercebido pela alta administração que promoveu mudanças na estrutura organizacional. Isso mostrou que um bom desempenho de custo é fruto de diversas variáveis que afetam um determinado projeto e não apenas do GE.

d) Influência do GPPGE no desempenho de tempo: O desempenho dos projetos em relação a tempo não foi bom. Apesar de muitos projetos apresentarem datas limite para entrega, os projetos atrasavam. Apenas $28.0 \%$ dos projetos foram concluídos com desempenho adequado, mas foi possível observar uma evolução no desempenho de tempo no período analisado. Isso se deve ao melhor estabelecimento e conhecimento dos modelos (MDS e MGP) e de um acompanhamento cada vez maior dos clientes a respeito do tempo. A adoção de modelos ágeis para endereçar problemas de excesso de burocracia e falta de maior interação com as partes interessadas também visava auxiliar a melhoria do desempenho de tempo. Todos os quatro processos que pertencem ao GPPGE tiverem baixo nível de APGEL e somente a coleta de requisitos teve associação com melhores níveis de desempenho de tempo. A aplicação do MDS, com maior dedicação ao processo de coleta de requisitos, realizando o levantamento e até mesmo a definição do escopo neste processo, fez com que houvesse maior APGEL. O desempenho de tempo, assim 
como o de custo, motivou o BANCO a realizar a mudança organizacional visando melhorias nos projetos de SI.

Como contribuição adicional, compreende-se o método de pesquisa proposto, que pode ser replicado em novas pesquisas para avaliação do GE.

Nos projetos analisados o GE não foi uma variável que teve um alto grau de associação com os desempenhos de custo e tempo, podendo explicá-los adequadamente. Por outro lado, o GE mostrou ser um fator de forte influência nos projetos, pois ensejou e mudanças na organização, sendo foco das alterações realizadas para se alcançar melhores desempenhos.

A pesquisa possibilitou a publicação de quatro artigos ciêntificos, em dois congressos, um simpósio e uma revista. Contribuiu ainda com a instituição analisada, o BANCO, provendo informações e sugestões de adaptações na forma de trabalho do novo modelo proposto.

Como continuação da pesquisa pretende-se replicar o estudo em outras instituições para possibilitar ampliar as contribuições para o campo de gerenciamento de projetos, a serem obtidas por meio das lições aprendidas nos projetos realizados em outras organizações. 


\section{Referências ${ }^{1}$}

ABRAMOVICI, A. Controlling scope creep. PM Network, Pennsylvania, v. 14, n. 1, p. 44-48, 2000 .

AGILEALLIANCE Manifesto Ágil, 2001. Disponível em: <http://agilemanifesto.org/>. Acesso em: 16 fev. 2014.

AHMED, S. et al. A methodology to manage the changing requirements of a software project. In: COMPUTER INFORMATION SYSTEMS AND INDUSTRIAL MANAGEMENT APPLICATIONS (CISIM), 2010, Kraków. Proceedings... Kraków: Faculty of Physics and Applied Computer Science, 2010. p. 319-327.

ALBERTIN, A. L. Aumentando as chances de sucesso no desenvolvimento e implementação de sistemas de informações. Revista de Administração de Empresas, v. 36, n. 3, p. 61-69, 1996.

ALP, N.; STACK, B. Scope management and change control process study for project-based companies in the construction and engineering industries. In: TECHNOLOGY MANAGEMENT FOR EMERGING TECHNOLOGIES (PICMET), 2012, Vancouver. Proceedings... Vancouver: Sheraton Wall Centre Hotel, 2012. p. 2427-2436.

AMARAL, D. C.; CONFORTO, E. C. Escritório de projetos e gerenciamento ágil: um novo enfoque para a estrutura de apoio à gestão de projetos ágeis. In: $6^{\circ}$ CONGRESSO BRASILEIRO DE GESTÃO DE DESENVOLVIMENTO DE PRODUTO, 2007, Belo Horizonte. Anais... Belo Horizonte: UFMG, 2007. p. 415-452.

ANGIONI, M.et al. Integrating XP project management in development enviroments. Journal of Systems Architeture, New York, v. 52, n. 11, p. 619-626, 2006.

BECK, K. Programação Extrema Explicada. Porto Alegre: Bookman, 2004.

BOEHM, B. W. A spiral model of software development and enhancement. Computer, v. 21, n.5, p. 61-72, 1988.

BOMFIN, D. F.; NUNES, P. C.; HASTENREITER, F. Gerenciamento de projetos segundo o guia PMBOK: desafios para os gestores. Revista de Gestão e Projetos, v. 3, n. 3, p. 58-87, 2012.

\footnotetext{
${ }^{1}$ De acordo com a Associação Brasileira de Normas Técnicas. NBR 6023.
} 
BUREK, P. Influence of the scope statement on the WBS. In: PMI GLOBAL CONGRESS (PMI), 2011, Marseille. Proceedings... Dallas: Gaylord Texan Resort \& Convention Center, 2011. p. 621-657.

BUREK, P. The ABC Basics of the WBS. In: PMI GLOBAL CONGRESS (PMI), 2013, New Orleans. Proceedings... New Orleans: Ernest N. Morial Convention Center, 2013

BURNETT, R. C. et al. O Desenvolvimento de Software Aplicando a Técnica Joint Application Design, PPGEP, Paraná, n.56, 2010. Disponível em: <http://www.pg.utfpr.edu.br/ppgep/Ebook/ARTIGOS/56.pdf>. Acesso em: 29 jun. 2014.

CANFORA, G.; CERULO, L. Impact analysis by mining software and change request repositories. In: 11TH IEEE INTERNATIONAL SYMPOSIUM SOFTWARE METRICS, 2005, Como. Proceedings... Como: Villa Olmo, 2005. p. 9-29.

CAWLEY, O.; WANG, X.; RICHARDSON, I. Lean/agile software development methodologies in regulated environments-state of the art, Lean Enterprise Software and Systems, Ireland, v. 65, p. 31-36, 2010.

CHIN, G. Agile Project Management: how to succeed in the face of changing project requirements, New York: Amacon, 2004.

CLEMENTS, J. P.; GIDO, J. Gestão de projetos, São Paulo: Thomson, 2007.

COHN, M., FORD, D. Introducing an agile process to an organization. IEEE Computer Magazine, Florida, v. 36, n. 6, p. 74-78, 2003.

CRUZ, F. Scrum e PMBOK: unidos no gerenciamento de projetos, Rio de Janeiro: Brasport, 2013.

CORDEIRO, E. S. Modelagem descritiva iterativa e incremental de processo de software. Florianópolis: Universidade Federal de Santa Catarinam, 2003. Dissertação (Mestrado em Ciência da Computação) - Área de concentração de sistema de computação. 199 p.

DAVIS, M. M.; AQUILANO, N. J.; CHASE, R. B. Fundamentos da administração da produção, Porto Alegre: Bookman, 2001.

DAVIS, A. M., ZWEIG, A. Requirements Management Made Easy, PM Network, Pennsylvania, v. 14, n. 12, p.61-63, 2000.

DEKKERS, C. Scope management: 12 steps for ICT Program Recovery. CrossTalk: The Journal of Defense Software Engineering, v. 23, n. 1, p.16-21, 2010. 
DEKKERS, C. Increase ICT Project Success with Concrete Scope Management. In: PMI Global CONGRESS PROCEEDINGS, 2007, Hong Kong. Proceedings... Hong Kong, 2007.

DIAS, M. V. B. Um novo enfoque para o gerenciamento de projetos de desenvolvimento de software. São Paulo: Universidade de São Paulo, 2005. Dissertação (Mestrado em Administração) - Faculdade de Economia, Administração e Contabilidade. 212 p.

EDMILSON; A. M. et al. Estratégia de Investimentos em Tecnologia da Informação e Comunicação e a Evolução da Indústria Bancária Brasileira: Análise Geral e dos Maiores Bancos Privados. Revista Gestão \& Tecnologia, v. 13, n. 1, p. 151-176, 2013.

ELRAGAL, A. A.; LAUDON J. P.; LAUDON K. C. Management Information Systems: Managing the Digital Firm, England: Pearson Education, 2013.

FILHO, J. R.; LUDMER, G. Sistemas de informação: que ciência é essa?. Revista de Gestão de Tecnologia e Sistemas de Informação, v. 2, n. 2, p. 151-166, 2005.

FILHO, T. F. Os cinco problemas mais frequentes nos projetos das organizações no Brasil: Uma análise crítica. Revista de Gestão e Projetos, v. 4, n. 2, p. 213-237, 2013.

FREITAS, E. C.; PRODANOV, C. C. Metodologia do trabalho científico: Métodos e Técnicas da Pesquisa e do Trabalho Acadêmico, Novo Hamburgo: Feevale, 2013.

FROTA, L. C. Gerenciamento de escopo em projetos. Distrito Federal: Universidade Gama Filho, 2010. Monografia (Especialização em Gestão de Projetos). 52 p.

GASIK, S. A model of project knowledge management. Project Management Journal, Pennsylvania, v. 42, n. 3, p. 23-44, 2011.

HIGHSMITH, J. Agile Project Management: creating innovative products, Boston: Addisson-Wesley, 2004.

HOSSENLOPP, R. Needs to know about requirements. In: PMI GLOBAL CONGRESS, 2005, Endinburgh. Proceedings... Endinburgh: Edinburgh International Conference Centre \& Sheraton Grand Hotel, 2005. p. 12-34.

HU, E.; LIU, Y. IT Project Change Management. In: INTERNATIONAL SYMPOSIUM ON COMPUTER SCIENCE AND COMPUTATIONAL TECHNOLOGY, 2008, Shanghai. Proceedings... Shanghai, 2008.

IBBS, C. W.; WONG, C. K.; KWAK, Y. H. Project change management system. Journal of Management in Engineering, Indiana, v.17, n.3, p. 159-165, 2003. 
IEEE COMPUTER SOCIETY. SWEBOK: Guide to the software engineering Body of Knowledge, 2004.

IIBA, A. Guide to the business analysis body of knowledge (BABOK Guide), 2009.

IPMA INTERNATIONAL PROJECT MANAGEMENT ASSOCIATION. ICB - IPMA Competency Baseline. Nijkerk: IPMA, 2006.

JONASSON, H. Determining Project Requirements - Best pratices and Tips. In: PMI GLOBAL CONGRESS PROCEEDINGS, 2007, Atlanta. Proceedings... Atlanta, 2007.

KASSAB, M.; DANEVA, M.; ORMANDJIEVA, O. Scope management of non-functional requirements. In: EUROMICRO 2007 - OF THE 33RD EUROMICRO CONFERENCE ON SOFTWARE ENGINEERING AND ADVANCED APPLICATIONS, 2007, Germany. Proceedings... Germany, 2007, p. 409-417.

KASSAB, M.; ORMANDJIEVA, O.; DANEVA, M. A Metamodel for Tracing Non-functional Requirements, Computer Science and Information Engineering. In: WRI WORLD CONGRESS, 2009, Los Angeles. Proceedings... Los Angeles, 2009, p. 687-694.

KAYED, O. Seven steps to dynamic scope design, PM Network, Pennsylvania, v. 17, n. 12, p.44-46, 2003.

KHAN, A. Project scope management, Cost Engineering, Morgantown, v. 48, n. 6, p. 12-16, 2008.

KUMAR, V. S. Effective Requirements Management. In: PMI GLOBAL CONGRESS, 2006, Seattle. Proceedings... Seattle, 2006, p. 321-354.

LIMA, I. R.; FREIRE, T. C.; COSTA, H. A. X. Implantação e Adaptação do SCRUM em um Laboratório de Pesquisa e Desenvolvimento de Projetos de Software, Revista de Sistemas de Informação da FSMA, n.9, p. 16-23, 2012.

MACHADO, M.; MEDINA, S. G. SCRUM - Método Ágil: uma mudança cultural na Gestão de Projetos de Desenvolvimento de Software, Revista Científica Intr@ ciência, Guarujá, p. 58-71, 2009.

MADEO, R. C. B. et al. Sistemas de Informação no Mercado de Ações: Papel Estratégico e Impactos Éticos, Sociais e Políticos. In: VIII SIMPÓSIO BRASILEIRO DE SISTEMAS DE INFORMAÇÃO (SBSI 2012), 2012, São Paulo. Anais... São Paulo: Universidade de São Paulo, Trilhas Técnicas, 2012. v. 1. p. 432-443.

MARTIN, P. K.; TATE, K. What's in a Project Plan?, PM Network, 2000. 
MARTINS, F. M. J. Métodos formais na concepção e desenvolvimento de sistemas interactivos. Braga: Universidade do Minho, 1995. Dissertação (Doutorado em Ciências da Computação) - Escola de Engenharia. 296 p.

MARTINS, G. A. Estudo de caso: uma estratégia de pesquisa, São Paulo: Atlas, 2006.

MATTOS, J. L.; GUIMARÃES, L. S. Gestão da tecnologia e inovação: uma abordagem prática, São Paulo: Saraiva, 2005.

MCKINSEY Global Banking Pools. Disponível em: <http://www.mckinsey.com/>. Acesso em: 24 jun. 2014.

MERHI, D. 40 ferramentas e técnicas de gerenciamento, Rio de Janeiro: Brasport, 2007.

MILLHOLLAN, C. Scope change control: control your projects or your projects will control you!, In: PMI GLOBAL CONGRESS, 2008, Colorado. Proceedings... Colorado, 2008.

NAZÁRIO, P. A importância de sistemas de informação para a competitividade logística. Revista Tecnologística, p.28-40, 1999.

NAKASHIMA, D. T. V.; CARVALHO, M. D. Identificação de riscos em projetos de TI. In: XXIV Encontro Nac. de Eng. de Produção (ENEGEP), Porto Alegre, 2004. Anais... Porto Alegre, 2004.

NERUR, S.; MAHAPATRA, R.; MANGALARAJ, G. Challenges of Migrating to Agile Methodologies. Communications of the ACM, v. 48, n. 5, p. 72-78, 2005.

OGC, OFFICE OF GOVERNMENT COMMERCE. PRINCE2 - Projects in Controlled Environments. Londres: OGC, 1996.

PALMER, S. R.; FELSING, M. A practical guide to feature-driven development, New Jersey: Prentice Hall, 2001.

PARIDA, P. Essence of Waterfall Model. Disponível em: <http://ezinearticles.com/?EssenceOf-Waterfall-Model\&id=352291>. Acesso em: 29 jun. 2014.

PÉREZ, F. J. S. Scope Management with graphics. In: PMI GLOBAL CONGRESS, 2004, Anaheim. Proceedings... Anheim, 2004.

PETERS, T. Rompendo as Barreiras da Administração, A Necessária Desorganização para Enfrentar a Nova Realidade, São Paulo: Harbra, 1993.

PINTO, S. A. O. Gerenciamento de projetos: análise dos fatores de risco que influenciam o sucesso de projetos de sistemas de informação. 2002. Dissertação (Mestrado em 
Administração) - Faculdade de Economia, Administração e Contabilidade, Universidade de São Paulo, São Paulo, 2002.

PMDOCUMENTS Project Management Documents and Templates. Disponível em: <http://www.pmdocuments.com/>. Acesso em: 28 jun. 2014.

PMI. A guide to the project management body of knowledge (PMBOK Guide), Newton Square: Project Management Institute, v. 5, 2013.

POWELL, J. W. Meeting expectations. PM Network, 2003.

PRADO, E. P. V., CASTRO, R. P. S., ALBUQUERQUE, J. P. Barreiras na implantação de sistemas de informação em uma instituição de saúde: a importância dos fatores humanos e de gerenciamento. RACEF Revista de Administração, Contabilidade e Economia da FUNDACE, v.1, p.6, 2010.

PRESSMAN, R. S. Engenharia de Software, São Paulo: AMGH Editora Ltda., v. 7, 2011.

RIBEIRO, R. L. O. Gerenciando projetos com prince2, Rio de Janeiro: Brasport, 2011.

RUPARELIA, N. B. Software development lifecycle models. In: SIGSOFT SOFTW. ENG, 2010, Santa Fe. Proceedings... Santa Fe, 2010.

SALADIS, F. P. Bringing the PMBOK guide to life. In: PMI GLOBAL CONGRESS, 2006, Seattle. Proceedings... Seattle, 2006.

SAMPIERI, R.H.; COLLADO, C. H.; LUCIO, P.B. Metodologia de pesquisa, Porto Alegre: Penso, 2006.

SANTOS, R. L. L. Proposta de um modelo para inspeção da documentação gerada pelo grupo de processos de planejamento da gestão de escopo em projetos de sistema de TI de organizações públicas. 2010. Dissertação (Mestrado em Engenharia Aeronáutica e Mecânica) - Produção, Instituto tecnológico de aeronáutica, São José dos Campos, 2010.

SAYÃO, M.; STAA, A. V.; LEITE, J. C. S. P. Qualidade em Requisitos. Monografias em ciência da computação - PUC, Rio de Janeiro, n.47, ed.3; 2003.

SCHMIETENDORF, A.; DIMITROV, E.; DUMKE, R. R. Process models for the software development and performance engineering tasks. In: 3RD INTERNATIONAL WORKSHOP ON SOFTWARE AND PERFORMANCE, Rome. Proceedings... Rome, 2002, p. 211-218.

SENE, P. F. Gerenciamento ágil de projetos. 2010. Dissertação (Pós-Graduação em Gerência de Projetos com ênfase nas Práticas do PMI) - Universidade São Judas Tadeu, São Paulo, 2010. $63 \mathrm{p}$. 
SOARES, M. S. Comparação entre metodologias ágeis e tradicionais para o desenvolvimento de software. INFOCOMP Journal of Computer Science, v. 3, n. 2, p. 8-13, 2004.

SOARES, M. S. Metodologias ágeis extreme programming e scrum para o desenvolvimento de software. Revista Eletrônica de Sistemas de Informação, v. 3, n. 1, 2004.

SOMMERVILLE, I. Engenharia de Software, São Paulo: Pearson Addison-Wesley, v. 8, 2007.

STANDISH GROUP. Chaos Report, 2014. Disponível em: <www.standishgroup.com>. Acesso em: 08 abr. 2014.

TAKEUCHI, H.; NONAKA, I. The new new product development game. Harvard Business review, p. 137-146, 1986.

UDO, N.; KOPPENSTEINER, S. Will agile development change the way we manage software projects?, In: PMI GLOBAL CONGRESS , 2003, Pennsylvania. Proceedings... Pennsylvania, 2003.

VAlle, A. B.; SOARES, C. A. P.; JUNIOR, J. F.; SILVA, L. S. F. Fundamentos do Gerenciamento de Projetos. Rio de Janeiro: Editora FGV, 2007.

VARGAS, R. V. Gerenciamento de projetos: Estabelecendo diferenciais competitivos, Rio de Janeiro: Brasport, v. 6, 2003.

VEZZONI, G. Identificação e análise de fatores críticos de sucesso em projetos, Ribeirão Preto: UNISEB, 2011.

WANG, Y. R.; GIBSON, G. E. J. A study of preproject planning and project success using ANNs and regression models. In: 25TH INTERNATIONAL SYMPOSIUM ON AUTOMATION AND ROBOTICS IN CONSTRUCTION, 2010, Lithuania. Proceedings... Lithuania, 2010. p. 341-346.

WARD, G. F. The WBS Dictionary - Extending the work breakdown structure. In: PROJECT MANAGEMENT INSTITUTE ANNUAL SEMINARS \& SYMPOSIUM, 2001, Tennessee. Proceedings... Tennessee, 2001.

YIN, R. K. Estudo de caso: planejamento e métodos. Porto Alegre: Bookman, ed. 5, 2011. 


\section{Apêndice A - Critérios da lista de verificação e grupos de processos}

\begin{tabular}{|c|c|}
\hline $\begin{array}{c}\text { Processo de } \\
\text { Planejamento }\end{array}$ & Pergunta \\
\hline \multirow{6}{*}{ Planejamento do GE } & (C1) O documento apresenta as informações sobre o processo "coletar os requisitos"? \\
\hline & (C2) O documento apresenta as informações sobre o processo "criar a EAP"? \\
\hline & (C3) O documento apresenta as informações sobre o processo "definir o escopo"? \\
\hline & $\begin{array}{l}\text { (C4) O documento apresenta como será obtida a aceitação formal das entregas do } \\
\text { projeto concluídas? }\end{array}$ \\
\hline & (C5) O documento apresenta o processo de priorização dos requisitos? \\
\hline & $\begin{array}{l}\text { (C6) O documento apresenta os processos para controlar como as solicitações de } \\
\text { mudança de escopo serão processadas? }\end{array}$ \\
\hline \multirow{8}{*}{ Coleta de requisitos } & (C7) O campo "justificativa" especifica o benefício de se fazer os requisitos? \\
\hline & (C8) As situações atuais foram especificadas? \\
\hline & (C9) O campo importância está preenchido de forma a possibilitar diferenciação? \\
\hline & (C10) O documento apresenta os requisitos de suporte e treinamento? \\
\hline & (C11) O documento apresenta os requisitos funcionais? \\
\hline & (C12) O documento apresenta os requisitos não-funcionais? \\
\hline & (C13) O documento apresenta os requisitos organizacionais? \\
\hline & (C14) Os requisitos deixam claro o que está sendo solicitado? \\
\hline \multirow{4}{*}{ Definição do escopo } & (C15) O documento define as restrições do projeto? \\
\hline & (C16) O documento descreve o escopo do produto? \\
\hline & (C17) O documento descreve os critérios de aceitação do produto? \\
\hline & (C18) O documento descreve os entregáveis do projeto? \\
\hline
\end{tabular}




\begin{tabular}{|c|c|}
\hline \multirow[t]{3}{*}{$\begin{array}{l}\text { Processo de } \\
\text { Planejamento }\end{array}$} & Pergunta \\
\hline & (C19) O documento lista as premissas do projeto? \\
\hline & (C20) Tem o quadro de volumetria preenchido? \\
\hline \multirow{5}{*}{ Criação da EAP } & (C21) A EAP tem decomposição do trabalho a ser realizado durante todo o projeto? \\
\hline & $\begin{array}{c}\text { (C22) A EAP tem um pacote de trabalho que se refere a entregáveis identificados do } \\
\text { projeto? }\end{array}$ \\
\hline & (C23) Foi criada uma estrutura gráfica de decomposição para representar a EAP? \\
\hline & (C24) Há um detalhamento/dicionário da EAP \\
\hline & $\begin{array}{c}\text { (C25) Os pacotes de trabalho são decompostos o suficiente para estabelecer tempo e } \\
\text { recursos necessários para sua entrega? }\end{array}$ \\
\hline
\end{tabular}




\section{Apêndice B - Questionário sobre influências nos resultados dos projetos}

Instruções de preenchimento: Para cada projeto apresentado abaixo, assinalar o impacto e frequência dos problemas listados, inserindo um "x" nas células correspondentes.

Este questionário será utilizado com finalidade da realização de uma pesquisa a respeito do gerenciamento de projetos para o programa de pós

Gestor de Projetos: Nome do gestor de projetos

Projeto: Código do projeto - Título do projeto

\begin{tabular}{|c|c|c|c|c|c|}
\hline \multirow[b]{2}{*}{ Problemas no projeto } & \multicolumn{5}{|c|}{ Impacto desse problema nos resultados de custo ou prazo } \\
\hline & Muito baixa & Baixa & Média & Alta & Muito alta \\
\hline Identificação tardia de mudanças, retrabalho excessivo & & & & & \\
\hline Conflitos entre membros da equipe & & & & & \\
\hline Recursos de desenvolvimento inadequados & & & & & \\
\hline Conflitos e choques entre os envolvidos no projeto (stakeholders) & & & & & \\
\hline Inserção de tecnologia necessária & & & & & \\
\hline Lentidão e falta de objetividade no levantamento dos requisitos & & & & & \\
\hline Interrupções na fase de análise & & & & & \\
\hline Ênfase excessiva em documentações em forma de texto e burocracia de aprovação & & & & & \\
\hline Digite aqui alguma opção adicional, caso necessário & & & & & \\
\hline Digite aqui alguma opção adicional, caso necessário & & & & & \\
\hline
\end{tabular}




\section{Apêndice C - Influências dos processos de planejamento do GE nos resultados, de acordo com os gerentes de projetos}

\begin{tabular}{|c|c|}
\hline Projeto & \% de influência do escopo \\
\hline Projeto 1 & $64 \%$ \\
\hline Projeto 2 & $55 \%$ \\
\hline Projeto 3 & $63 \%$ \\
\hline Projeto 4 & $64 \%$ \\
\hline Projeto 5 & $62 \%$ \\
\hline Projeto 6 & $61 \%$ \\
\hline Projeto 7 & $76 \%$ \\
\hline Projeto 8 & $60 \%$ \\
\hline Projeto 9 & $60 \%$ \\
\hline Projeto 10 & $71 \%$ \\
\hline Projeto 11 & $50 \%$ \\
\hline Projeto 12 & $42 \%$ \\
\hline Projeto 13 & $30 \%$ \\
\hline Projeto 14 & $94 \%$ \\
\hline Projeto 15 & $72 \%$ \\
\hline Projeto 16 & $76 \%$ \\
\hline Projeto 17 & $82 \%$ \\
\hline Projeto 18 & $82 \%$ \\
\hline Projeto 19 & $13 \%$ \\
\hline Projeto 20 & $78 \%$ \\
\hline Projeto 21 & $70 \%$ \\
\hline Projeto 22 & $75 \%$ \\
\hline Projeto 23 & $60 \%$ \\
\hline Projeto 24 & $43 \%$ \\
\hline Projeto 25 & $67 \%$ \\
\hline
\end{tabular}

\begin{tabular}{|c|c|}
\hline Projeto & \% de influência do escopo \\
\hline Projeto 26 & $81 \%$ \\
\hline Projeto 27 & $85 \%$ \\
\hline Projeto 28 & $85 \%$ \\
\hline Projeto 29 & $35 \%$ \\
\hline Projeto 30 & $69 \%$ \\
\hline Projeto 31 & $68 \%$ \\
\hline Projeto 32 & $45 \%$ \\
\hline Projeto 33 & $42 \%$ \\
\hline Projeto 34 & $68 \%$ \\
\hline Projeto 35 & $40 \%$ \\
\hline Projeto 36 & $43 \%$ \\
\hline Projeto 37 & $51 \%$ \\
\hline Projeto 38 & $50 \%$ \\
\hline Projeto 39 & $64 \%$ \\
\hline Projeto 40 & $70 \%$ \\
\hline Projeto 41 & $43 \%$ \\
\hline Projeto 42 & $43 \%$ \\
\hline Projeto 43 & $43 \%$ \\
\hline Projeto 44 & $43 \%$ \\
\hline Projeto 45 & $61 \%$ \\
\hline Projeto 46 & $74 \%$ \\
\hline Projeto 47 & $91 \%$ \\
\hline Projeto 48 & $85 \%$ \\
\hline Projeto 49 & $40 \%$ \\
\hline Projeto 50 & $48 \%$ \\
\hline
\end{tabular}




\section{Anexo A - Documento texto de escopo do projeto}

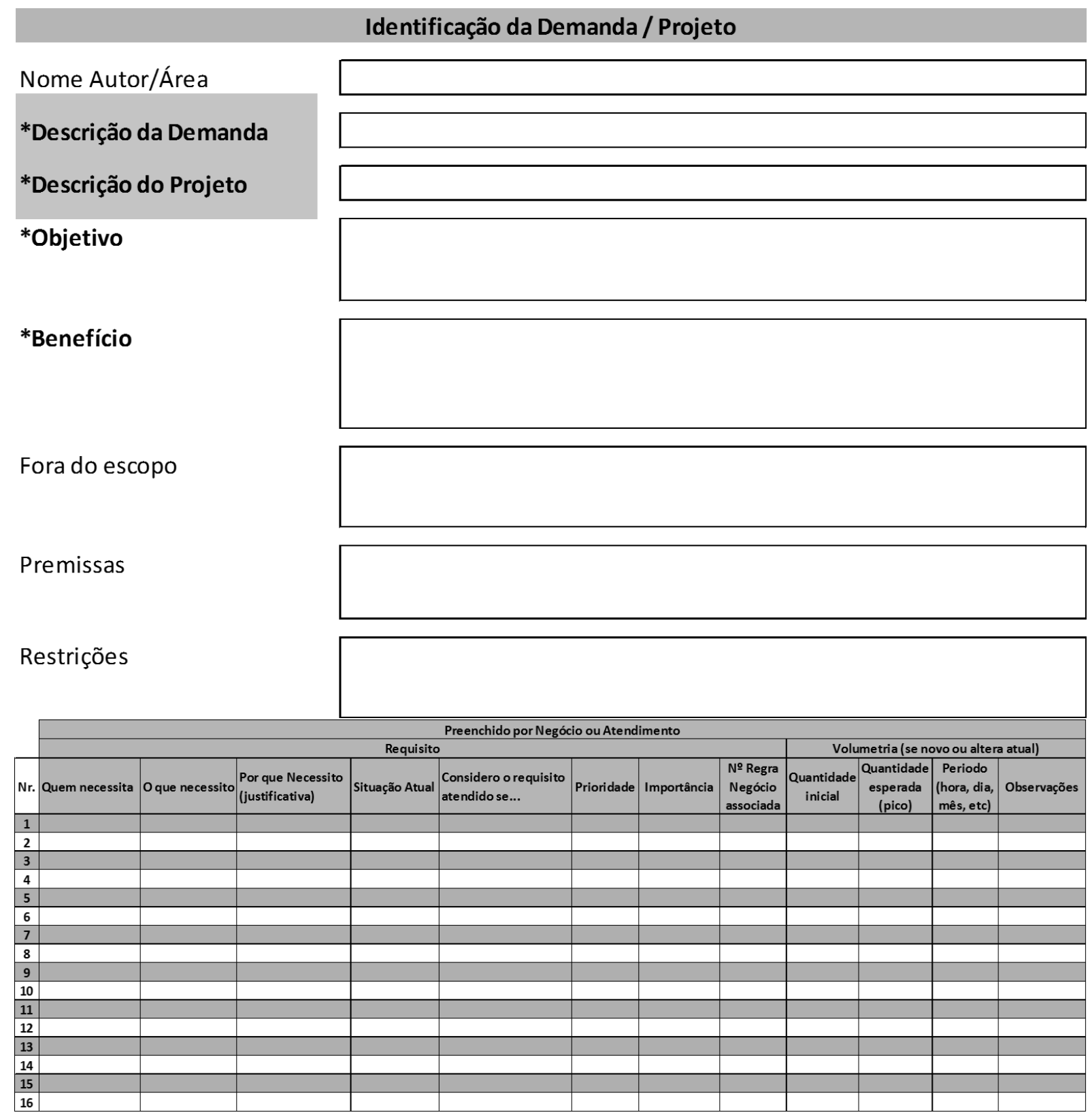




\section{Anexo B - Documento planilha eletrônica de escopo do projeto}

\section{Detalhamento da Demanda (Preenchido pelo Solicitante)}

Introdução

Premlseas *

Restriço日e *

Glossarlo de Termos *

ReferAnclas *

Criterlos para Anallse de Vlabilldade *

Relação de Envolvidos*

\begin{tabular}{|l|l|l|l|}
\hline Papel * Area* & \multicolumn{1}{c|}{ Nome do Contato* } & Fone \\
\hline Solicitantes & & & \\
\hline Usuários & & & \\
\hline Sistemas e envolvidos & & & \\
\hline Arquitetura & & & \\
\hline Metodologia & & & \\
\hline Outros & & & \\
\hline$\ldots$ & & & \\
\hline
\end{tabular}

Obs.: A Relaça de Envolvidos devera ser complementada por 7 .

Necessidades

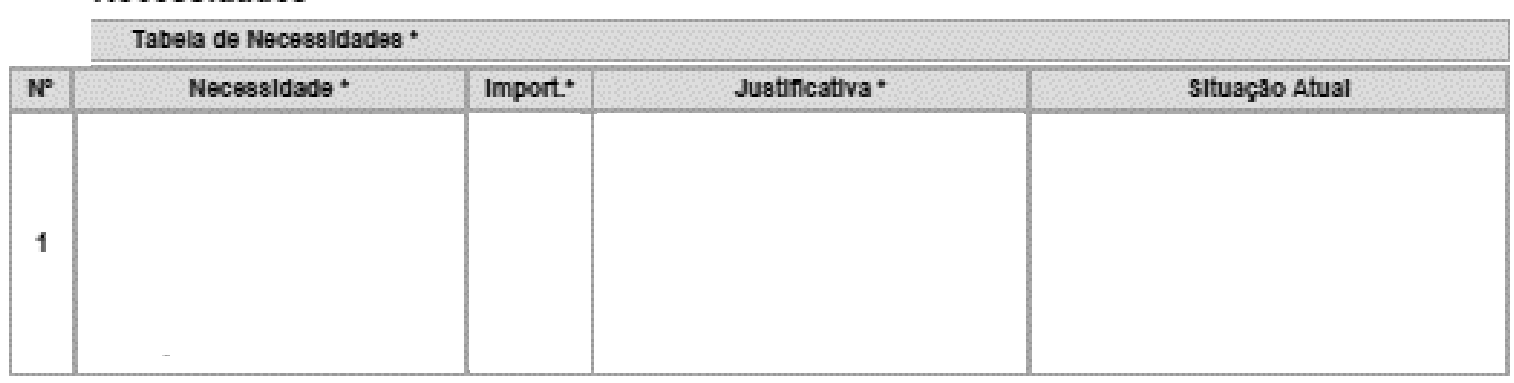

Regras de Negoclo*

\begin{tabular}{|c|c|c|}
\hline$N^{*}$ & Descriçao & No Necesaldades Relaclonadas \\
\hline 1 & & \\
\hline
\end{tabular}

